\title{
Classification and Mapping of Recreation and Ecotourism Areas in West Virginia
}

Ishwar Dhami

West Virginia University

Follow this and additional works at: https://researchrepository.wvu.edu/etd

\section{Recommended Citation}

Dhami, Ishwar, "Classification and Mapping of Recreation and Ecotourism Areas in West Virginia" (2013). Graduate Theses, Dissertations, and Problem Reports. 344.

https://researchrepository.wvu.edu/etd/344

This Dissertation is protected by copyright and/or related rights. It has been brought to you by the The Research Repository @ WVU with permission from the rights-holder(s). You are free to use this Dissertation in any way that is permitted by the copyright and related rights legislation that applies to your use. For other uses you must obtain permission from the rights-holder(s) directly, unless additional rights are indicated by a Creative Commons license in the record and/ or on the work itself. This Dissertation has been accepted for inclusion in WVU Graduate Theses, Dissertations, and Problem Reports collection by an authorized administrator of The Research Repository @ WVU.

For more information, please contact researchrepository@mail.wvu.edu. 


\title{
Classification and Mapping of Recreation and Ecotourism Areas in West Virginia
}

\author{
Ishwar Dhami \\ Dissertation submitted to the \\ Davis College of Agriculture, Natural Resources and Design \\ at West Virginia University \\ in partial fulfillment of the requirements for the degree of \\ Doctor of Philosophy in \\ Forest Resources Science
}

\author{
Committee \\ Jinyang Deng, Ph.D., Chair \\ Chad Pierskalla, Ph.D. \\ Jamison Conley, Ph.D. \\ Michael P. Strager, Ph.D. \\ Robert C. Burns, Ph.D. \\ Morgantown, West Virginia \\ 2013
}

Keywords: Recreation Opportunity Spectrum, Forest-based ecotourism, Analytic Hierarchy Process, Sensitivity analysis 


\title{
ABSTRACT \\ Classification and Mapping of Recreation and Ecotourism Areas in West Virginia
}

\author{
Ishwar Dhami
}

Travel and tourism are recognized as the largest and fastest growing economic sector in the world. Different recreational and tourism sites can provide different types of activities based on their unique characteristics. Like any other form of tourism, the growth of ecotourism is dependent on the flow of visitors and therefore, marketing for a destination requires identifying various characteristics of the destination and preferences of stakeholders. The main aim of this dissertation is to classify and map recreation and ecotourism areas in West Virginia. The dissertation is presented in the form of three essays. The first essay classifies and maps classes of Recreation Opportunity Spectrum (ROS) in the state and examines its relationship with the travel and tourism generated revenues. Results showed that most of the areas in the state are Rural (R) followed by Semiprimitive Nonmotorized (SPNM) and Roaded Natural (RN). Visitors' travel spending was significantly associated with the urban class. The second essay identifies and maps forest-based ecotourism areas in the state using six different criteria and visitors' preferences. Pairwise comparison of Analytic Hierarchy Process (AHP) was used to compute the criteria weights from questionnaire survey of visitors. Significant variations were found in visitors' preferences. Areas under Class IV and Class V of naturalness continuum of both weighted and unweighted ecotourism maps covered more than half of the state's area, suggesting higher prospects for promoting forest-based ecotourism in the state. The results also indicated that each class changed in size when visitors' preferences were applied. The third essay performs sensitivity analysis of the criteria weights derived from visitors and experts' survey and maps the robust suitable areas for forest-based ecotourism areas in the state. Similar to essay two, pairwise comparison of AHP was used to compute criteria weights from experts. Results indicated that about one third of the state's area was highly suitable and not sensitive to the variations of criteria weights. The finding of this dissertation demonstrated ROS classes and forest-based ecotourism areas in the state which could provide helpful information to the resource managers and policy makers in terms of recreation and tourism development, marketing, and promotion. Results of the study were mapped using Geographic Information System (GIS) and Geographic Data Analysis (GeoDa) software.

Keywords: Recreation Opportunity Spectrum, Forest-based ecotourism, Sensitivity analysis. 


\section{DEDICATION}

I dedicate this dissertation to my wonderful family: to my father, Tika Singh Dhami, whom I am indebted to for his guidance and support; to my mother, Indira Dhami, for her love and encouragement; to my siblings, Dr. Bhageshwar Dhami and Sanjay Dhami, for their

understanding and friendship. Finally, I dedicate this work with special thanks to my loving wife Sudiksha Joshi and beautiful daughter Ishika Dhami for being there for me. 


\section{ACKNOWLEDGEMENT}

I would like to acknowledge all the individuals and institutions who made this dissertation possible. First and foremost, I would like to express my deep and sincere gratitude to my advisor, Dr. Jinyang Deng for providing me the research assistantship for my doctoral degree. His understanding and encouraging personality and his guidance have provided the basis for this dissertation.

I am deeply grateful to my committee member, Dr. Chad Pierskalla, Dr. Michael Strager, Dr. Rober Burns, and Dr. Jamison Conley for their constructive comments, suggestions, and support throughout the study period.

I would like to acknowledge Mr. Steve Harouf, GIS specialist, West Virginia Division of Forestry, for providing spatial data needed for this study, and staff from West Virginia Division of Tourism and two welcome centers (I- 68 west and I-79 south) for their assistance in the survey.

I am also grateful to all the visitors and experts who participated in the questionnaire survey. Without your time and participation this study would not have been possible!

I would also like to thank my wife Sudiksha Joshi and friends Rogelio Andrada II and Daniel Servian for helping me during the survey.

I enjoyed working with all in the Division, thank you all for your support. 


\section{TABLE OF CONTENTS}

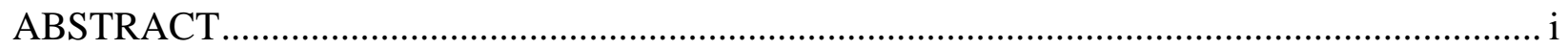

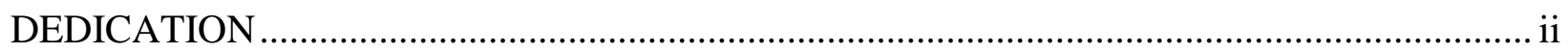

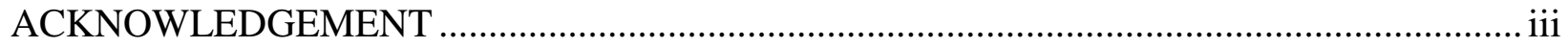

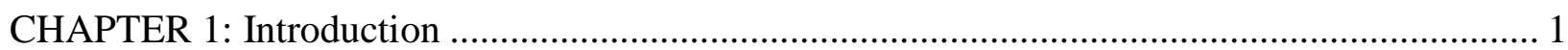

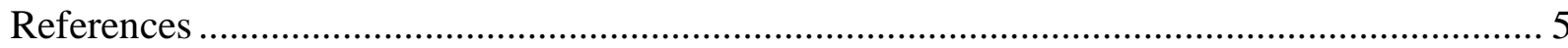

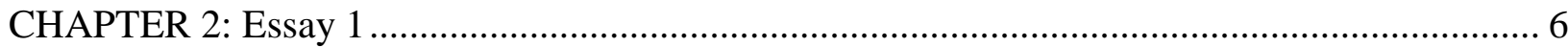

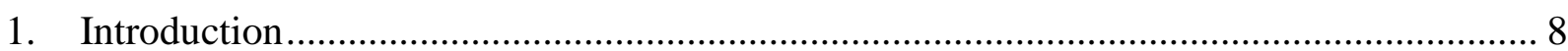

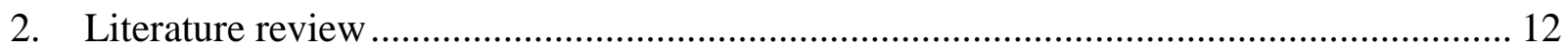

2.1 The Recreation Opportunity Spectrum................................................................. 13

2.2 The Recreation Opportunity Spectrum and GIS........................................................... 16

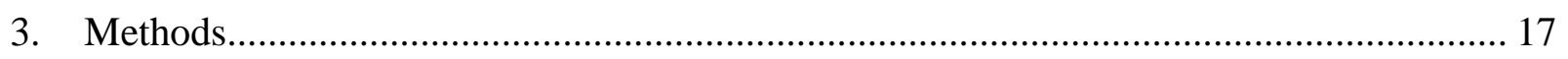

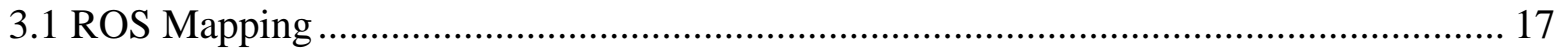

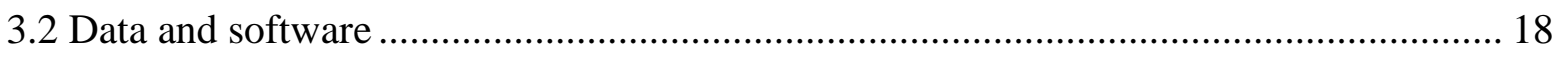

3.3 GIS methods for mapping ROS classes............................................................... 19

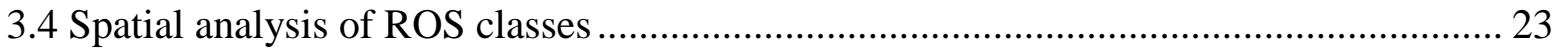

3.4.1 Spatial autocorrelation analysis ......................................................................... 23

3.4.2 Regression Analysis .................................................................................... 24

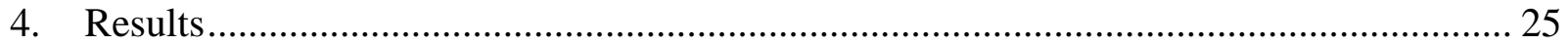

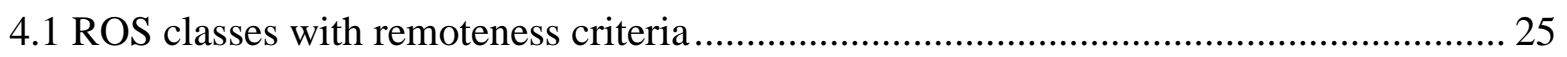

4.2 ROS classes with remoteness and size criteria .......................................................... 26

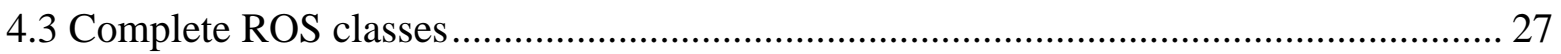

4.4 ROS class for Pocahontas County ………………….................................................. 30

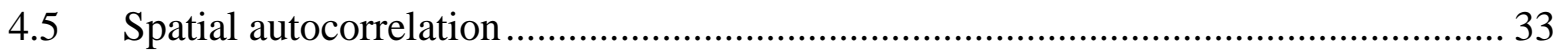

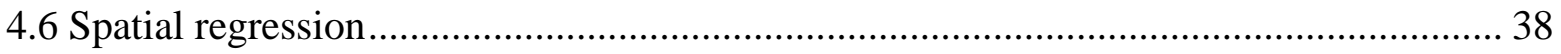

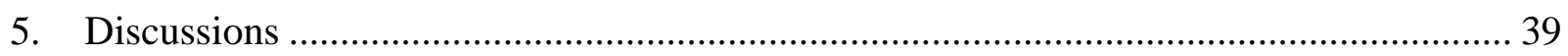

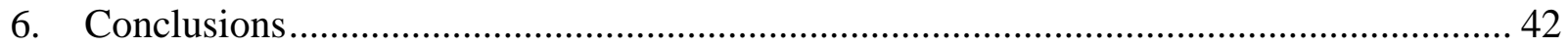

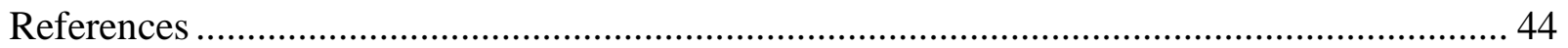




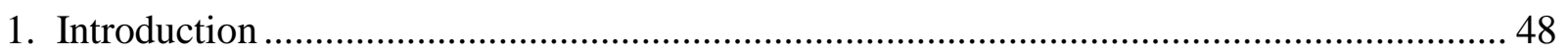

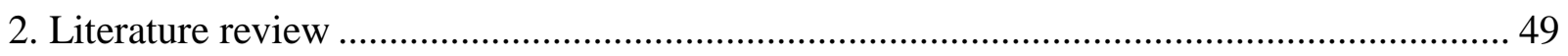

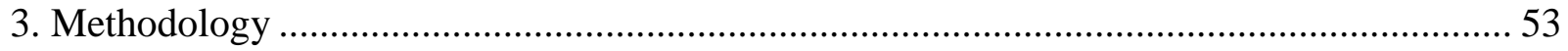

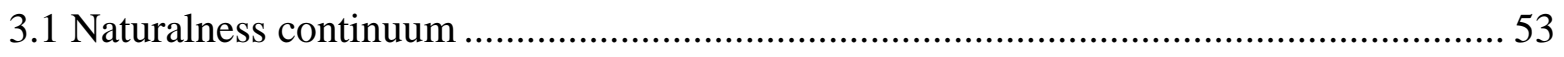

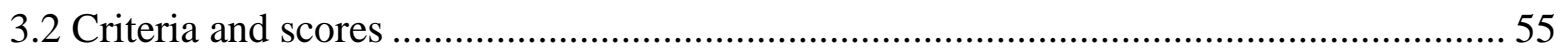

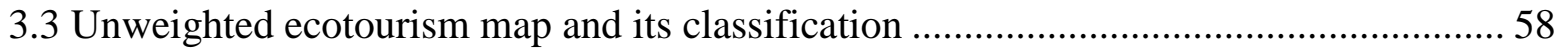

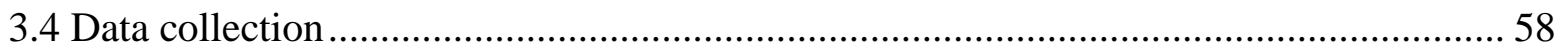

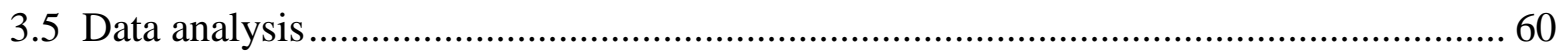

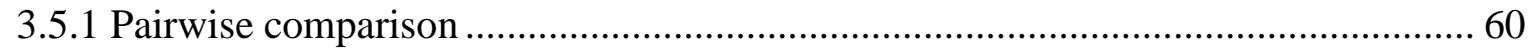

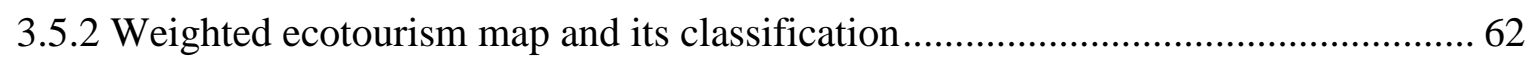

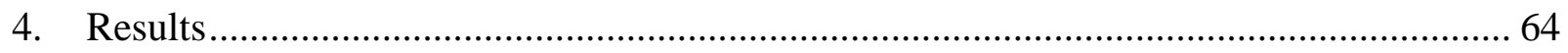

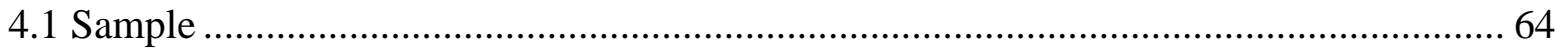

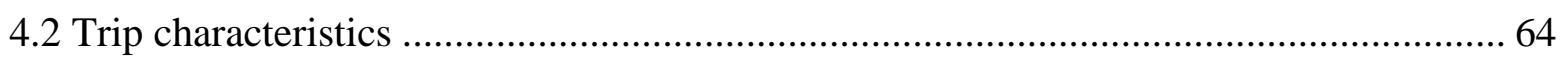

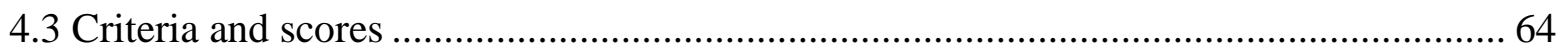

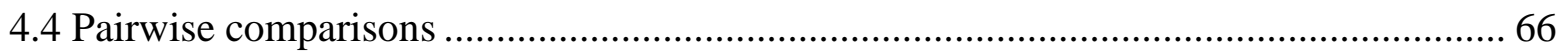

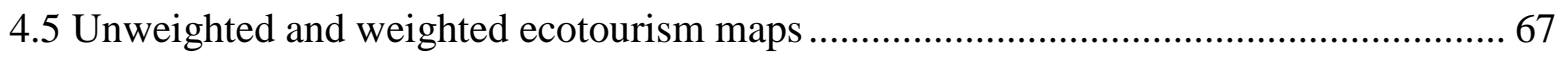

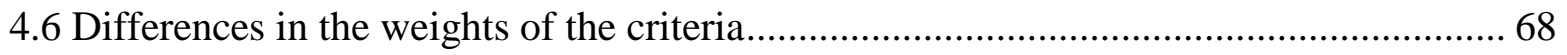

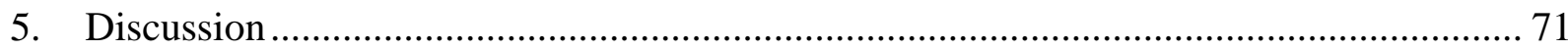

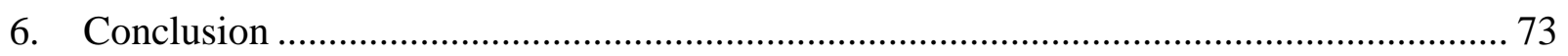

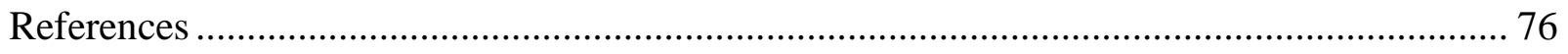

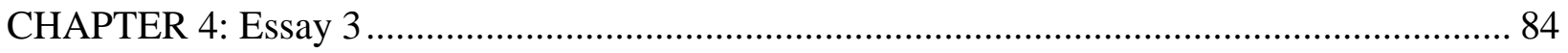

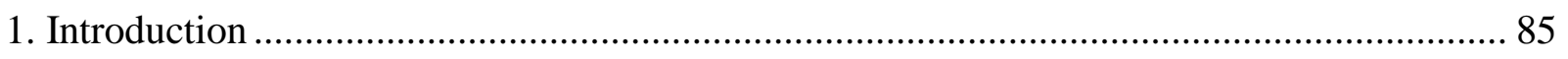

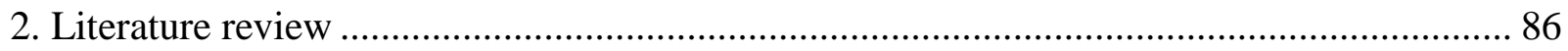

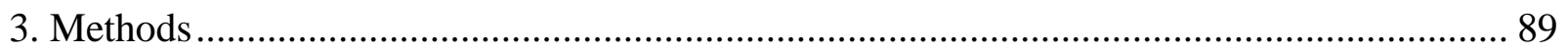

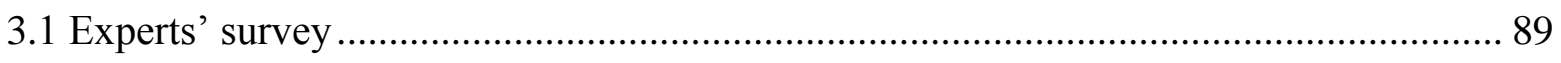

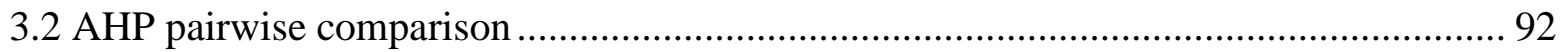

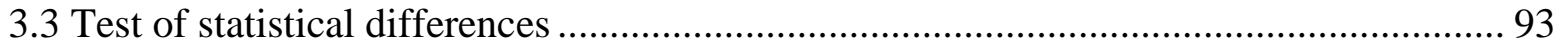

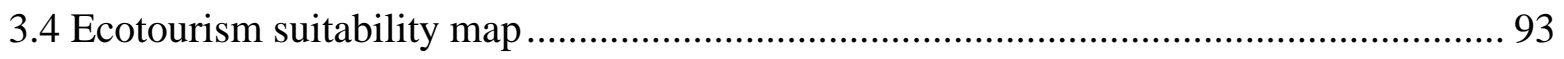

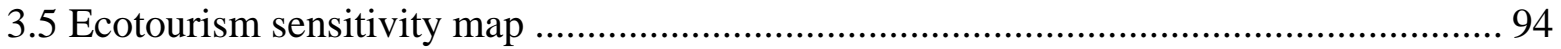


3.6 Classified ecotourism suitability and sensitivity map ......................................... 94

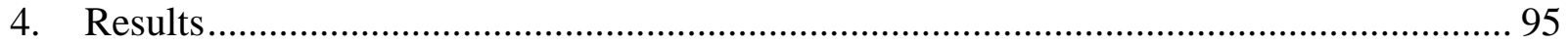

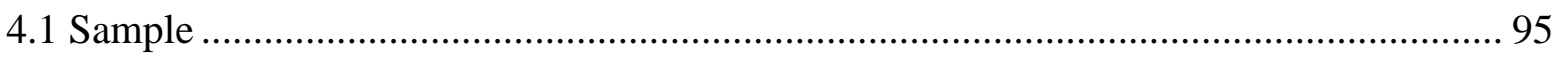

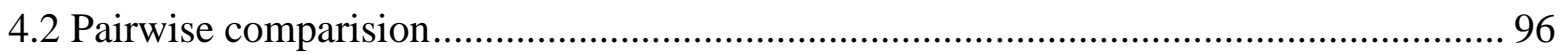

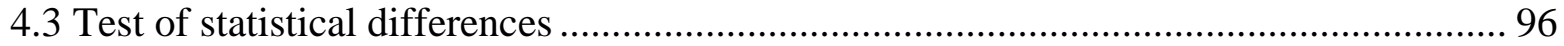

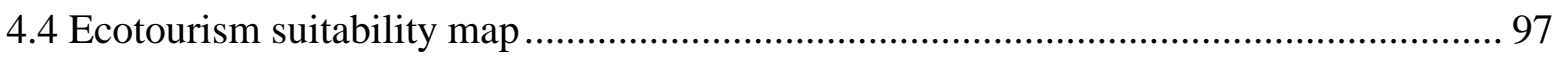

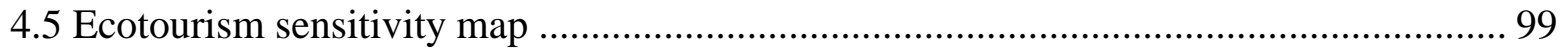

4.6 Classified ecotourism suitability and sensitivity map ........................................... 105

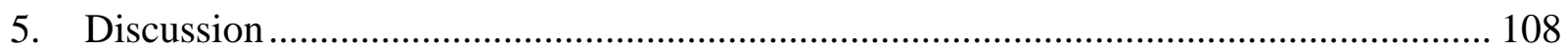

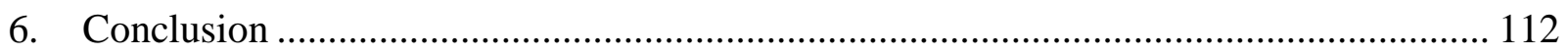

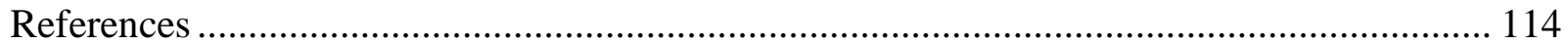




\section{LIST OF TABLES}

\section{CHAPTER 2: Essay 1}

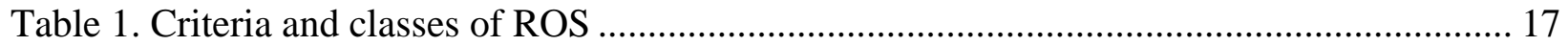

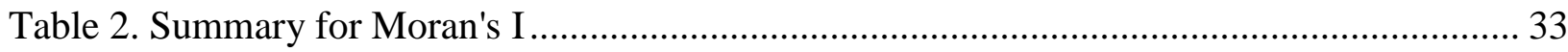

Table 3. Summary result from OLS model............................................................................ 38

\section{CHAPTER 3: Essay 2}

Table 1. Criteria and scores used to identify forest-based ecotourism areas in West Virginia. ... 56

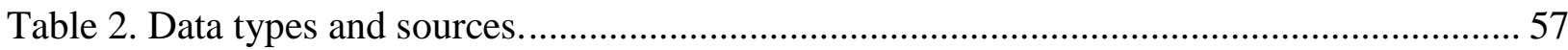

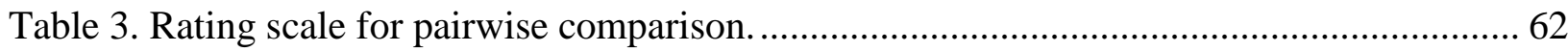

Table 4. Percent distribution of areas for each criterion measured by scores from 1 to 5 ............. 66

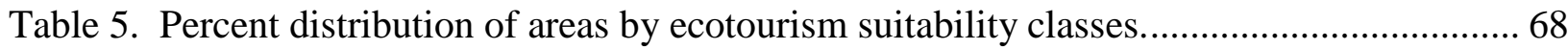

Table 6. Comparison of mean weights of criteria among various visitor groups........................ 70

\section{CHAPTER 4: Essay 3}

Table 1. Pairwise comparison of the criteria for forest-based ecotourism in West Virginia........ 91

Table 2. T-test statistics for the difference in criteria weights calculated for the visitors' survey

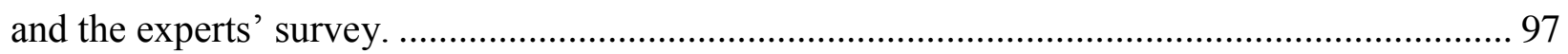

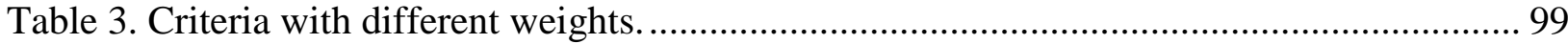

Table 4. Summary statistics of ecotourism suitability maps........................................................ 103 


\section{LIST OF FIGURES}

\section{CHAPTER 2: Essay 1}

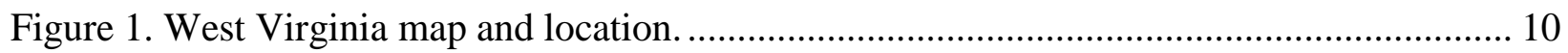

Figure 2. Summarized flowchart showing the process for ROS classification............................. 20

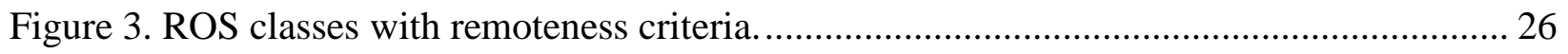

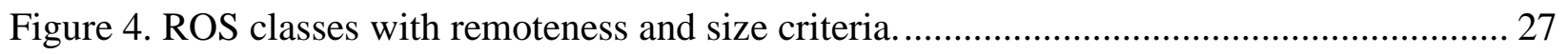

Figure 5. Land ownership map for West Virginia. ................................................................... 28

Figure 6. ROS class and land ownership map for West Virginia ................................................ 28

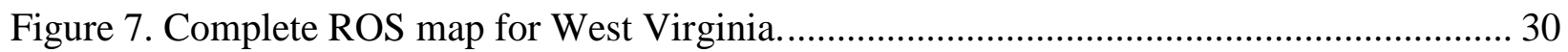

Figure 8. ROS class land ownership map for Pocahontas County. ............................................. 31

Figure 9.. ROS class for Pocahontas County ........................................................................... 31

Figure 10. ROS class and existing recreational areas in Pocahontas County............................... 32

Figure 11. LISA map for total Semiprimitive Nonmotorized......................................................... 34

Figure 12. LISA map for total Semiprimitive Motorized ........................................................... 34

Figure 13. LISA map for public Semiprimitive Nonmotorized................................................ 35

Figure 14. LISA map for public Semiprimitive Motorized ……..................................................... 35

Figure 15. LISA map for private Semiprimitive Nonmotorized................................................... 36

Figure 16. LISA map for private Semiprimitive Motorized ........................................................ 36

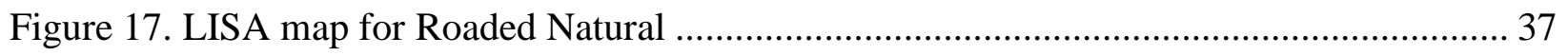

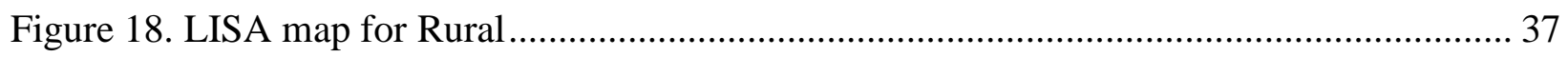

\section{CHAPTER 3: Essay 2}

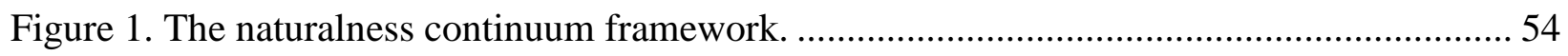

Figure 2. Survey locations for the study. Adapted from Welcome centers, West Virginia......... 59

Figure 3. Various West Virginia maps based on the criteria score for (a) distance from logging (b) slope (c) distance from mining (d) presence of wildlife (e) presence of vegetation (f) remoteness.

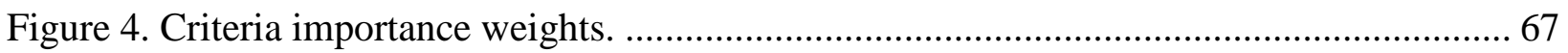

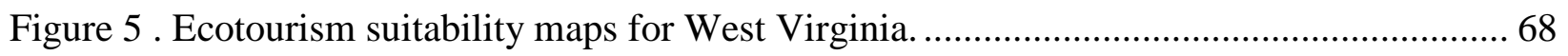




\section{CHAPTER 4: Essay 3}

Figure 1. Criteria importance weights from the visitors' and experts' preferences....................... 96

Figure 2. Weighted ecotourism map (base map). ………......................................................... 98

Figure 3. Ecotourism suitability maps created each with twice the criteria weights of the base map (a) distance from logging (b) slope (c) distance from mining (d) presence of wildlife (e)

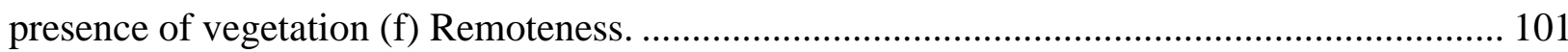

Figure 4. Ecotourism suitability maps created each with half the criteria weights of base map (a) distance from logging areas (b) slope (c) distance from mining (d) presence of wildlife (e) presence of vegetation (f) Remoteness .

Figure 5. Standard deviation map based on the base map, maps with criteria weights doubled, and maps with criteria weights halved. 104

Figure 6. (a) Ecotourism suitability map with $25 \%$ of the high scored areas as highly suitable and and (b) ecotourism sensitivity map with $25 \%$ of the highest scores classified as highly sensitive

Figure 7. Combined ecotourism suitability and sensitivity map............................................... 106

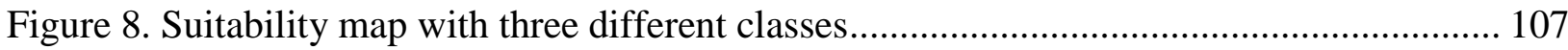

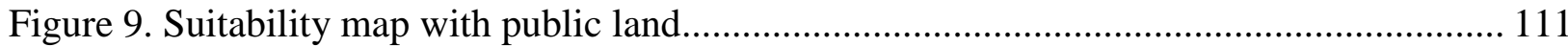




\section{CHAPTER 1: Introduction}

The terms recreation and tourism are difficult to define and differentiate as they are interrelated and imply different things to different people. For the purpose of this study, tourism is defined as "the activities of persons travelling to and staying in places outside their usual environment for not more than one consecutive year for leisure, business and other purposes" (United Nation World Tourism Organization, 1995, p.1). Recreation is defined as "activity voluntarily undertaken, primarily for pleasure and satisfaction, during leisure time" (Pigram, 1983, p. 3), and therefore recreation may take place anywhere even while not engaging in tourism.

Over the past six decades, tourism has grown as the largest and fastest-growing economic sectors in the world with continued expansion and diversification of destinations and services. Despite occasional shocks like rising gas prices and increased threat of terrorism, international tourist arrivals have shown virtually uninterrupted growth from 277 million in 1980 to 528 million in 1995, and to 1,035 million in 2012 (United Nations World Tourism Organization, [UNWTO], 2013). According to the UNWTO estimate, this number is expected to increase by $3.8 \%$ annually from 2010 to 2020 . In 2012 , tourism receipts were estimated at about $\$ 1,075$ billion worldwide, an increase of 4\% compared to 2011 (UNWTO, 2013). In the same year, the U.S.was ranked second in international tourist arrivals (67 million) and first in international tourism receipts with $\$ 126.2$ billion (UNWTO Tourism Highlights, 2013). Outdoor recreation in U.S reached its highest participation level in 2011 wherein 141.1 million outdoor participants or 49.34\% of U.S. population enjoyed various forms of outdoor recreation. Outdoor recreation contributes $\$ 646$ billion annually to the U.S. economy, supports nearly 6.1 million jobs across 
the U.S., and generates $\$ 80$ billion in annual federal, state and local tax revenue (Outdoor Industry Association, 2012).

West Virginia, a state located in the eastern U.S., has experienced increase in travel spending by 5.60\% annually since 2000. In 2010 travel spending by all overnight and day visitors in West Virginia was over $\$ 4.27$ billion, equivalent to $\$ 11.70$ million per day (Dean Runyan Associates, 2010). Also, in the same year, visitor spending in the state directly supported about 44,400 jobs with earnings of $\$ 988$ million, and generated $\$ 582$ million in local and state tax revenues (Dean Runyan Associates, 2010). This indicates that travel and tourism is gaining popularity in the state. Therefore, information on location and size of the available recreational and tourism areas would not only help recreational managers to accommodate large number of visitors but also help to provide quality recreation experiences to the visitors.

Recreation and tourism resources are often recognized as the most important assets for rural development (Dillman, 1979; Galston \& Baehler, 1995; Haas, 1990; Knapp \& Graves, 1989; Snepenger, Johnson \& Rasker, 1995). Studies have found that rural areas with recreational and tourism resources experience higher economic growth than the US average (McGranahan, 1999; Deller, Tsai, Marcouiller \& English 2001). For promoting tourism in an area, it is important to examine existing recreational opportunities and the distribution of recreation related economic benefits throughout the area.

Therefore, the first essay of this dissertation (Chapter 2) conducted a spatial analysis of recreation opportunity spectrum and travel/tourism generated revenues in West Virginia. The chapter classified and mapped different classes of recreation opportunities based on biophysical characterics and examined their relationship with travel spending. The findings of the study 
would help visitors to get detailed information about recreation opportunities in the state and also help managers to promote tourism in the area.

Tourism is a multidimensional phenomenon and dependent not only on recreational resources but also on other factors like social, cultural, natural, spatial and economic factors of the areas. Therefore, selection of areas for tourism development requires consideration of different criteria. To address this, Chapter 3 of this dissertation classified, and mapped tourism areas, specifically forest-based ecotourism areas in West Virginia using six different criteria and also incorporated preferences of visitors' on the selected criteria. The term ecotourism was introduced in the early 1980 s to address the environmental and social consequences of tourism. Ecotourism, as an alternative to mass tourism, was advocated to espouse the goal of symbiosis through the integration of natural resources, environmental education, and sustainable management. Since 78\% West Virginia lands are forested, classification and mapping of forestbased ecotourism using visitors' preference could help to attract more tourists to the state. The resultant map would help potential visitors to identify their preferred ecotourism areas in the state. The results would also benefit agencies responsible for resource planning and management to assess the potential for activities to be offered within the area in the context of overall setting and current resources of the areas. Also, information on the size of ecotourism areas would help to determine the type of ecotourism activities available like areas suitable for excursions only or those with limited overnight stays.

In addition to visitors' preferences, experts' knowledge is also important in determining the importance of criteria while classifying and mapping of forest-based ecotourism areas, as experts knowledge tend to be more holistic. Further, the mapped ecotourism areas in chapter 3 incorporated the preferences of visitors involved in the study and in order to make it more stable, 
effect of variations of the criteria weight in the output map need to be examined. Therefore, chapter 4 of this dissertation highlights the importance of sensitivity analysis in mapping forestbased ecotourism areas in West Virginia. The resultant map created shows the existing robust areas suitable for forest-based ecotourism and also provided information on the potential robust areas for promoting ecotourism in the state. This information could be helpful in terms of destination development, marketing, and promotion. 


\section{References}

Dean Runyan Associates. (2011). Economic impact of travel on West Virginia: 2000-2010 Detailed state and county estimates. Retrieved October 29, 2013, from http://www.wvcommerce.org/App_Media/assets/doc/travelandrec/industry/marketing/20 10\%20Economic\%20Impact.pdf

Deller, S.C., Tsai, T.S., Marcouiller, D.W., \& English, D.B.K. (2001). The role of amenities and quality of life in rural economic growth. American Journal of Agricultural Economics, 83(2), 352-365.

Dillman, D. A. (1979). Residential preferences, quality of life, and the population turnaround. American Journal of Agricultural Economics, 61(5), 960-966.

Galston, W.A., \& Baehler, K. J. (1995). Rural development in the United States: connecting theory, practice, and possibilities. Washington, DC: Island Press.

Haas, G., Aukerman, R., Lovejoy, V., \& Welch, D. (2004). Water recreation opportunity spectrum users' guidebook. US Department Interior, Bureau of Reclamation, Denver, Colorado.

Knapp, T. A., \& Gravest, P. E. (1989).On the role of amenities in models of migration and regional development. Journal of Regional Science, 29(1), 71-87.

McGranahan, D.A. (1999). Natural amenities drive rural population change. USDA Agricultural Economic Report No. 781.

Outdoor Industry Association. 2012. Outdoor Recreation Participation Report. 2012. Outdoor Industry Association, Boulder, Colorado. Retrieved September 30, 2013, from http://www.asla.org/uploadedFiles/CMS/Government_Affairs/Federal_Government_Affa irs/OIA_OutdoorRecEconomyReport2012.pdf

Pigram, J. (1983). Outdoor Recreation and Resource Management. London, Croom Helm Ltd p.3.

Snepenger, D. J., Johnson, J. D., \& Rasker, R. (1995). Travel-stimulated entrepreneurial migration. Journal of Travel Research, 34(1), 40-44.

United Nation World Tourism Organization (UNWTO). (1995). Concepts, definitions, and cassifications for tourism tatistics-Technical Mannual No.1. United Nation World Tourism Organization, Madrid, Spain.

United Nation World Tourism Organization (UNWTO). (2013). United Nation World Tourism Organization (UNWTO:2012 annual report. Madrid, Spain: The author. Retrieve from http://dtxtq4w60xqpw.cloudfront.net/sites/all/files/pdf/annual_report_2012.pdf

United Nation World Tourism Organization (UNWTO). (2013). Tourism Highlights. 2013

Edition. Retrieved from

http://dtxtq4w60xqpw.cloudfront.net/sites/all/files/pdf/unwto_highlights13_en_lr_0.pdf 


\title{
CHAPTER 2: Essay 1
}

\section{Spatial Analysis of Recreation Opportunity Spectrum and Travel/Tourism Generated \\ Revenues: A Case of West Virginia}

\begin{abstract}
The Recreation Opportunity Spectrum (ROS) is a conceptual and organizational framework that classifies recreation opportunities into six classes ranging from Primitive (P) to Urban (U) based on attributes of the physical, social, and managerial settings. The ROS framework helps recreation managers determine the existing supply of opportunities available in an area. Previous studies have found that rural areas with higher level of natural and artificial amenities such as scenic beauty, recreational sites, and tourism resources experience higher rates of economic growth. Thus, the objective of this essay is to assess ROS classes in West Virginia and to examine the relationship between different ROS classes and travel spending in the state. Geographic Information System (GIS) and Geographic Data Analysis (GeoDa) software were used to analyze and visualize the results of the study. It was found that most of the areas in West Virginia were Rural (R) followed by Semiprimitive Nonmotorized (SPNM) and Roaded Natural (RN). Cluster analysis showed that counties with more ROS classes (SPNM, SPM and RN) were largely concentrated in the eastern or central eastern part of the state. Regression analysis showed that visitors' travel spending was significantly associated with the urban class. Results of the study would be helpful in providing recommendations to the visitors on the type of sites they should target based on their preferences. The results would also benefit agencies responsible for resource planning and management to assess activities that can be conducted within the context
\end{abstract}


of overall setting and available resources. Finally, the ROS map prepared for this study would help future researchers evaluate the changes in the ROS map over time.

Keywords: Recreation Opportunity Spectrum, Spatial autocorrelation, Spatial regression, Geographic Information System, Geographic Data Analysis 


\section{Introduction}

Outdoor recreation is one of the major forms of recreation in U.S. According to the report by Outdoor Industry Association (OIA), outdoor recreation reached its highest participation level in the past five years in 2011 wherein nearly half of the U.S. population enjoyed various forms of outdoor recreation (OIA, 2012). Due to the increasing demand for outdoor recreation, recreational managers are looking for detailed information on location and size of available opportunities in their locality to provide quality recreation experiences to the visitors.

One of the major objectives of recreational mangers is to satisfy diverse recreational demands of visitors. Studies of outdoor recreation have revealed great diversity in recreationists' preferences. This diversity extends to the recreationists themselves, who express their needs and wants through a variety of processes (Shelby \& Heberlein, 1986). For example, some recreationalists prefer to camp in modern areas, some prefer in primitive areas while others prefer areas that lie in between the two.

Another objective of recreation management is to understand how public's demands are shaped by environmental and recreational resources. Different recreational sites can offer different recreational activities and use levels based on their unique characteristics (Haas, Aukerman, Lovejoy, \& Welch, 2004). U.S. Forest Service and the U.S. Bureau of Land Management have implemented recreation opportunity spectrum (ROS) framework as part of integrated land and resource management planning process (Buist \& Hoots, 1982). ROS, initially developed by U.S.Forest Service, is a tool used for the planning and management of diverse outdoor recreation opportunities (Brown, Driver \& McConnell, 1978). The objective of ROS is to help recreation managers determine the existing supply of opportunities available in a given area. In order to enjoy a special kind of recreation experience and subsequent benefits, 
recreationists seek to participate in recreation activities as well as specific recreation settings (Haas, Aukerman, Lovejoy, \& Welch, 2004). ROS classes adopted by the U.S. Forest Service are based on recreation settings (physical, social and managerial) and include six different zones: Primitive (P), Semiprimitive Nonmotorized (SPNM), Semiprimitive Motorized (SPM), Roaded natural (RN), Rural (R), and Urban (U). The characteristics of individual zones are well described in ROS User Guide by U.S. Forest Service, 1982.

Recreational resources have been recognized as one of a major pulling factor to promote the tourism industry. Recreation and tourism resources are often assumed to be the most important assets that cause seasonal and permanent residential development in rural communities (Dillman, 1979; Knapp \& Graves, 1989; Haas, 1990; Galston \& Baehler, 1995; Snepenger, Johnson \& Rasker, 1995). Also, the role of natural resources in explaining economic growth patterns in the rural areas is becoming widely accepted within the rural development literature (Isserman ,2001; Power, 1988). Studies have found that rural areas with more natural and artificial resources such as scenic beauty, recreational sites, and tourism resources experience higher rates of economic growth than the US average (McGranahan, 1999; Deller, Tsai, Marcouiller \& English, 2001). These findings suggest that regions with higher recreational opportunities can pursue mass tourism for rapid economic growth which can be measured in terms of increase in the employment and the income level. The distribution of employment and income also varies from place to place depending on the recreational opportunities being offered. For tourism promotion in the area, it is necessary to assess existing recreational opportunities and spatially examine how recreation related economic benefits are distributed throughout the area. Recreational opportunities are abundant in West Virginia (Figure 1), a state in the eastern U.S. 
This is the only state in the nation which is located entirely within the Appalachian Mountain range, and is also called "The Mountain State".

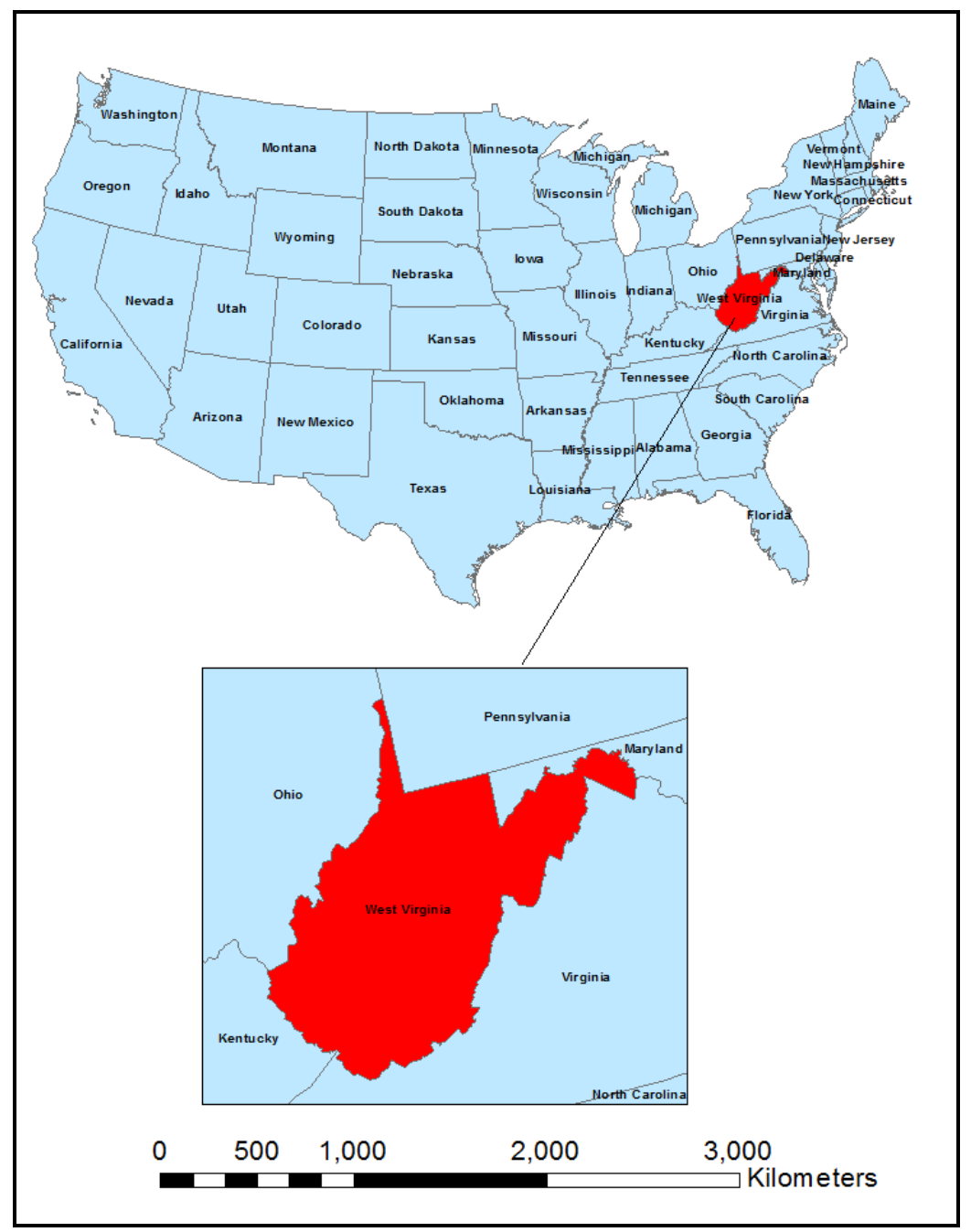

Figure 1. West Virginia map and location

The state offers numerous recreational opportunities that are unique and are not easily available within the surrounding states. There are six national park units, three national forests, thirty six state parks, nine state forests, and seventy eight Wildlife Management Areas (WMAs) across the state. In addition, the state is home to many rivers, lakes, springs, and golf courses, among others. Besides its natural beauty, it is also a destination for people interested in outdoor activities such as camping, skiing, whitewater rafting, rock climbing, fishing, hiking, mountain 
biking, and hunting. Since the intensity and diversity of demands for recreation are growing in the state, recreational managers are looking for suitable locations for providing available recreational opportunities across the state. However, outdoor recreation studies considering the role of spatial scale in planning and management are rare (Morse, Hall, \& Kruger, 2008). A regional approach to planning and managing recreational opportunities has been rarely considered. Jubanville and Becker (1983) suggest single-site planning can lead to a loss of diversity of opportunities over time if the larger context is not considered. The ROS approach has mostly been used at a small and local scale. Applying these approaches to the regional and national level is necessary to fully understand spatial patterns as managers are concerned about recreational opportunities across a landscape. This will allow regional managers to compare individual recreational areas to one another and focus their efforts on resource protection, restoration, and management. Therefore, it is important to have knowledge on different recreational opportunities at the regional and national level so that they can be advertised accordingly to satisfy the diverse need. This study, thus, uses the concept of a regional approach to planning and managing recreational opportunities and determines the ROS classes for the entire state of West Virginia.

Tourism has been playing an important role in promoting economic development in West Virginia. As tourism development is largely dependent on the availability of recreational opportunities in the area, spatial assessment of ROS classes and its relationship with travel spending in the area can provide information to tourism planners, resource managers, and policy makers about the contribution of each ROS class in the local economic development. Thus, the general objective of this study is to classify West Virginia land into ROS classes and determine its association with travel/tourism generated revenues in the state. The specific objectives of this 
study are to: map ROS classes in West Virginia, assess spatial autocorrelation of ROS classes, and examine the association of ROS classes with travel spending in the state. The results of this study would help visitors to locate their desired classes and also help land managers to better manage these ROS classes and understand their relationship with economic benefits.

\section{Literature review}

The increasing public demand for diverse recreation opportunities has led to the development of several zoning frameworks aimed at effective planning and management of recreational areas. In the late 1930s, it was proposed that forests of different types should be planned and managed for distinct recreation activities (Marshall, 1938). In the early 1960s, a formal classification system for recreation managers began to emerge in the literature. A wildland planning handbook classified lands from "wilderness" to "semi-urban" (Carhart, 1961) and the Outdoor Recreation Resources Review Commission (ORRRC) suggested a six-class framework for public lands from primitive to high-density use areas (ORRRC, 1962). Since the formulation of these frameworks, various other types recreation classification/planning systems have been developed: Recreation Opportunity Spectrum (ROS) (Brown et al., 1978), Limits of Acceptable Change (LAC) (Stankey, Cole, Lucas, Peterson, \& Frissell, 1985), Visitor Impact Management (VIM) (Graefe, Kuss \& Vaske, 1990), and Visitor Experience and Resource Protection (VERP) (Manning, 2001). Among these frameworks, ROS has been widely used and implemented by a number of federal land managing agencies including the U.S.Forest Service, the U.S. Bureau of Land Management, and most recently, the U.S. Bureau of Reclamation (Buist \& Hoots, 1982; Driver, Brown, Stankey \& Gregoire, 1987; Haas, Aukerman, Lovejoy \& Welch, 2004). 


\subsection{The Recreation Opportunity Spectrum}

ROS is a planning and management framework for determining recreational opportunities in a variety of settings (Driver \& Brown, 1978; Clark \& Stankey, 1979; Kaltenborn \& Emmelin, 1993). The U.S. Forest Service adopted ROS in the early 1970s to manage variety of recreational demands placed on its wildlands (Driver \& Brown, 1978; Clark \& Stankey, 1979; Sowman, 1987). In terrestrial environments, this spectrum of opportunities has been divided into six land management classes from 'primitive' to 'urban' type settings (Driver \& Brown, 1978; Clark \& Stankey, 1979). Different settings have different levels of physical alterations to the environment, remoteness, size, user density, and different levels and types of management actions (Kaltenborn \& Emmelin, 1993). The 'primitive setting', at one end of spectrum, assumes that users attracted to the area prefer remote areas with no developed facilities, minimum level of management, and a very low density of other people (Clark \& Stankey, 1979). This setting is also assumed to provide experiences like closeness to nature, tranquility, isolation, self-reliance, and challenge. The 'urban settings', at other end of the spectrum, are designed to provide a developed environment with high density and intensively managed experiences. Greater opportunities toward this end of the continuum are provided for competitive involvement, affiliation, and social enjoyment (Driver, Brown, Stankey \& Gregoire, 1987). Physical, social and managerial settings were used to further describe each of the various opportunity classes along the spectrum (Driver \& Brown, 1978). The physical setting comprised of human structures such as roads as well as its biophysical and cultural-historic resources. Users and their behaviors, equipment and other personal possessions they bring along, identify attributes of the social setting. The managerial setting reflects involvement of the administering agency such as on site presence of management personnel and types of services offered. Features of these three characteristics of 
the ROS settings have the potential to influence the types of activities and experience opportunities provided along the spectrum.

Since the introduction of ROS, it has been widely accepted as the most influential conceptual framework in recreation planning and management in a variety of settings, and has inspired the creation of other recreation/tourism planning frameworks. For example, Butler and Waldbrook (1991) adapted the basic concept of ROS and developed the Tourism Opportunity Spectrum (TOS), a comprehensive planning approach for managing tourist activities in natural environments. Six basic factors with several sub factors were identified to create hard, medium and soft adventure classes along the continuum. Hard adventure class consisted of undeveloped areas with no facilities and less contact with other people. Dawson (2001) refined TOS continuum by including five different settings of tourism management: ecotourism, nature-based tourism, rural tourism, rural-urban tourism and urban tourism. Of the five setting, ecotourism incorporated difficult or controlled access, minimal user impacts, limited infrastructure, infrequent interactions, and non-motorized conveyances similar to the characteristics of hard adventure in Butler and Waldbrook (1991). Urban tourism, on the other end of the spectrum, included features like easy access, higher impacts, extensive infrastructure, extensive user interactions and motorized conveyances.

Another spectrum, the Ecotourism Opportunity Spectrum (ECOS) (Boyd \& Butler, 1996) was also based on the concept of ROS and specifically devised for ecotourists. In ECOS, ecotourists are placed on a continuum based on their relative positions on a number of characteristics. Ecospecialists were positioned at one end of the continuum and were described as tourists enjoying in the local natural and cultural environment with minimal or no infrastructure; 
while the other end of continuum were ecogeneralists who participated in larger groups as part of organized eco-tour packages.

More recently, Haas, Aukerman, Lovejoy, and Welch (2004) developed the Water Recreation Opportunity Spectrum (WROS) which is also an extension of ROS. The goal of the WROS is to provide planners and managers with a framework for conserving a spectrum of quality and diverse water recreation opportunities. Like ROS, WROS also consists of six classes described as zones and were based on varying distances from developed and populated cities. The classes across a spectrum range from urban to primitive including suburban, rural developed, rural natural, and semi primitive. Both ROS and WROS are planning frameworks that assume that the quality recreational experiences are best provided by a range of opportunities along a continuum from developed to undeveloped.

Following its initial application and tests, ROS has been used in planning and management of recreational resources around the world. Perez-Verdin, Lee, and Chavez (2008) found that the ROS framework performed appropriately in planning forest recreation in two natural protected areas of southern Durango, Mexico, and recommended ROS for recreation planning purposes of other forest areas in the country. Darcy, Rosaline, Rick, Peter, and Philip (2010) used ROS as a basis of investigation and incorporated recreational users into marineprotected area planning in British Columbia, Canada. The concept of ROS has also been widely adapted in Australia and New Zealand in the field of resource management (McCool, Clark \& Stankey, 2007). The widespread use of the ROS suggests that it has been established as an important tool in the field of resource planning and management. 


\subsection{The Recreation Opportunity Spectrum and GIS}

Using and mapping ROS provides visual information of the recreational opportunities in the given area which can be used for planning, budgeting, and managing the resources as well as instructing visitors (Haas, Aukerman, Lovejoy, \& Welch, 2004). When applied with GIS, the ROS approach can be used for the development of recreation policies in a given location (Gobster, Gimblett, \& Kelly, 1987)

An early approach to spatially modeling physical landscapes was the mapping of wilderness perception by Kliskey and Kearsley (1993) using ROS. The study used rule based descriptive model for wilderness attributes such as the level of risk, skills required, and noise. Most studies so far have used ROS mapping for small areas. For example, Pierskalla, Siniscalchi, Selin and Fosbender (2007) mapped ROS classes in the Spruce Knob-Seneca Rocks National Recreation Area, West Virginia and used it to compare with recreational activities map. Flanagan and Anderson (2008) used GIS and mapped perceived wilderness to support protected area management by comparing the extent of perceived wilderness in Colorado's San Juan National Forest to ROS class groupings. Perez-Verdin, Lee and Chavez (2008) mapped ROS classes using GIS in two natural protected areas of southern Durango, Mexico. Xiao, Jia and Jiang (2012) mapped forest based recreation opportunity spectrum in the suburban mountainous region of Beijing, China using GIS.

Joyce and Sutton (2009) used GIS and developed ROS for all of New Zealand. However, this study did not use the original ROS classes as several of the categories and corresponding criteria were altered to reflect the country landscape and types of recreation opportunities therein. Also, they used only vector (points, lines and polygons) overlay to create ROS map which does not demonstrate the full capability of GIS. Overlay analysis for finding locations meeting certain 
criteria are often best done using raster (grid based) overlay (Environmental System Research Institute, 2007). This study, therefore, uses the concept of a regional approach and identifies the ROS classes in West Virginia using ROS criteria used by U.S. Forest Service. Also, both raster and vector datasets are used to accomplish the objective of the study.

\section{Methods}

\subsection{ROS Mapping}

In this study, physical setting criteria of ROS criteria applied by Pierskalla, Siniscalchi, Selin and Fosbender (2007) with modifications was used to determine the amount and distribution of ROS classes in West Virginia (Table 1). Advances in GIS mapping allowed for clearer delineation of areas under the SPNM, RN, and U classes of ROS applied by Pierskalla et al (2007) and the criteria were modified accordinagly.

Table 1. Criteria and classes of ROS

\begin{tabular}{llll}
\hline & Remoteness & Size & Structures \\
\hline Primitive $(\mathrm{P})$ & $\geq 3$ mi from all roads & 5000 acres & None \\
Semiprimitive & $<3$ mi from all roads and $\geq 1 / 2$ mile & 2500 acres & Minimal \\
Nonmotorized & from improved and unimproved & & \\
$($ SPNM) & roads & & \\
& & & \\
Semiprimitive & $<1 / 2$ mile from unimproved roads and & 2500 acres & Minimal \\
Motorized & $\geq 1 / 2$ mile from improved roads & & \\
$($ SPM $)$ & & & None \\
Roaded Natural & $<1 / 2$ mile from improved roads & ownership) \\
(RN) & & & \\
\hline
\end{tabular}




\begin{tabular}{llll}
\hline Table 1 (continued) & & \\
& Remoteness & Size & Structures \\
\hline Rural (R) & $<1 / 2$ mile from improved roads & None & Readily apparent \\
& & & (Private Ownership) \\
Urban (U) & $<1 / 2$ mile from improved roads & None & Dominant (Developed \\
& & & areas) \\
\hline
\end{tabular}

Criteria used include physical settings described by remoteness (i.e., distance from roads), size (i.e., number of acres), and evidence of structures (i.e. land ownership and developed areas). Different characteristics of each class were used to classify the state into six classes from $\mathrm{P}$ to U.

The criteria in the table were used in a conditional manner to identify different classes of ROS. For example, for a parcel of land to be classified as $\mathrm{P}$, it has to meet all of the following criteria: over 5000 acres in size, at least 3 miles from all roads, and no evidence of structures. Remaining classes were classified similarly using their respective criteria.

\subsection{Data and software}

Data for this study include shapefiles (vector) of counties detailed state boundary, roads, land ownership and incorporated places for West Virginia. Road data were downloaded from U.S. census TIGER/Line file for 2012. Data for land ownership were downloaded from U.S. Geological Survey, 2012. Information on incorporated places from U.S. census 2010 was used to display developed areas. Information on county wise travel spending in 2010 was obtained from the report "Economic Impact of Travel on West Virginia 2000-2010: Detailed State and County Estimates" prepared by Dean Runyan Associates (2010). Travel spending in this study includes spending by all overnight and day visitors in West Virginia in accommodation and in different types of businesses with expenditures on food services, recreation, local transportation, and retail 
purchases. Visitors include U.S. residents, foreign visitors, and West Virginia residents travelling within the state that were not commuting nor undertaking other routine travels. Raster maps created in this study consists of cell size 30 by $30 \mathrm{~m}$. ArcGIS version 10 by Environmental Science Research Institute (ESRI) was used for analyzing and displaying ROS maps. Geographic Data Analysis (GeoDa) version 1.4.6 was used for spatial autocorrelation and spatial regression.

\subsection{GIS methods for mapping ROS classes}

This section includes the detailed explanation of methods that has been used to map ROS classes. A summary of procedures undertaken is provided in Figure 2 


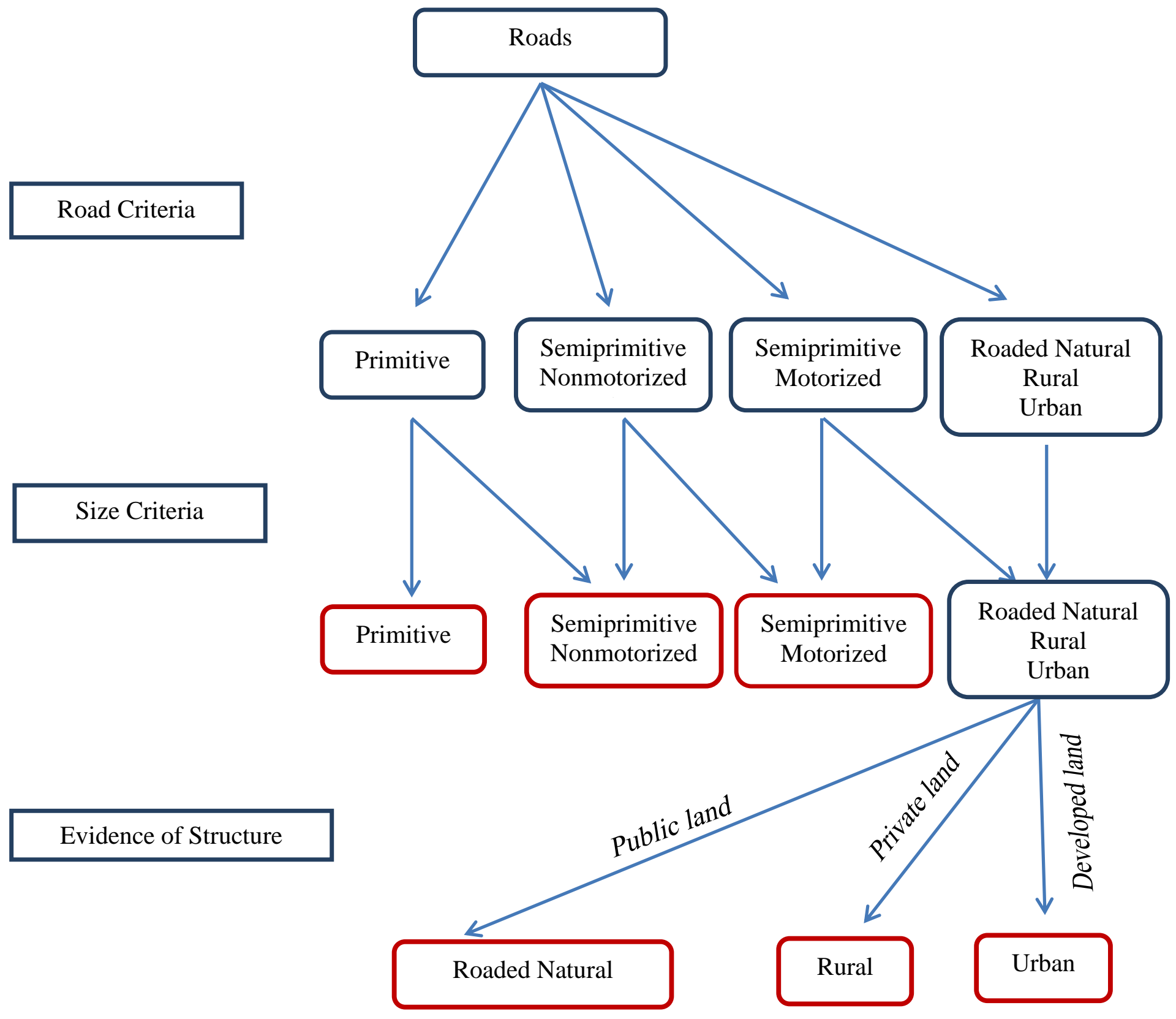

Figure 2. Summarized flowchart showing the process for ROS classification 


\section{Step 1: ROS classes with remoteness criteria}

Remoteness criteria require roads as an input to differentiate different classes of ROS. Road shapefile was split into improved and unimproved roads based on usage. Roads that were constructed and maintained for the use of highway-type vehicles with more than two wheels were considered as improved roads. Loose surface roads and logging roads were considered as unimproved roads. In road layer from TIGER/Line file does not have information about the surface type, therefore roads with names were classified as improved roads and roads without names as unimproved roads. To verify this, 50 random unnamed roads were overlayed in high resolution aerial photographs in GIS. It was found that all the unnamed roads were either logging or loose surface roads. Based on the information on roads, distance grid for all roads, improved roads, and unimproved roads were created.

$\mathrm{P}$ class provides the most remote recreation opportunities and was the first to be classified in this assessment. To identify $\mathrm{P}$, areas that were at least 3 miles or 4828.03 meters away from roads were determined using the conditional statement $($ Con("all road" $>=4828.03,1,0)$ ) with unique value 1 given to $\mathrm{P}$ areas. Since the display unit of GIS was in meters, miles were converted into meters for analysis. The resultant map showed suitable areas for $\mathrm{P}$ with grid value 1 and unsuitable areas with grid value zero. Similarly, potential areas for SPNM and SPM were determined using conditional statements: (Con (("all road" < 4828.03) \& ("unimproved_road" >= 804.67) \& ("improved_road" >= 804.67), 2, 0)) and (Con (("improved_road">= 804.67) \& ("unimproved_road" < 804.67), 3, 0)), respectively. For areas under SPNM and SPM, grid values 2 and 3 represent areas suitable for those classes and value zero represents unsuitable areas. Since RN, R, and U shared the same conditions for remoteness criteria, these classes were grouped together with conditional statement (Con (("improved_road" < 804.67), 4, 0). Finally, 
all the layers representing different classes were added in raster calculator to get remoteness adjusted map for ROS classes with values 1, 2 and 3 representing P, SPNM and SPM areas, respectively and value 4 representing grouped $\mathrm{RN}, \mathrm{R}$ and $\mathrm{U}$ areas.

\section{Step 2: ROS classes with remoteness and size criteria}

In this step, map created for remoteness criteria was analyzed to confirm whether different ROS classes satisfy the size criterion of the respective classes or not. For this, raster based remoteness criteria map was converted to polygon and calculation of area in acres for each polygon was done in GIS. Polygons that did not satisfy the size criterion for the assigned class were merged with the neighboring lower class. For example, for an area to be P, size of the polygon should be least 5000 acres. If a P class polygon doesn't satisfy this size criterion, then this polygon would be merged into neighboring SPNM class. To do this, all the polygons that didn't satisfy the size criterion for that class were selected using query (("GRIDCODE" $=1$ AND "AREA" <5000) OR ("GRIDCODE" = 2 AND "AREA" <2500) OR ("GRIDCODE" = 3 AND "AREA" <2500). The selected polygons were then merged into their neighboring polygons. Once the size criterion for each ROS class was adjusted, the polygons were then converted back to raster grids. The map created in this step thus showed the ROS classes adjusted for remoteness and size criteria. Similar to the remoteness criteria, RN, R, and U classes share the same conditions for size criteria, therefore they were grouped together.

\section{Step 3: Complete ROS}

In this step, evidence of structures map was created with three classes: public, private, and developed areas (incorporated places). The map created with unique values for public, private, and developed areas was overlayed to the map of ROS classes from the second step. Since ROS and land ownership classes have unique values, ROS classes in public and private 
lands were obtained by combining both maps. P, SPNM and SPM did not take landownership criteria into consideration, thus areas of these classes under different ownerships were reclassified to get the final ROS classes. In final ROS map, grouped RN, R, and U areas with public landownership were classified as $\mathrm{RN}$, private landownership was classified as $\mathrm{R}$ and developed areas was classified as U, respectively. With all the six classes classified, the resultant map created at this stage was the final map of different ROS classes.

\subsection{Spatial analysis of ROS classes}

\subsubsection{Spatial autocorrelation analysis}

Spatial autocorrelation measures the similarity (or dissimilarity) of values of an attribute that are close spatially (Chi \& Zhu, 2008). Clusters of high high values or low low values of an attribute depict positive spatial autocorrelation whereas locations wherein neighboring values of an attribute tend to be very different from each other (e.g., high value location surrounded by low value neighbors) depict negative spatial autocorrelation. Among the various indices used to measure spatial autocorrelation, Moran's I statistic is perhaps the most widely-used (Getis, 2008). Moran's I statistic measures the degree of linear association by considering both the attribute values and their locations simultaneously (Griffith, 1987). Since Moran’s I measures spatial autocorrelation across the entire study area, it is often viewed as a global Moran's I. Although Moran's I is useful for analyzing data sets in a relatively homogeneous region, the results may be misleading in regions with several spatial regimes (e.g., localized areas depicting both positive and negative spatial autocorrelation) (Anselin, 1996). In such cases, a set of Local Indicators of Spatial Association (LISA), such as local Moran’s I (Anselin, 1995; Cliff \& Ord, 1973, 1981), G and $\mathrm{G}^{*}$ statistics (Ord \& Getis, 1995), and K statistic (Getis, 1984; Ord \& Getis, 1995) need to 
be applied. LISA allows for the decomposition of a global measure into contributions from individual observations and identifies outliers.

Percentage of ROS classes per county was calculated and spatial correlation was run to determine the spatial distribution of clustering. Global spatial autocorrelation (Moran's I) was calculated using queen contiguity weight matrix to determine the clustering of ROS classes. LISA was used to examine the spatial distribution of clustered variables. In this study, local Moran's I significance and cluster maps for the univariate ROS classes in West Virginia were created using GeoDa. GeoDa bases local Moran's I maps on LISA such that the sum of the Local Moran's I statistics is proportional to the Global Moran's I value (GeoDa Center).

The result of cluster analysis in GeoDa comes with different values and colors. Normally, white areas indicate polygons that have values that are not significant, High-High (bright red) areas indicate polygons that have high values with neighboring polygons' values also being high; Low-Low (bright blue) areas indicate polygons that have low values, and are neighbored with polygons that also have low values; Low-High (light blue) indicates polygons that have low values with neighboring polygons' values being high. High-Low (light red): indicates polygons that have high values with neighboring polygons' values being low.

\subsubsection{Regression Analysis}

A linear regression model assumes that the error terms are independently, identically, and normally distributed (e.g., Draper \& Smith, 1998; Fox, 1997; Greene, 2000). However, in cases where the variables are spatially autocorrelated, one or more of the assumptions may not hold. Spatial lag and spatial error are the two primary types of spatial autocorrelation discussed. Spatial lag occurs when the dependent variable in location $i$ is affected by independent variables in location $i$ as well as in location $j$. This violates the assumption of independent observations 
and the linear regression results are biased and inconsistent (Fischer \& Getis, 2009). Spatial error occurs when the observations themselves are not correlated, but the error terms are correlated and therefore the regression results become inconsistent (Fischer \& Getis, 2009). The relationship between travel spending and the ROS classes was first estimated using Ordinary Least Square (OLS). Traveling spending was used as a dependent variable and percentage of ROS classes as independent variables. Lagrange multiplier (LM) diagnostics on the OLS for the spatial lag dependence or the spatial error dependence were not found to be significant. Therefore, OLS estimates were used in the study.

\section{Results}

\subsection{ROS classes with remoteness criteria}

ROS classes with remoteness criteria show that most of the state's land falls under the combined RN, R, and U class (82.161\%), followed by SPM (12.365\%), SPNM(5.472\%) and P $(0.001 \%)$. Areas under RN, R, and U classes are scattered throughout the state whereas most of land under SPNM, SPM, and P classes were located in the eastern part of the state (Figure 3). 


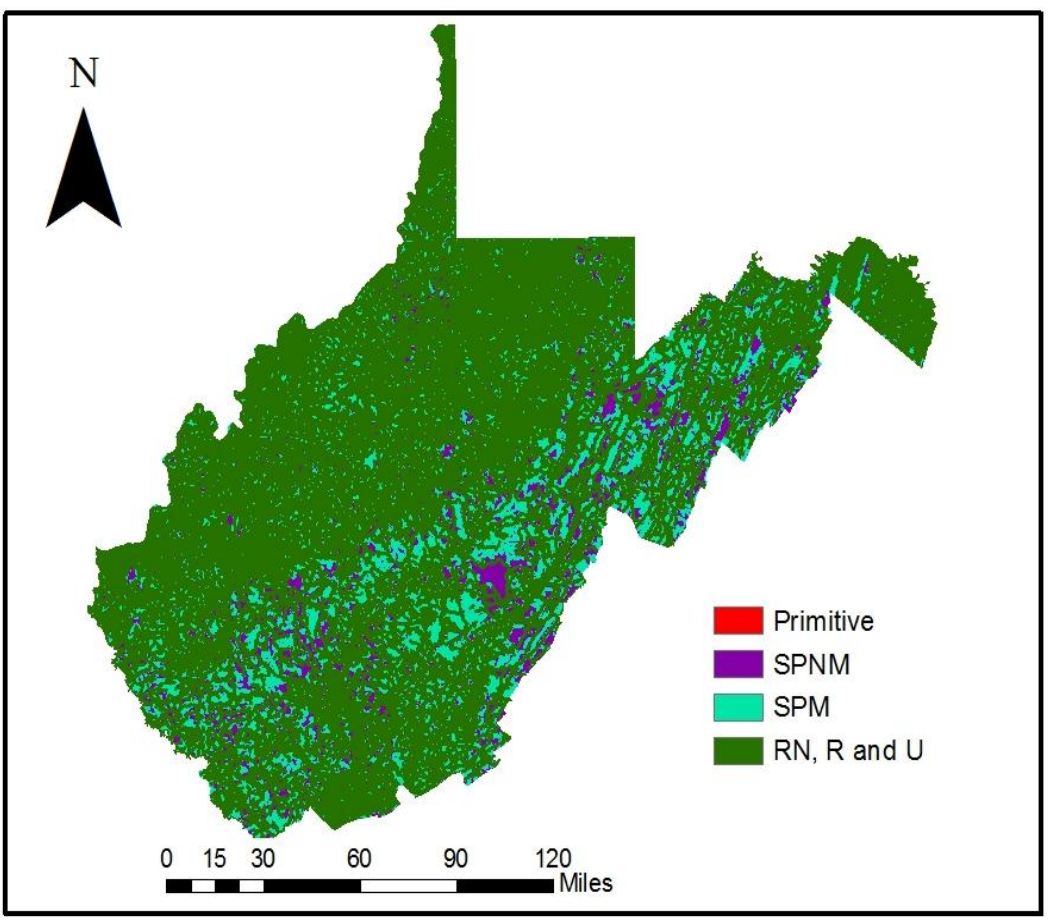

Figure 3. ROS classes with remoteness criteria

\subsection{ROS classes with remoteness and size criteria}

The vector file created 14,361 polygons for West Virginia. When the size criterion was taken into consideration, it was found that two polygons which were classified as $\mathrm{P}$ in the remoteness criteria were less than 5000 acres in size, and therefore they did not meet the size criterion to be classified as P and were merged with the neighboring SPNM polygons. Further, only 214 polygons were found larger than 2500 acres and met the size criterion to be classified as SPNM and SPM.

14,135 of the remaining polygons had area less than 2500 acres, and were therefore merged into the neighboring $\mathrm{RN}, \mathrm{R}$ and $\mathrm{U}$ class polygons.

Raster map of ROS classes with remoteness and size criteria (Figure 4) shows no P class as none of polygons satisfied the size criteria. Thus, ROS map in this stage contains only three classes. Combined RN, R, and U class constituted the majority of land in West Virginia 
(90.32\%), followed by SPM (7.23\%), and SPNM (2.45\%). The distribution of the different classes in this step was similar to that in 4.1 .

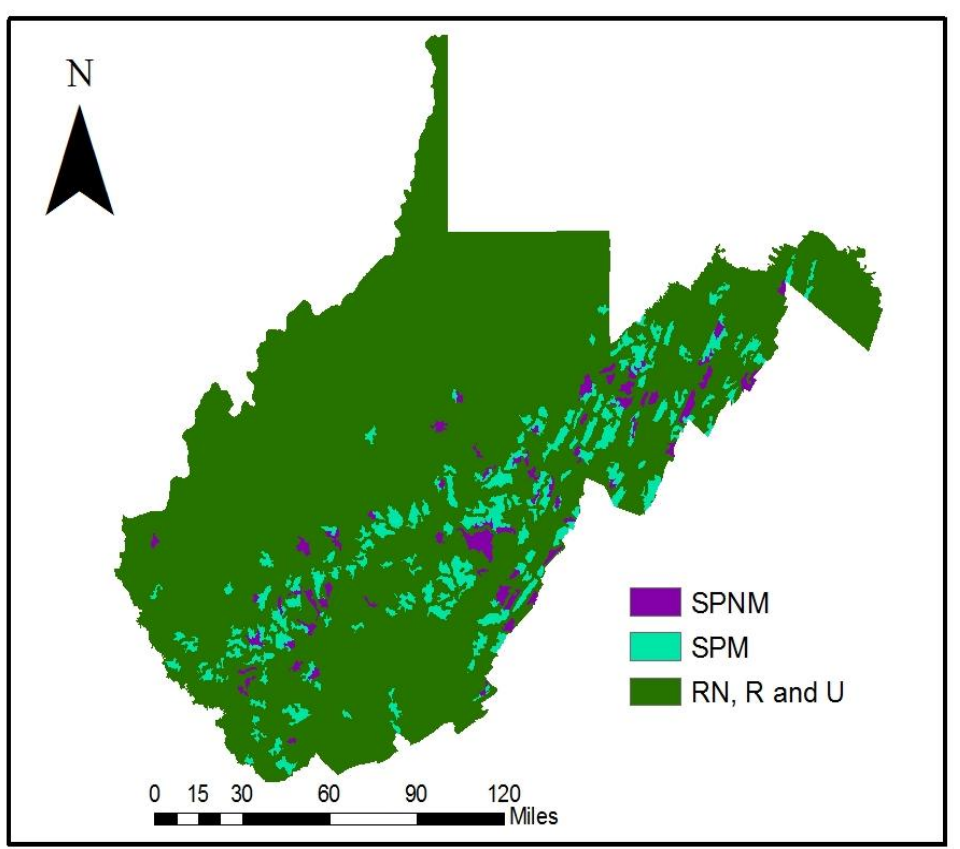

Figure 4. ROS classes with remoteness and size criteria

\subsection{Complete ROS classes}

The figure 5 below shows the land ownership map for West Virginia. The majority of the land was privately owned (86.35\%), followed by public land (10.35\%), and urban areas $(3.29 \%)$. 


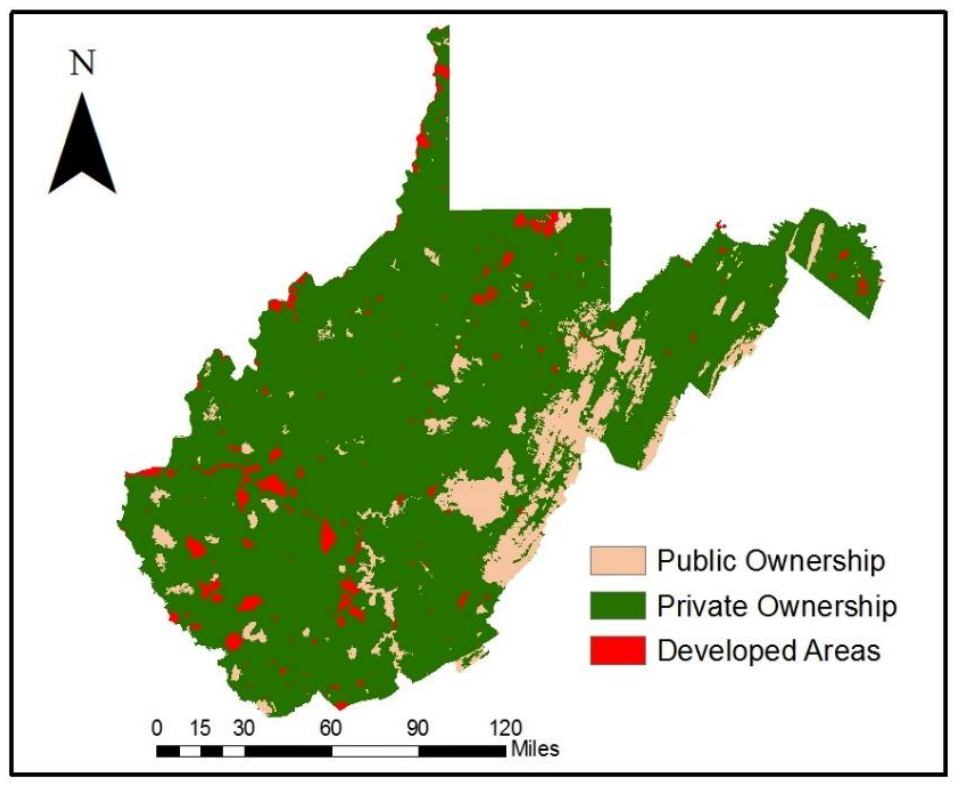

Figure 5. Land ownership map for West Virginia

The land ownership map was overlayed with the map of ROS classes with remoteness and size criteria to get ROS classes with ownership of land (Figure 6).

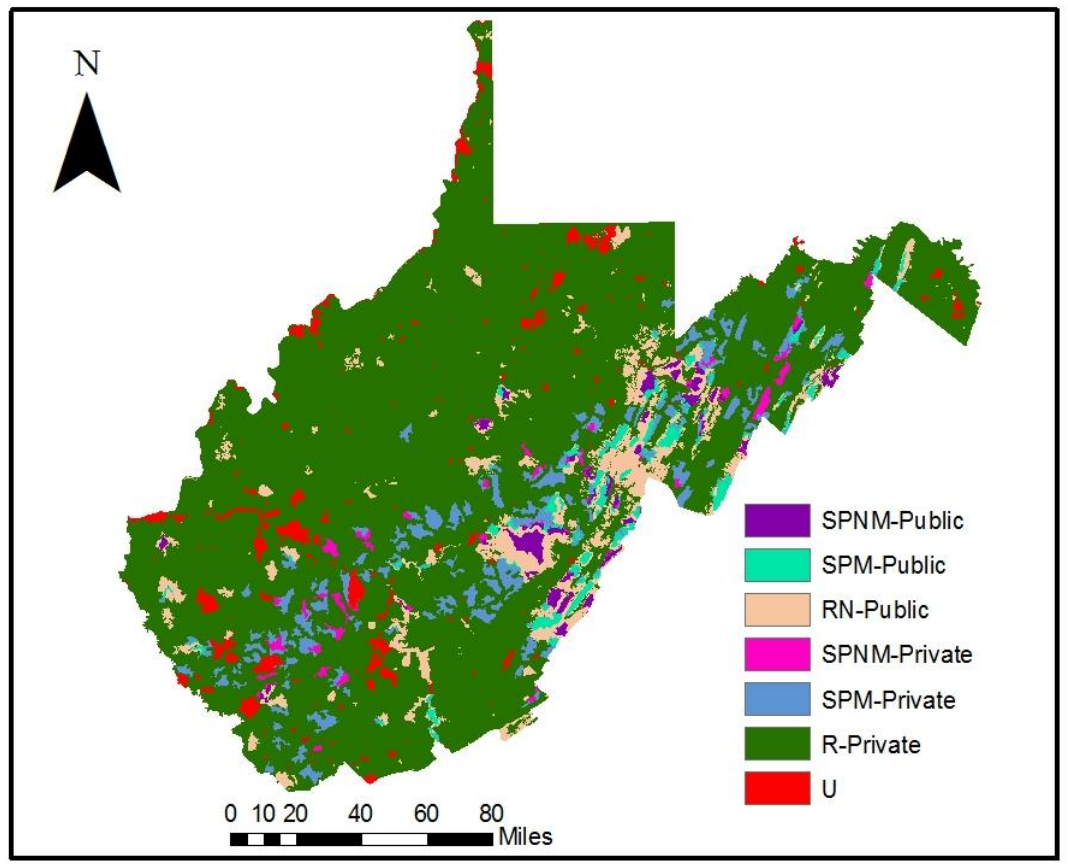

Figure 6. ROS class and land ownership map for West Virginia 
It was found that $1.34 \%$ of land under SPNM and $1.88 \%$ of land under SPM classes were public; $1.10 \%$ of land under SPNM and $5.35 \%$ of land under SPM were private; RN covered $7.13 \%$ of public land; R covered $79.90 \%$ of private land and U occupied $3.29 \%$ of the developed areas. Since SPNM and SPM did not have specific land ownership criteria, they were grouped together to show the final ROS class (Figure 7). 


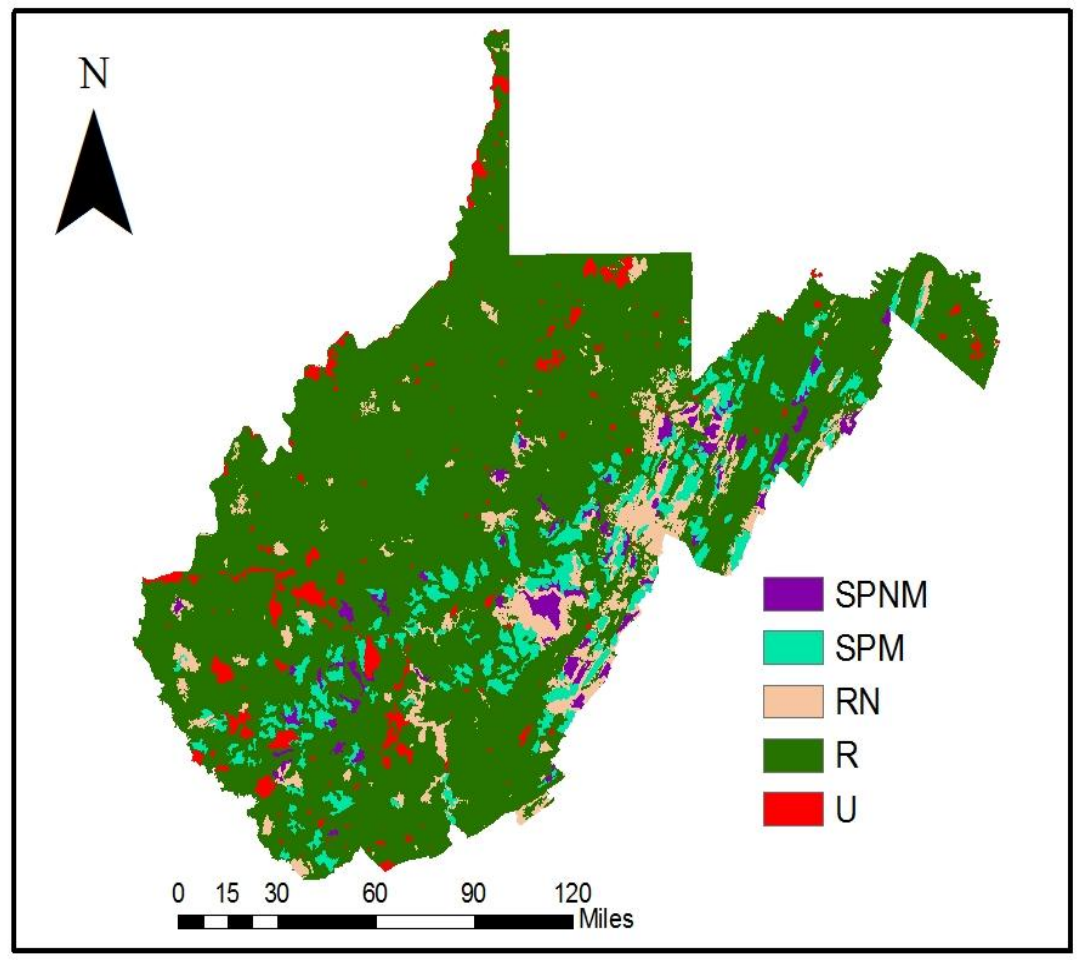

Figure 7. Final ROS map for West Virginia

Final map of ROS indicated that R made up the largest class, accounting for $79.90 \%$ of the entire study area, followed by SPM (7.23\%), RN (7.13\%), U(3.29), and SPNM (2.45\%). There was no $\mathrm{P}$ class as the size criterion was not met.

\subsection{ROS class for Pocahontas County}

From figures 7 and 8, ROS map with land ownership and final ROS map for any area in West Virginia can be extracted. For example, figures 8 and 9 show the ROS map with land ownership and final ROS map for Pocahontas county of West Virginia, respectively. 


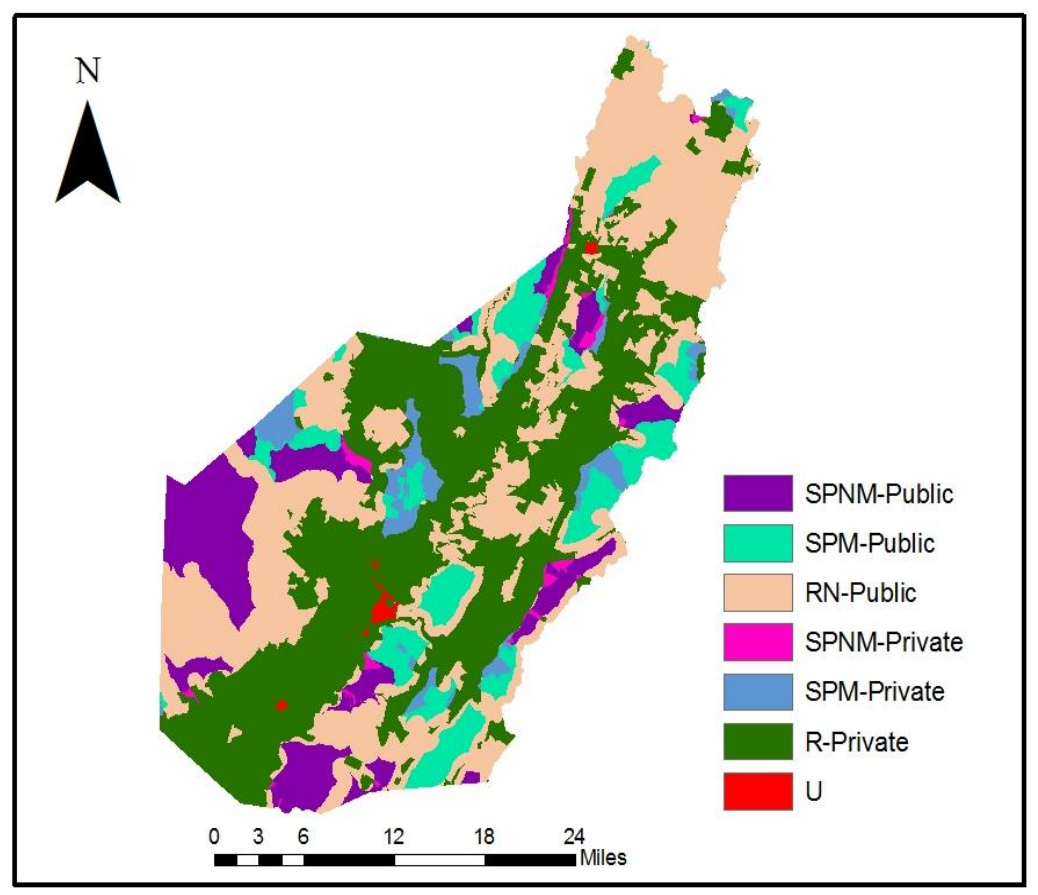

Figure 8. ROS class land ownership map for Pocahontas County

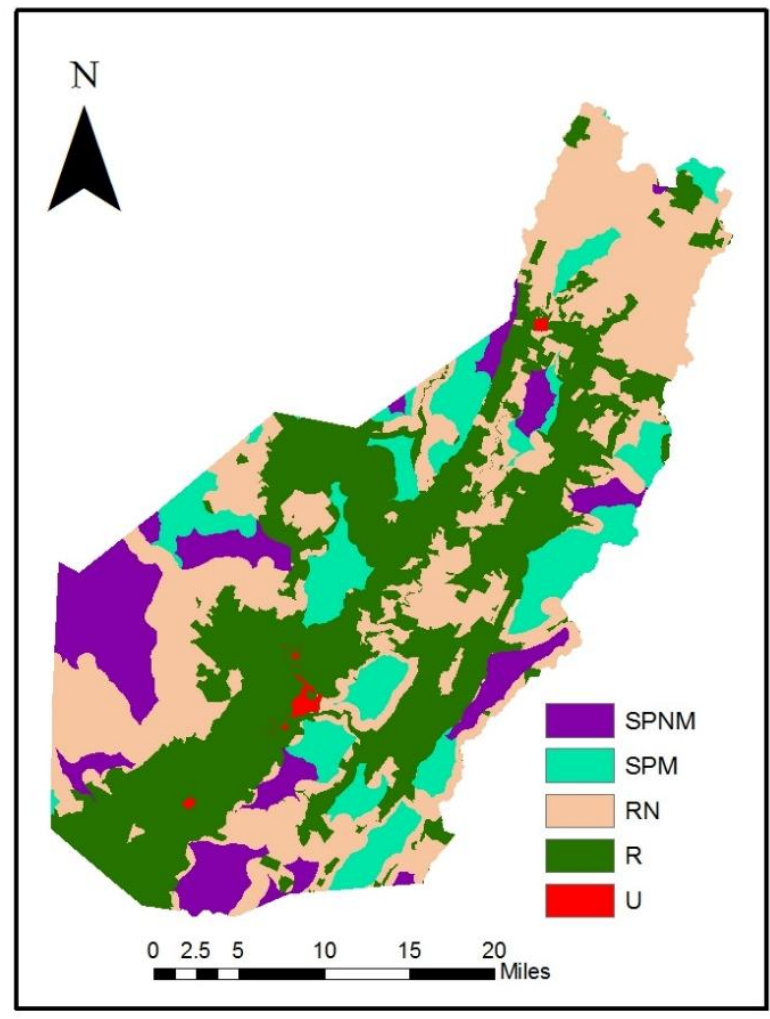

Figure 9. ROS class for Pocahontas County 
To verify the results of the study, a map that displays existing recreation areas in the state were overlayed on the complete ROS map for the county (Figure 10). It was found that most of recreation areas were under the SPNM, SPM, and RN classes.

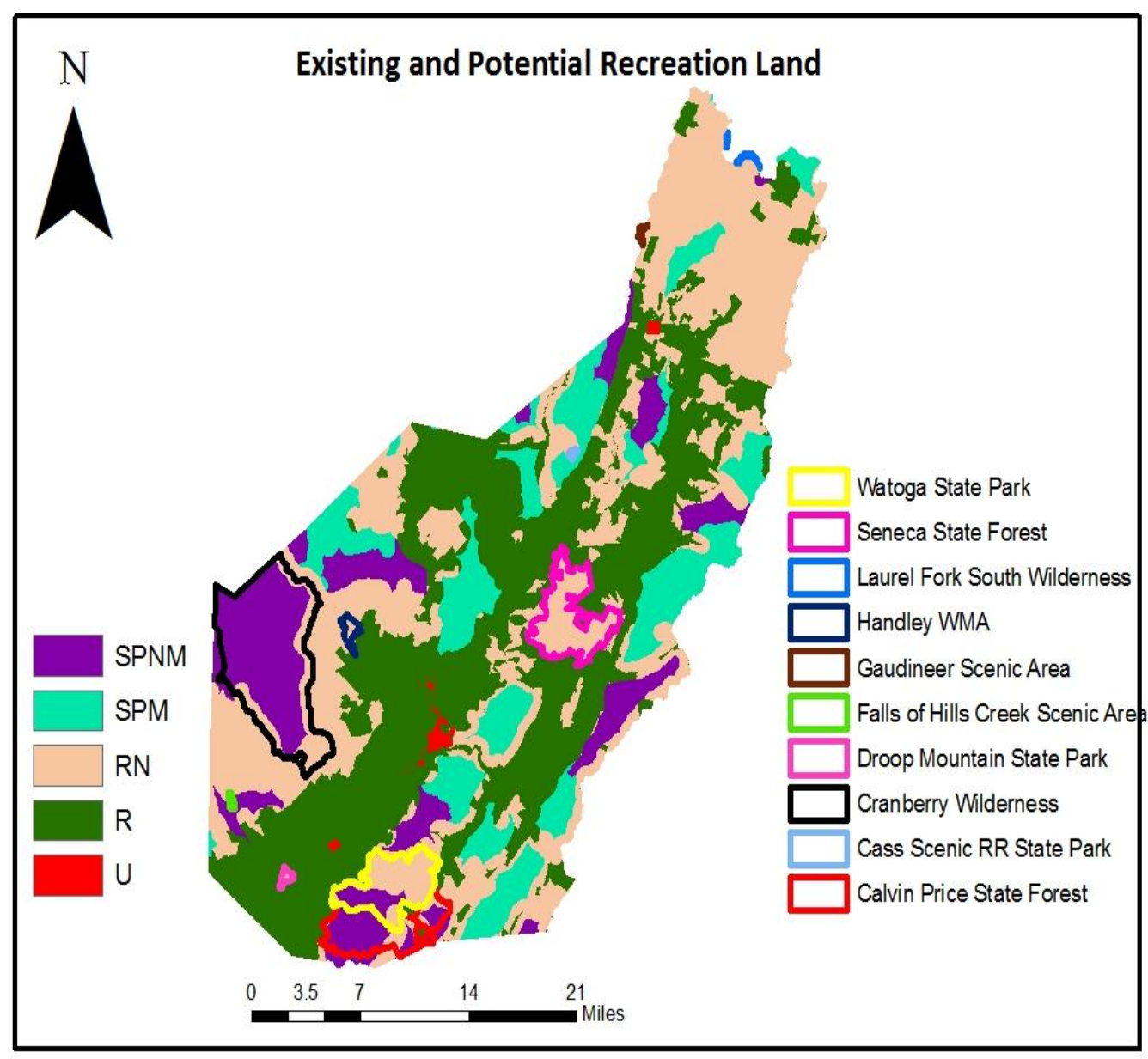

Figure 10. ROS class and existing recreational areas in Pocahontas County 


\subsection{Spatial autocorrelation}

Results from the Moran's I showed that all the variables were found to have significant spatial autocorrelation at 5\% level of significance except travel spending of 2010 and U class (Table 2).

Table 2. Summary for Moran's I

\begin{tabular}{lll}
\hline Variables & Moran's I value & P-value \\
\hline Travel spending (2010) & 0.01 & 0.25 \\
SPNM & 0.34 & 0.00 \\
SPM & 0.52 & 0.00 \\
Public SPNM & 0.33 & 0.01 \\
Public SPM & 0.52 & 0.00 \\
Private SPNM & 0.28 & 0.01 \\
Private SPM & 0.40 & 0.00 \\
RN & 0.50 & 0.00 \\
R & 0.41 & 0.00 \\
U & 0.01 & 0.23 \\
\hline
\end{tabular}

Figures $11,12,13,14,15,16,17$, and 18 display the results from LISA for total SPNM, total SPM, public SPNM, public SPM, private SPNM, private SPM, RN, and R, respectively. 


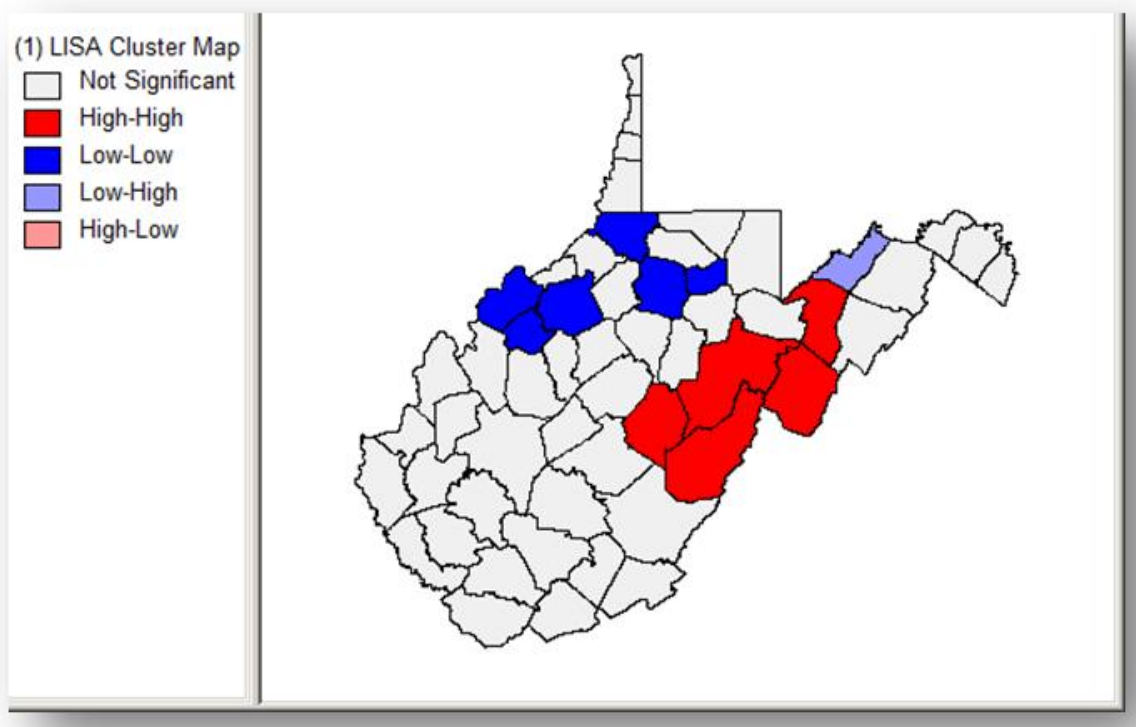

Figure 11. LISA map for total semiprimitive nonmotorized

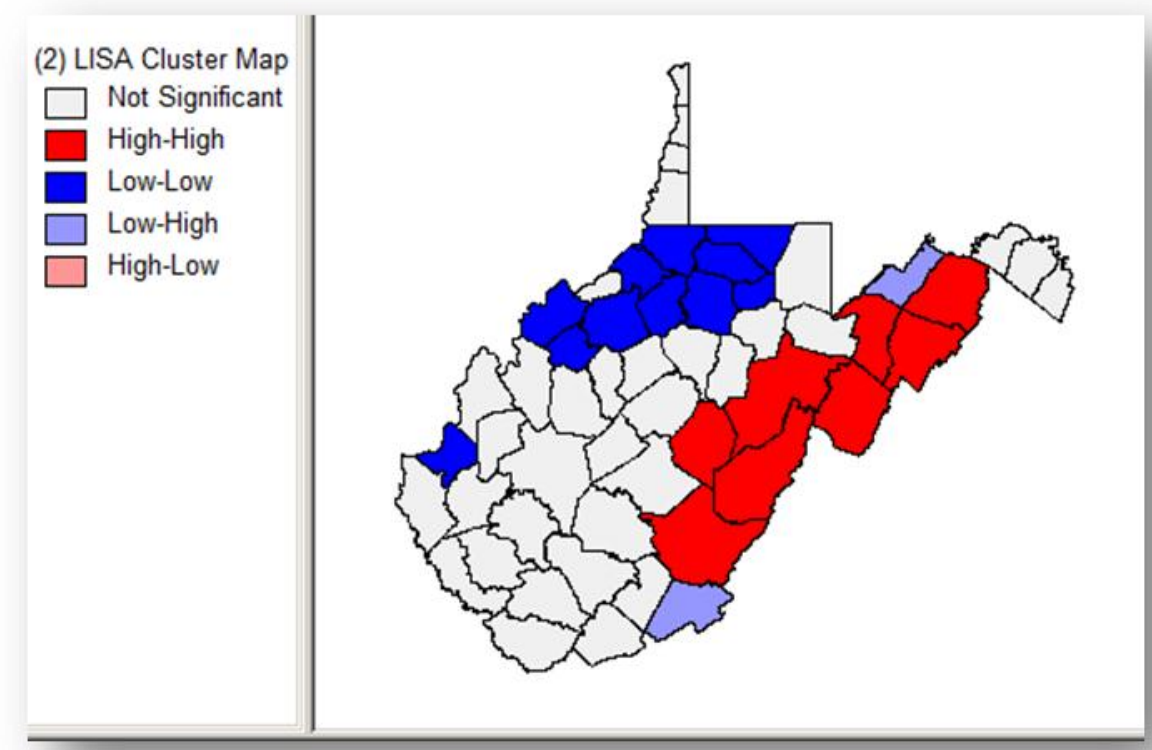

Figure 12. LISA map for total semiprimitive motorized 


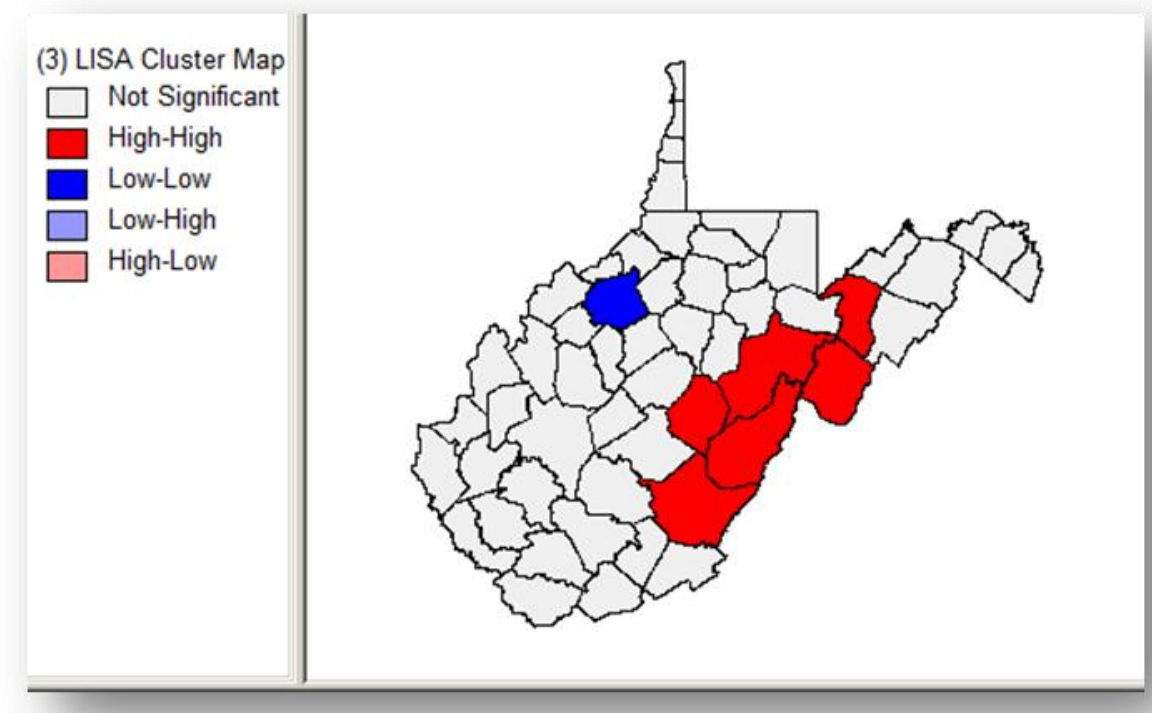

Figure 13. LISA map for public Semiprimitive Nonmotorized

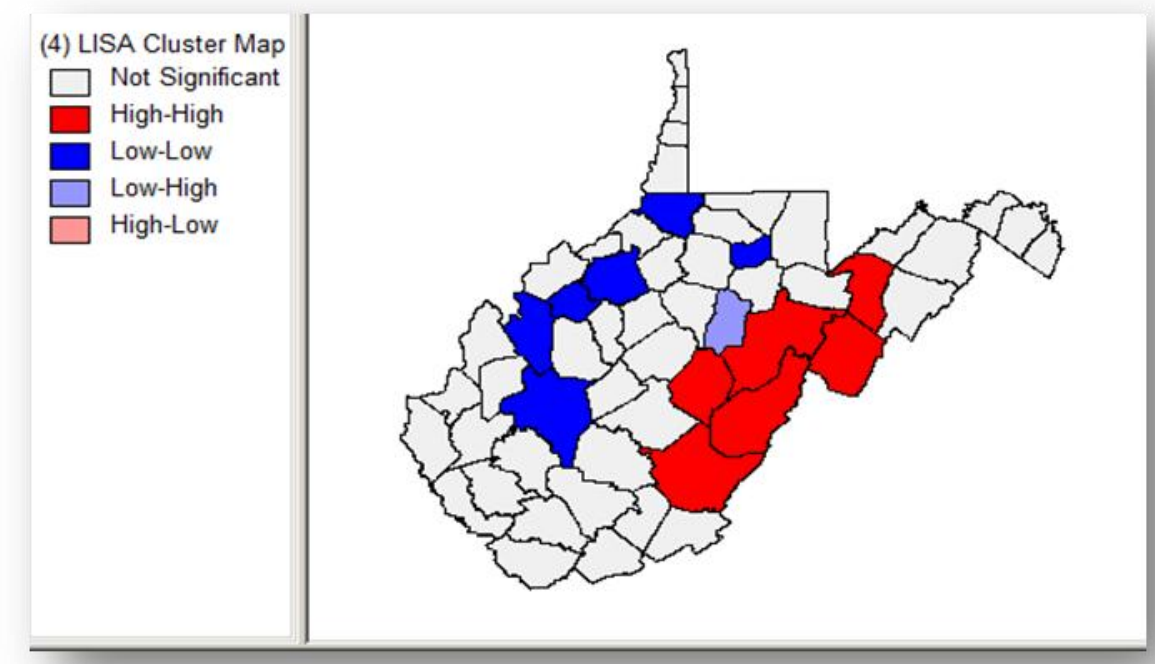

Figure 14. LISA map for public Semiprimitive Motorized 


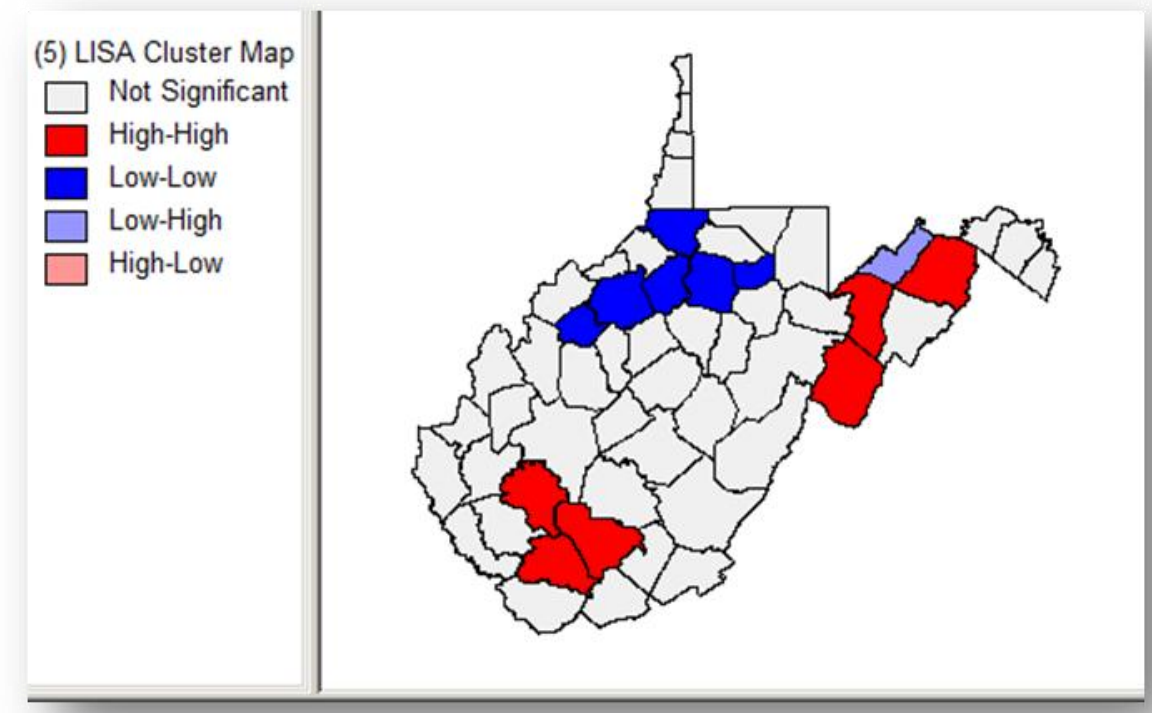

Figure 15. LISA map for private Semiprimitive Nonmotorized

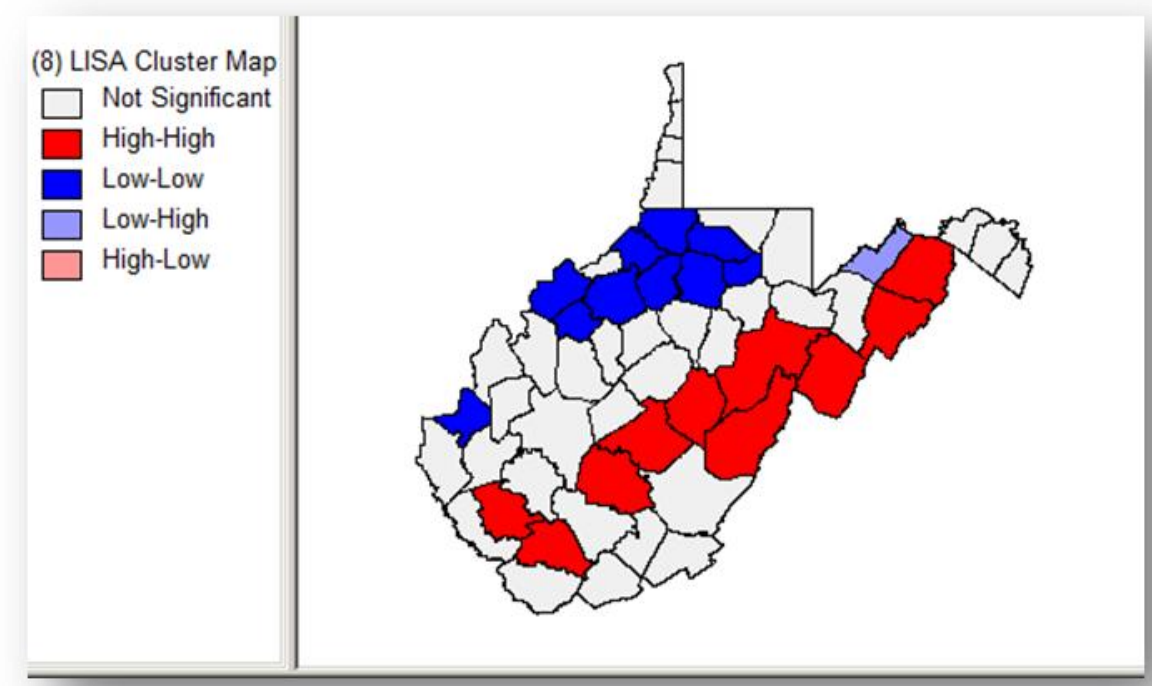

Figure 16. LISA map for private Semiprimitive Motorized 


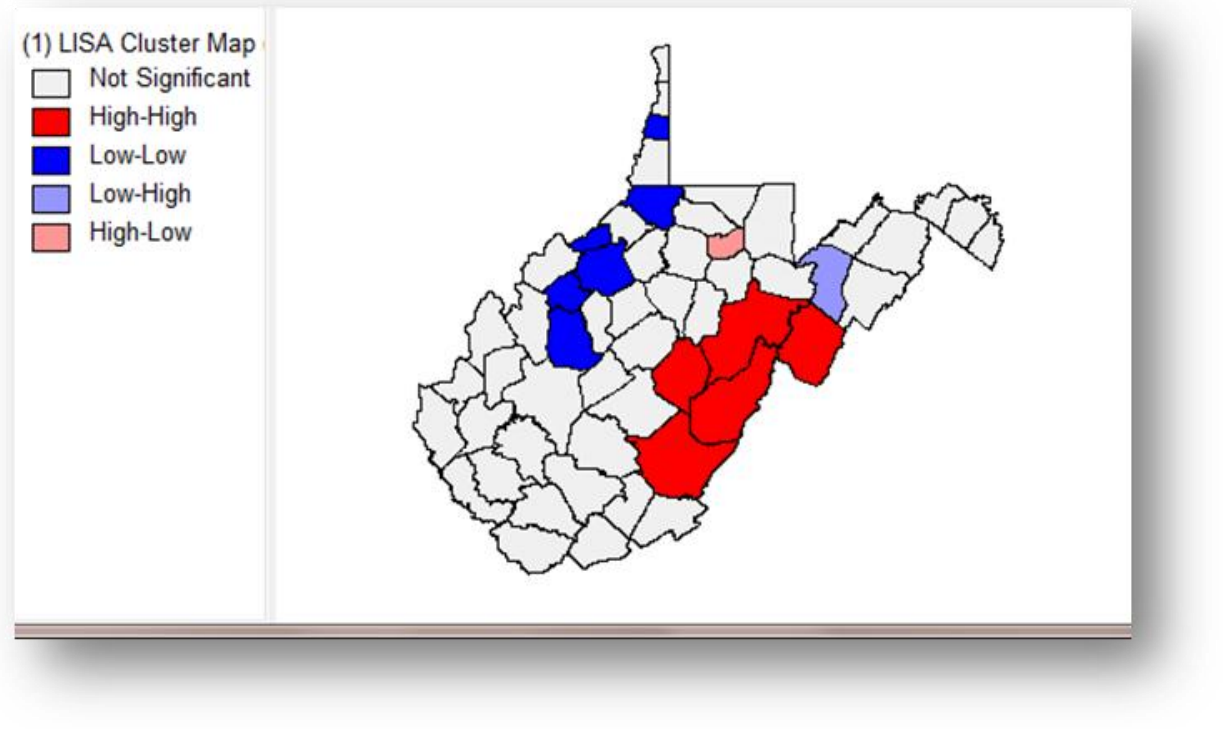

Figure 17. LISA map for Roaded Natural

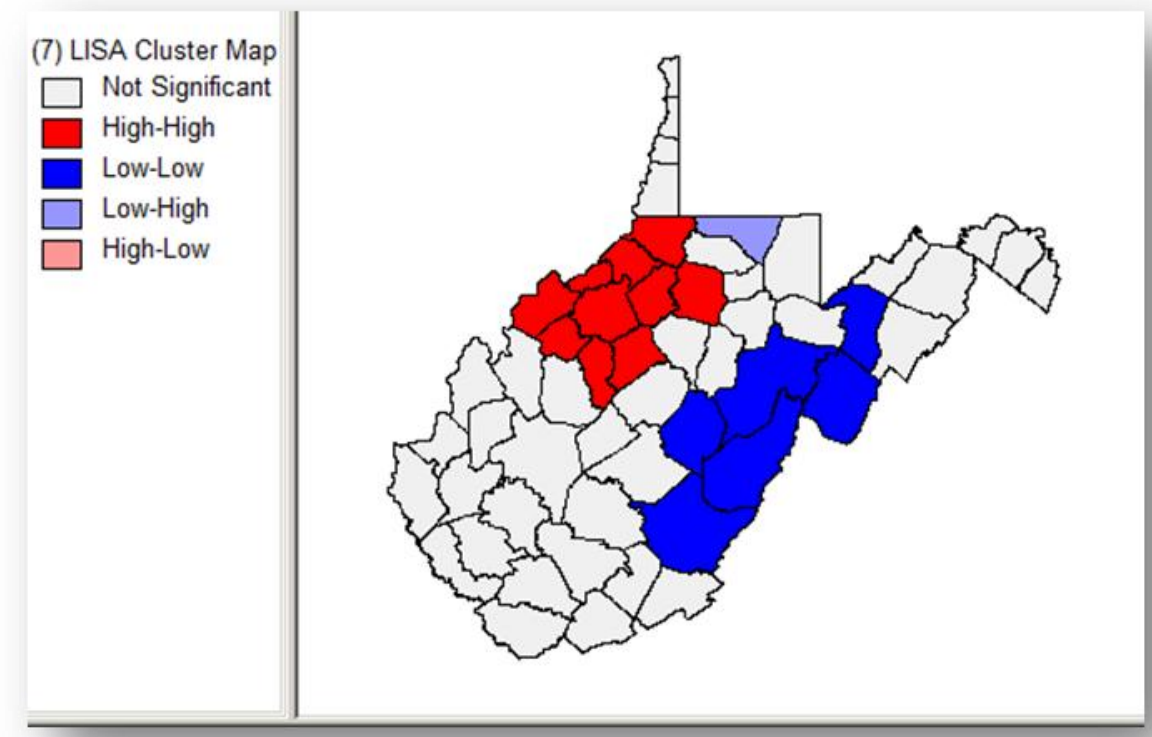

Figure 18. LISA map for Rural

For SPNM, SPM, public SPNM and private SPM significant high-high clustering was found in the north eastern counties of West Virginia whereas low-low clustering was found in the north western counties of the state. This indicates that the eastern part of the state has 
counties with higher SPNM, SPM, public SPNM and private SPM classes. For R, significant high-high clustering was found in the north western part of the state indicating the highly rural nature of the region whereas low-low clustering was found in the north eastern counties.

\subsection{Spatial regression}

Table 3 presents the OLS regression results. Significant positive relationship was found between urban and travel spending of $2010(p<0.05)$. Other variables were not found to be significant. The result suggests that a county with more urban class (accommodation, restaurants, shopping centers, festivals and museum) tended to have more travel spending than others. Travel spending with SPNM, SPM, RN, and R also had positive relationship though the effects were not significant. Also, the model explains $24 \%$ of the variations in the dependent variable.

Table 3. Summary result from OLS model

\begin{tabular}{llc}
\hline Variables & Coefficient & P-value \\
\hline Intercept & $-6.98^{*}$ & 0.06 \\
SPNM & 4.69 & 0.84 \\
SPM & 3.78 & 0.76 \\
RN & 0.78 & 0.92 \\
R & 0.29 & 0.91 \\
U & $13.89 * * *$ & 0.00 \\
\hline F-value & 3.13 & 0.01 \\
Moran's I & 0.76 & 0.44 \\
Adjusted R square & 0.24 & 0.85 \\
Lagrange Multiplier (lag) & 0.04 & 0.81 \\
Lagrange Multiplier (error) & 0.06 & \\
\hline
\end{tabular}




\section{Discussions}

This study developed ROS model and classified West Virginia land into different classes based on physical setting criteria. Results showed that most of the areas in the state were $\mathrm{R}$ followed by SPNM and RN. Specifically, the majority of areas in the western part of state were $\mathrm{R}$ and thus suitable for rural/heritage based tourism. Areas in the eastern part of the state were suitable for both nature and rural/heritage based tourism as SPNM, SPM, RN and R classes were found in the area. $\mathrm{P}$ areas were not found in the state as none of the areas met all the three criteria of the $\mathrm{P}$ category in ROS.

The ROS map was also compared with a map of public areas in the state. It was found that the class SPNM, SPM and RN represented state parks, state forests, national forests, wilderness areas, wildlife management, and scenic areas. The ROS map also delineated potential areas for different classes of recreation along the spectrum. ROS map with land ownership showed that $5.35 \%$ of SPM and $1.10 \%$ of SPNM fall under private ownership. This implied that private land ownership can promote different kinds of recreational activities in their land and help overall tourism in the state. The final ROS map showed that about $2.45 \%$ of the state could cater to tourists who value wilderness (SPNM). Further, $14.36 \%$ of the state could be suitable for tourists who value wilderness but also desire some form of amenities (SPM and RN). This was validated by overlaying campsite locations in the ROS map which showed that most campsites were located in SPM and RN. Areas under RN and U class are suitable for tourists who value amenities and accessibility. The ROS maps of West Virginia (Figures 6 and 7) can be used to extract ROS classes with land ownership as well as final ROS classes for any given area (Figures 8 and 9) 
Cluster analysis indicated that counties with high percentage of ROS classes were found largely concentrated in the eastern or central eastern part of state. Public areas in this region consisted of Appalachian National Scenic Trail, Bluestone National Scenic River, Chesapeake \& Ohio Canal National Historical Park, Chesapeake Bay Gateways Network, Gauley River National Recreation Area, and New River Gorge National River. National and state forest in this part comprised of Monongahela National Forest and Caanan Valley, Blackwater Falls, and Greenbrier State Forest.

U class of ROS did not exhibit a distinct clustering pattern as compared with other ROS classes. However, regression analysis showed that visitors' travel spending were significantly associated with the $\mathrm{U}$ class. This implied that counties with large $\mathrm{U}$ areas offer recreation opportunities as well as a variety of services that the visitors seek: accommodations, restaurants, shopping, and entertainment like gambling and racetracks. Counties with more of the other ROS classes but less of the $\mathrm{U}$ class were found to have less visitors spending. Marketing of the existing recreational opportunities offered by the different ROS classes in such counties could attract more spending in the areas.

GIS and GeoDa were found to be a useful tool in analyzing and visualizing the outputs of ROS. There were, however, certain limitations that might have influenced the findings of the study. First, the study used only physical setting criteria of ROS since information on managerial and social setting for the entire state were not available. This may have caused variations in the overall ROS results. Thus, the results of this study would provide detailed information on the nature of recreation opportunities based on environmental surrounding of the areas rather than on the behavior of recreationists and managing agencies. Second, the study used road layer information from U.S. census TIGER/Line where surface type for road was not specified. This 
inhibited the ability to distinguish between improved and unimproved roads for the state. Attempts were made to classify the roads and check for validity in a small area however, the accuracy of road information might also have overall influence on the resulting map. Third, the study used back and forth conversion of vector and raster data which can reduce the accuracy of area calculation for each class and might affect overall results. Fourth, ground truthing could be used to further improve the results of the study. For example, several random points in each ROS class could be selected with locational (longitude and latitude) information. Using a Global Positioning System (GPS) unit, exact location of these points on the ground could be determined, and their attributes (remoteness, size, if possible, and naturalness) could be compared with ROS results to determine their accuracy. Wall et al. (1997) class descriptions could also serve as a qualitative tool to determine whether or not each of the ROS classes has a certain "feel" to it. For example, while checking SPNM area, we can look for whether distance limitations effectively provide a sense of solitude or vehicular traffic could still affect the experience in the area, whether the vegetation looks undisturbed, or the distant clear cuts or strip mines suggest human interference. These issues challenge setting inconsistencies and raise the use of viewshed analysis in the mapping ROS classes. For example, particular location might meet the criteria for SPNM, however land adjacent to it may not meet the criteria which would impact overall classification. Therefore, ground truthing would help estimate the accuracy of GIS results for identifying recreation opportunities.

Finally, inclusion of other tourism related information like natural and cultural resources, tourism businesses, tourism employments and weather based tourism activities could provide more light in explaining travel spending. 


\section{Conclusions}

This study presented a methodology for mapping ROS classes for West Virginia. Results indicated that state is suitable for wide spectrum of recreation opportunities from SPNM to U, as shown by different classes in the final ROS map. P areas were also found using the remoteness criterion of ROS but the areas failed to meet the size criterion (>5000 acres). The result also indicated the diversity of recreation lands in the state, with the most-represented ROS classes in the private (or modified) landscapes i.e. rural class, and the least-represented categories in SPNM class of the spectrum. GIS and GeoDa were found to be useful tools in analyzing and visualizing the outputs of classification, cluster, and regression analysis. Also, the framework demonstrated in this study is flexible as new rules and criteria can be added or modified to fit the context of the study area.

The tourism and recreation industry aims to attract more tourists by advertising the destination characteristics. Mapping ROS classes at regional level provides information on the type and size of ROS available in the area that could benefit agencies responsible for resource planning and management to assess the potential activities within the area and advertise them accordingly. Also, the results of this study will help determine management practices that could be undertaken to generate certain classes within the state. For, example, certain roads in the region would have be closed or rerouted to maintain P class. ROS mapping will also provide information to land use planners, land owners, and resource managers on existing recreation opportunities to assist them in making decisions on appropriate land uses. Finally, the long term studies dealing with the changes in the size of the ROS classes and trends of visitors could provide important insights in better planning for tourism in the area. 
The results of OLS suggest that there is a gap between what a county has in terms of nature based resources and what the county is receiving in terms of economic benefits. Therefore, if increased travel spending is the objective of policy makers, then the state needs to pay attention to nature and heritage based tourism.

The ROS map prepared for this study would also help future researchers to incorporate social and managerial settings of ROS to develop complete ROS map for the state and evaluate the changes in the ROS map over time. 


\section{References}

Anselin, L. (1995). Local indicators of spatial association-LISA. Geographical analysis, 27(2), 93-115.

Anselin, L. (1996). The Moran scatterplot as an ESDA tool to assess local instability in spatial association. In M. Fischer, H. J. Scholten, \& D. Unwin (Eds.), Spatial analytical perspectives on GIS (pp. 111-125). London, England: Taylor \& Francis.

Boyd, S. W., \& Butler, R. W. (1996). Managing ecotourism: an opportunity spectrum approach. Tourism Management, 17(8), 557-566.

Brown, P. J., Driver, B. L., \& McConnell, C. (1978). The opportunity spectrum concept and behavioural information in outdoor recreation resource supply inventories: background and application. In: Integrated inventories of renewable natural resources: proceedings of the workshop, January 1978, Tucson, Arizona (Edited by HG Lund et al.). USDA Forest Service, General Technical Report, (RM-55), 73-84.

Buist, L.J., \& Hoots, T. A. (1982). Recreation opportunity spectrum approach to resource planning. Journal of Forestry, 80(2), 84-86.

Butler, R. W., \& Waldbrook, L. A. (1991). A new planning tool: the Tourism Opportunity Spectrum. Journal of Tourism Studies, 2(1), 2-14.

Carhart, A. (1961). Planning for America's Wildlands. Harrisburg, PA: The Telegraph Press.

Chi, G., \& Zhu, J. (2008). Spatial regression modesl for demographic analysis. Population Research and Policy Review, 27(1), 17-42.

Clark, R. N., \& Stankey, G. H. (1979). The recreation opportunity spectrum: a framework for planning, management, and research. USDA Forest Service, General Technical Report, (PNW-98).

Cliff, A., \& Ord, J. K. (1973). Spatial autocorrelation. London: Pion Limited.

Cliff, A., \& Ord, J. K. (1981). Spatial processes, models and applications. London: Pion Limited.

Darcy, L. G., Rosaline, C., Rick, R., Peter, K., \& Philip, D. (2010). Incorporating recreational users into marine protected area planning: a study of recreational boating in British Columbia, Canada. Environment Management, 46(2), 167-180.

Dawson, C. P. (2001). Ecotourism and nature-based tourism: one end of the tourism opportunity spectrum? In S. F. McCool and R.N. Moisey (Eds.), Tourism, recreation and sustainability: Linking culture and the environment (pp. 41-53). New York: CABI.

Dean Runyan Associates. (2011). Economic impact of travel on West Virginia: 2000-2010 Detailed state and county estimates. Retrieved October 29, 2013, from http://www.wvcommerce.org/App_Media/assets/doc/travelandrec/industry/marketing/20 10\%20Economic\%20Impact.pdf

Deller, S.C., Tsai, T.S., Marcouiller, D.W., \& English, D.B.K. (2001). The role of amenities and quality of life in rural economic growth. American Journal of Agricultural Economics, 83(2), 352-365.

Dillman, D. A. (1979). Residential preferences, quality of life, and the population turnaround. American Journal of Agricultural Economics, 61(5), 960-966.

Driver, B. L., \& Brown, P. J. (1978). The opportunity spectrum concept and behavioural information in outdoor recreation resource supply inventories: a rationale. In: Integrated inventories of renewable natural resources: proceedings of the workshop, January 1978, 
Tucson, Arizona (Edited by HG Lund et al.).USDA Forest Service, General Technical Report, (RM-55), 24-31.

Draper, N. R., \& Smith, H. (1998). Applied regression analysis. New York:: Wiley.

Driver, B. L., Brown, P. J., Stankey, G. H., \& Gregoire, T. G. (1987). The ROS planning system: evolution, basic concepts, and research needed. Leisure Sciences, 9(3), 201-212.

Fox, J. (1997). Applied regression analysis, linear models, and related methods. Thousand Oaks, CA: Sage Publications.

Galston, W.A., \& Baehler, K. J. (1995). Rural development in the United States: connecting theory, practice, and possibilities. Washington, DC: Island Press.

Getis, A. (1984). Interaction modeling using second-order analysis. Environment and Planning 16(2), 173-183.

Getis, A. (2008). A history of the concept of spatial autocorrelation: a geographer's perspective. Geographical Analysis, 40(3), 297-309.

Gobster, P.H., Gimblett, R., Kelley, B.B. (1987). Modeling forest recreation policy alternatives: a geographic information system approach. In: Proceeding of GIS, 87, American Society for Photogrammetry and Remote Sensing, Falls Church, California, 101-111.

Graefe, A., Kuss, F., \& Vaske, J. (1990). Visitor impact management: the Planning Framework, Washinton, DC: National Parks and Conservation Association.

Greene, W. H. (2000). Econometric analysis. Upper Saddle River, NJ: Prentice-Hall Inc.

Griffith, D.A. (1987). Spatial autocorrelation. Washinton, DC: Association of American Geographers.

Environmental System Research Institute. (2007). Retrieved from : http://webhelp.esri.com/arcgisdesktop/9.2/index.cfm?TopicName=Overlay_analysis

Flanagan, T. S., \& Anderson, S. (2008). Mapping perceived wilderness to support protected areas management in the San Juan National Forest, Colorado. Forest Ecology and Management, 256(5), 1039-1048.

Haas, W. (1990). Retirement migration: boon or burden? Journal of Applied Gerontology, 9(4),387-392

Haas, G., Aukerman, R., Lovejoy, V., \& Welch, D. (2004). Water recreation opportunity spectrum users' guidebook. US Department Interior, Bureau of Reclamation, Denver, Colorado.

Isserman, A. M. (2001).Competitive advantages of rural America in the next century. International Regional Science Review, 24(1), 38-58.

Joyce, K., \& Sutton, S. (2009). A method for automatic generation of the Recreation Opportunity Spectrum in New Zealand. Applied Geography, 29(3), 409-418.

Jubanville, A., \& Becker, R. (1983). Outdoor recreation management and planning: contemporary schools of thought. In S. R. Lieber \& D. Fesenmaier (Eds.), Recreation planning and Management (pp. 303-319). State College, PA: Venture.

Kaltenborn, B. P., \& Emmelin, L. (1993). Tourism in the high north: management challenges and recreation opportunity spectrum planning in Svalbard, Norway. Environmental Management, 17(1), 41-50.

Kliskey, A.D., \& Kearsley, G.W. (1993). Mapping multiple perceptions of wilderness in southern New Zealand. Applied Geography, 13(3), 203-223.

Knapp, T. A., \& Gravest, P. E. (1989). On the role of amenities in models of migration and regional development. Journal of Regional Science, 29(1), 71-87. 
Manning, R.E. (1997). Visitor experience and resource protection: a framework for managing the carrying capacity of national parks. Journal of Park and Recreation Administration, 19(1), 93-108.

Marshall, R. (1933). The People's Forest. New York: H. Smith and R. Haas.

McCool, S. F., Clark, R. N., \& Stankey, G. H. (2007). An assessment of frameworks useful for public land recreation planning. General Technical Report-Pacific Northwest Research Station, USDA Forest Service, (PNW-GTR-705).

McGranahan, D.A. (1999). Natural amenities drive rural population change. USDA Agricultural Economic Report No. 781.

Morse, W. C., Hall, T., \& Kruger, L. (2008). Improving the integration of recreation management with management of other natural resources by applying concepts of scale from ecology. Environmental Management, 43(4), 369-380.

Ord, J. K., \& Getis, A. (1995). Local spatial autocorrelation statistics: distributional issues and an application. Geographical Analysis, 27(4), 286-306.

Outdoor Recreation Resources Commission. (1962). Outdoor Recreation for America: A Report to the President and to the Congress. Outdoor Recreation Resources Review Commission.

Outdoor Industry Association. 2012. Outdoor Recreation Participation Report. 2012. Outdoor Industry Association, Boulder, Colorado. Retrieved September 30, 2013, from http://www.asla.org/uploadedFiles/CMS/Government_Affairs/Federal_Government_Affa irs/OIA_OutdoorRecEconomyReport2012.pdf

Perez Verdin, G., Lee, M. E., \& Chavez, D. J. (2008). Planning forest recreation in natural protected areas of southern Durango, Mexico. Madera Bosques, 14(1), 53-67.

Pierskalla, C.D., Sinisalchi, J.M., Selin, S. W., \& Fosbender, J. (2007). Using events as a mapping concept that complement existing ROS methods. Leisure Sceience, 29(1), 7189.

Power, T. (1988). The economic pursuit of quality. Armonk, New York: M.E. Sharpe.

Sowman, M.R. (1987). A procedure for assessing recreational carrying capacity of coastal resort areas. Landscape and Urban Planning, 14, 331-344.

Stankey, G.H., Cole, D.N., Lucas, R.C., Peterson, M.E., \& Frissell, S.S. (1985) The Limits of Acceptable Change (LAC) system for wilderness planning. USDA Forest Service General Technical Report INT-176.

Shelby, B., \& Heberlein, T. A. (1987). Carrying capacity in recreation settings. Corvallis, OR: Oregon State University Press.

Snepenger, D. J., Johnson, J. D., \& Rasker, R. (1995). Travel-stimulated entrepreneurial migration. Journal of Travel Research, 34(1), 40-44.

U.S. Department of Agriculture, Forest Service. (1982.) ROS Users Guide, August 1982, 38 p.

Wall, K., Brown, P., Dennis Turowski, A., Finnegan, L., Litz, V., Johnson, R. (1997). A GIS Application of the Recreation Opporunity Spectrum on the Coos Bay District of the Bureau of Land Management. General Technical Report PNW-94-2597 Portland, Oregon, U.S. Department of Agriculture, Forest Service, Pacific Northwest Forest and Range Experiment Station.

Xiao, S., Jia, L., \& Jiang, L. (2012). Forest recreation opportunity spectrum in the suburban mountainous region of Beijing. Journal of Urban Planning and Development, 138(4), 335-341. 


\title{
CHAPTER 3: Essay 2
}

\section{Identifying and Mapping Forest-Based Ecotourism Areas in West Virginia Incorporating Visitors' Preferences}

\begin{abstract}
This study identifies and maps forest-based ecotourism areas in West Virginia by incorporating visitors' preferences. Relative weights for ecotourism destination criteria were obtained using the Analytic Hierarchy Process based on a survey of 777 participants. The study classified the state into five levels of naturalness with areas under Class I being the least natural and Class V being the most natural. The presence of wildlife was found to be the most important criterion and slope was found to be the least. Results also showed significant variations in visitors' preferences. Areas under Class IV and Class V in both weighted and unweighted ecotourism maps covered more than half of the state's area, suggesting high prospects for promoting forest-based ecotourism in the state. The results further showed that each class changed in size when visitors' preferences were applied. The ecotourism maps created provide useful insights for visitors, destination managers, and decision makers.
\end{abstract}

Keywords: Forest-based ecotourism; Naturalness continuum; Geographic Information System; Analytic Hierarchy Process; Pairwise comparison; Criteria weight; Visitors' preferences; Suitability index 


\section{Introduction}

The sector of ecotourism is growing at a fast pace with an estimated yearly growth rate of 20-34\% since the 1990s (The International Ecotourism Society, 2006). In recent years, global ecotourism is estimated to generate as much as U.S. \$300 billion in revenues annually (Stronza \& Durham, 2008). As a form of tourism that aims to minimize environmental impacts and contributes to economic development of local communities, ecotourism has shown prospects for successfully funding conservation and sustainable development programs (Drumm \& Moore, 2002). Like any other form of tourism, the growth of ecotourism is dependent on the flow of visitors. Marketing tourism for a destination requires identifying various characteristics of the destination, desired visitor groups, and the best ways to reach and convince these groups to visit the destination. However, literature on ecotourism has been primarily focused on identifying desired (lucrative) visitor groups and identifying ways of reaching them (Lundberg, 1990). Identification of destinations by incorporating visitors' preferences of destinations has received little attention.

Identification and evaluation of ecotourism destinations require setting standards (Ziffer, 1989) to help decision-makers consider the impacts of choice-alternatives that involve policy priorities, trade-offs, and uncertainties (Jankowski, 1995). It has also been suggested that assessing the quality of natural areas would be more effective than assessing tourist facilities from a long-term sustainability perspective (Font \& Mihalic, 2002).

West Virginia is the third highest forested state (78\%) (West Virginia Division of Forestry, 2006) and also the second most rural state in the United States (West Virginia Department of Health and Human Resources, 2013). The state's extensive vegetation cover and natural landscape is home to various species of wildlife. Though the state is rural, it is within 500 
miles of $60 \%$ of the nation's population. In addition, West Virginia borders three of the top twelve states visited by U.S. tourists in 2009: Pennsylvania (7), Ohio (12), and Virginia (8) (U.S. Census Bureau, 2012).

Tourism is the second largest industry in West Virginia in terms of total economic impact and employment, second to coal mining and followed by forestry (West Virginia Division of Forestry, 2006). The 2010 annual report of the West Virginia Division of Tourism revealed that visitors preferred to visit national and state forests, national and state parks, and lakes and rivers during their trip, suggesting a great potential for ecotourism development in the state.

Accordingly, this study identifies and maps ecotourism areas in the state by incorporating visitors' preferences. Since $78 \%$ of the state's land cover is forested, the study specifically considers forest-based ecotourism areas in the state. The specific objectives are to: (i) create an unweighted ecotourism map based on the naturalness continuum, (ii) determine weights for forest-based ecotourism criteria from the visitors' perspective and use them to create a weighted ecotourism map, (iii) compare unweighted and weighted ecotourism maps, and (iv) determine differences in criteria weights among various visitor groups based on their demographics and travel characteristics. A weighted ecotourism map refers to an ecotourism suitability map where criteria weights derived from visitors' preferences were incorporated, while an unweighted ecotourism map is an ecotourism suitability map without the use of criteria weights.

\section{Literature review}

Understanding travelers' decision-making and destination selection process is an important factor in the identification of tourist destinations. Traveler decisions are complex and multifaceted where choices for different elements are interrelated and evolve in a decision process over time (Dellaert, Etterma, \& Lindh, 1998). Studies on tourists' travel choices suggest tourist 
destination selection is a key element in the travel decision-making process. Determining the factors that influence people's choice of destination is essential in developing appropriate strategies that incorporate the needs of potential tourists. Socio-economic factors such as age, income, gender, education, and place of residency affect travelers' preferences for choosing their destinations (Goodall \& Ashworth, 1988; Heung, Qu, \& Chu, 2001). Zhou, Cheng and Zhou (2006) found that gender, education, income, and travel expenditures had significant influences on tourists' and willingness to pay for certified ecotourism products.

Decision makers' preferences are precise filters of their destination choices (Goodall, 1991). A study by Eagles (1992) found that Canadian ecotourists expressed a stronger desire to visit wilderness, lakes and streams, mountains, national and provincial parks, rural areas, and coastal settings than other Canadian tourists. Pearce (1988) stated that preferences are revealed by travelers' choices of destinations and the activities in which they participated. Several studies on the preferences of travelers have used conjoint analysis (stated preference method) to describe and forecast tourist choice behavior (Suh \& McAvoy, 2005). However, preferences were not specifically addressed in the decision-making process of destination choice. Decrop (1999) noted that preference is a special case of attitudes where product alternatives are compared, and one is chosen over the other. Visitors choose the destinations based on their preferences of the considered criteria.

Various decision models have been proposed to explain travelers' decision-making process, and the destination choice set model developed by Um and Crompton (1990) has received substantial attention in tourism decision research. Destination choice is made through three stages of a sequential funneling process: composition of an awareness set consisting of many alternatives, an evoked set narrowed down to fewer alternatives, and a final destination choice. 
The process is affected by a set of criteria: personal (push) factors, destination attributes (pull factors), and constraints. However, complexity regarding the decision-making process leading to the choice of a travel destination has not received enough attention (Lam \& Hsu, 2006).

Various techniques are employed to aid in the decision-making process which is collectively termed as multi-criteria decision-making (MCDM) methods. These methods incorporate explicit statements of stakeholder preferences. Boyd, Butler, Haider, and Perera (1994) used Geographic Information System (GIS) to identify areas for ecotourism in Northern Ontario, Canada. The authors used seven attributes to express an area's degree of naturalness and they classified the areas into five classes based on a cumulative score. Bukenya (2012) combined GIS and a MCDM framework to rank national parks in Uganda based on four objectives: wildlife management potential, ecological value, susceptibility to encroachment, and revenue generation. Another study by Fung and Wong (2007) used IKONOS images, GIS, and multi-criteria evaluation techniques to evaluate the potential for ecotourism planning in Yan Chau Tong Marine Park and the surrounding areas of Hong Kong. The study assigned weights to the objectives (conservation vs. recreation). However, the relative importance of criteria was not assessed. Also, most studies on destination choice have used a 5-point or 7-point Likert scale for rating the importance of each criterion but little has been learned about the relative importance of each criterion (Hsu, Tsai, \& Wu, 2009).

Analytic Hierarchy Process (AHP) is one of the MCDM methods which involves pairwise comparison to create a ratio matrix and produces the relative preference weight for each criterion (Saaty, 1980). Many studies have used AHP for stakeholders' preference ranking in the travel and tourism field. Yang and Lee (1997) presented an AHP decision model for facility location selection which assisted managers in analyzing various location factors, evaluating location site 
alternatives, and making final location selections. Some researchers combined AHP with other techniques to select sites for facilities locations (e.g., Chuang, 2001; Ho, 2008). Deng, King and Bauer (2002) proposed a hierarchical structure to evaluate and rate 36 national and provincial parks for nature-based tourism in Victoria, Australia. Five components that contributed to the natural attractiveness of those parks were weighted and the parks were graded. Tzu-Kuang, Tsai, and $\mathrm{Wu}(2009)$ evaluated destination preferences of tourists and identified factors that influenced their destination choice using a 4-level AHP model. More recently, Lee, Huang, and Yeh (2010) also used AHP to elicit expert opinions on the factors affecting the attractiveness of forest-based recreation tourism in Taiwan.

AHP has also been widely integrated with GIS for site selection of species or physical structures, mapping environmental hazards, and other conservation and management activities. AHP and GIS have been used for aquaculture development (Aguilar-Manjarrez \& Ross, 1995; Hossain, Chowdhury, Das, Sharifuzzaman, \& Sultana, 2009), artificial reef development (Tseng, Chen, Huang, \& Liu, 2001), integrating marine fish culture within the tourism industry (Pérez, Telfer \& Ross, 2003), and landfill site selection (Sener, Suzen, \& Doyuran, 2006). Gemitzi, Tsihrintzis, Voudrias, Petalas, and Stravodimos (2007) also applied AHP and GIS for determining site suitability for construction of municipal solid waste landfills in the northeast continental part of Greece, and Yalcin (2008) conducted landslide susceptibility mapping in Ardesen, Turkey. These studies point to the importance of GIS as a useful tool for integrating information, assisting in the decision-making process, and in achieving more reliable results when combined with MCDM methods like AHP.

More recently, several studies have incorporated AHP and GIS to assess ecotourism destinations. For example, Kumari, Behera, and Tewari (2010) identified potential ecotourism 
sites in Sikkim state, India. Potential was measured based on five indicator indices, including wildlife distribution index, ecological value index, ecotourism attractiveness index, environmental resiliency index, and ecotourism diversity index. Bunruamkaew and Murayama (2011) prioritized potential ecotourism sites in Surat Thani province, Thailand based on five criteria and nine factors. Criteria weights and factors were calculated by applying the hierarchical structure of AHP analysis where experts were asked to determine the relative importance of each criterion and factor. The final ecotourism map was classified into four classes from highly suitable area to least suitable area. Similar to Bunruamkaew and Murayama (2011), Ullah and Hafiz (2013) identified suitable locations for ecotourism development in Cox's Bazar, Bangladesh, using five factors and fifteen criteria. However, the final map was classified into three classes from highly suitable to marginally suitable. These studies were mainly focused on identifying important criteria or factors without considering visitors' preferences. In view of this, this study incorporates visitors' preferences in identifying ecotourism sites using AHP and GIS.

\section{Methodology}

\subsection{Naturalness continuum}

Ceballos-Lascurain (1987, p.14) was among the first to define ecotourism as: "traveling to relatively undisturbed or uncontaminated natural areas with the specific objective of studying, admiring, and enjoying the scenery and its wild plants and animals, as well as any existing cultural manifestations (both past and present) found in these areas." Although definitions of ecotourism have evolved since then, the component 'nature' or 'nature-based' has remained in all definitions. Therefore, an attempt to identify and classify ecotourism areas would require assessing naturalness of the areas. The naturalness continuum for this study was replicated from 
that of Boyd, Butler, Haider, and Perara (1994), who identified areas best suited for different types of ecotourists and ecotourism experiences (Figure 1).

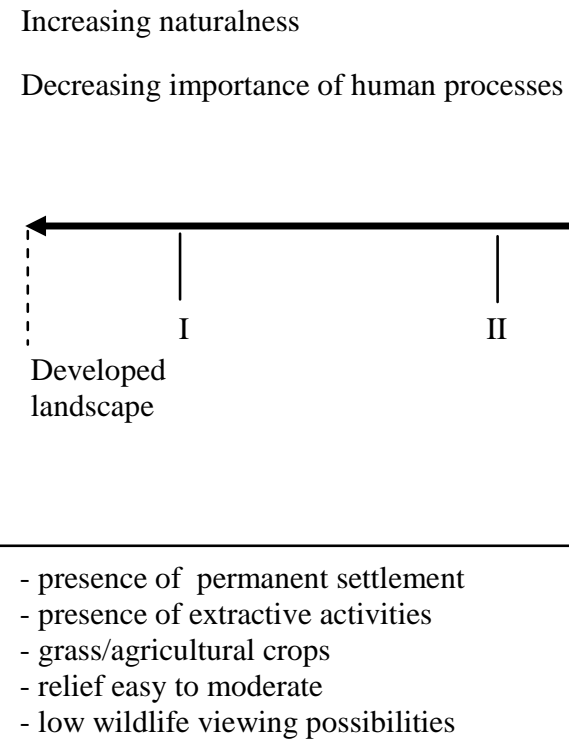

- presence of permanent settlement - presence of extractive activities

- grass/agricultural crops

- relief easy to moderate

- low wildlife viewing possibilities

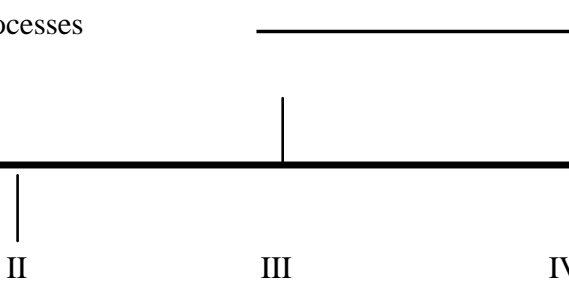

Natural landscapes

Increasing importance of natural processes

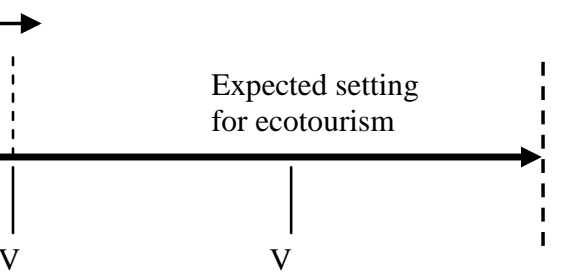

Pristine landscape
Class I Characteristics

- semi primitive motorized areas

- possibilities of logging/mining

- evergreen forest with few deciduous

- slope difficult to moderate

Class III Characteristics
- roaded natural

- sparse forest coverage (grassland)

- few wildlife viewing possibilities

- moderate slope

Class II Characteristics

- semi primitive non-motorized

- deciduous forest with few evergreen

- slope hard

- wildlife viewing possibilities

Class IV Characteristics
- primitive areas
- absence of extractive activities
- mixed forest coverage
- slope very steep
- high wildlife viewing possibilities

Class V Characteristics

Figure 1. The naturalness continuum framework. Adapted from "Identifying areas for ecotourism in Northern Ontario: application of a geographical information system methodology," by S.W. Boyd, R.W. Butler, W. Haider and A. Perera, 1994, Journal of Applied Recreation Research, 19(1), pp.41-66 
The higher end of the continuum represents seemingly pristine landscapes, while the lower end of the continuum represents developed landscape. West Virginia has undergone various forms of resource extraction activities over the past few hundred years, such as mining and logging. This extraction of resources has rendered pristine areas to be a rarity. Yet vast forested areas of the state can be classified according to varying degrees of naturalness. The naturalness continuum was then divided into five different classes to show the prospects for different levels of ecotourism experience opportunities in the state. Class I represents the lower end of spectrum; suitable for soft ecotourists or those who prefer visiting rural or urban destinations where modern services are available. On the other end of the continuum is Class V representing settings suitable for hard ecotourists or those who prefer visiting semi-wilderness or wilderness destinations where few, if any, services are available.

\subsection{Criteria and scores}

The naturalness continuum was developed using six criteria: distance from logging, slope, distance from mining, presence of wildlife, presence of vegetation, and remoteness. Water bodies also add value to the ecotourism destinations. However, water bodies vary in nature (waterfall, lakes, rivers, etc.), resulting in varying experiences to the visitors. Therefore, for the sake of generality, ecotourism based in the aquatic environment was excluded from this study.

Scores ranging from 1 to 5 were assigned to the different attributes within each criterion (Table 1). 
Table 1. Criteria and scores used to identify forest-based ecotourism areas in West Virginia

\begin{tabular}{|c|c|c|c|}
\hline Criteria & Attributes & Description & Score \\
\hline \multirow[t]{3}{*}{$\begin{array}{l}\text { Distance from } \\
\text { logging }\end{array}$} & $\begin{array}{l}\text { Active logging } \\
\text { present }\end{array}$ & Within 1 mile $(1.61 \mathrm{~km})$ from logging sites & 1 \\
\hline & $\begin{array}{l}\text { Area nearby active } \\
\text { logging }\end{array}$ & $\begin{array}{l}\text { Between } 1 \text { mile }(1.61 \mathrm{~km}) \text { to } 3 \text { miles }(4.83 \mathrm{~km}) \\
\text { from logging sites }\end{array}$ & 3 \\
\hline & $\begin{array}{l}\text { No logging } \\
\text { activities }\end{array}$ & Outside 3 miles $(4.83 \mathrm{~km})$ from logging sites & 5 \\
\hline \multirow[t]{3}{*}{ Slope } & Low slope & Less than 10 degree & 1 \\
\hline & Medium slope & 10-25 degree & 3 \\
\hline & High slope & $>25$ degree & 5 \\
\hline \multirow[t]{3}{*}{$\begin{array}{l}\text { Distance from } \\
\text { mining }\end{array}$} & $\begin{array}{l}\text { Operational and } \\
\text { abandoned mining } \\
\text { present }\end{array}$ & Within 1 mile $(1.61 \mathrm{~km})$ from mining sites & 1 \\
\hline & $\begin{array}{l}\text { Area nearby } \\
\text { operational and/or } \\
\text { abandoned mining }\end{array}$ & $\begin{array}{l}\text { Between } 1 \text { mile }(1.61 \mathrm{~km}) \text { to } 3 \text { miles }(4.83 \mathrm{~km}) \\
\text { from mining sites }\end{array}$ & 3 \\
\hline & $\begin{array}{l}\text { No mining } \\
\text { activities }\end{array}$ & Outside 3 miles $(4.83 \mathrm{~km})$ from mining sites & 5 \\
\hline \multirow{5}{*}{$\begin{array}{l}\text { Presence of } \\
\text { wildlife }\end{array}$} & Wildlife setting I & $0-54$ species & 1 \\
\hline & Wildlife setting II & $55-109$ species & 2 \\
\hline & Wildlife setting III & $110-163$ species & 3 \\
\hline & Wildlife setting IV & 164-217 species & 4 \\
\hline & Wildlife setting V & 218-272 species & 5 \\
\hline \multirow[t]{5}{*}{$\begin{array}{l}\text { Presence of } \\
\text { vegetation }\end{array}$} & $\begin{array}{l}\text { Grassland and } \\
\text { agriculture crops }\end{array}$ & $\begin{array}{l}\text { Includes area like grassland, pasture and } \\
\text { cultivated crops }\end{array}$ & 1 \\
\hline & Shrubland & $\begin{array}{l}\text { Areas dominated by shrubs; less than } 5 \text { meters } \\
\text { tall, including true shrubs, young trees in an early } \\
\text { successional stage or trees stunted from } \\
\text { environmental conditions. }\end{array}$ & 2 \\
\hline & Evergreen forest & $\begin{array}{l}\text { Includes trees generally greater than } 5 \text { meters tall; } \\
\text { more than } 75 \% \text { of the tree species maintain their } \\
\text { leaves all year; canopy is never without green } \\
\text { foliage. }\end{array}$ & 3 \\
\hline & Deciduous forest & $\begin{array}{l}\text { Includes trees generally greater than } 5 \text { meters tall; } \\
\text { more than } 75 \% \text { of the tree species shed foliage } \\
\text { simultaneously in response to seasonal change. }\end{array}$ & 4 \\
\hline & Mixed forest & $\begin{array}{l}\text { Includes trees generally greater than } 5 \text { meters tall; } \\
\text { neither deciduous nor evergreen species are } \\
\text { greater than } 75 \% \text { of total tree cover. }\end{array}$ & 5 \\
\hline \multirow[t]{5}{*}{ Remoteness } & Town/urban area & $\begin{array}{l}<1 / 2 \text { mile }(0.80 \mathrm{~km}) \text { from improved roads and } \\
\text { presence of settlement }\end{array}$ & 1 \\
\hline & $\begin{array}{l}\text { Roaded natural } \\
\text { and rural }\end{array}$ & $<1 / 2$ mile $(0.80 \mathrm{~km})$ from improved roads & 2 \\
\hline & $\begin{array}{l}\text { Semiprimitive } \\
\text { motorized }\end{array}$ & $\begin{array}{l}<1 / 2 \text { mile }(0.80 \mathrm{~km}) \text { from unimproved roads and } \\
\geq 1 / 2 \text { mile }(0.80 \mathrm{~km}) \text { from improved roads }\end{array}$ & 3 \\
\hline & $\begin{array}{l}\text { Semiprimitive } \\
\text { nonmotorized }\end{array}$ & $\begin{array}{l}<3 \text { miles }(4.83 \mathrm{~km}) \text { from all roads and } \\
\geq 1 / 2 \text { mile }(0.80 \mathrm{~km}) \text { from unimproved and } \\
\text { improved roads }\end{array}$ & 4 \\
\hline & Primitive & $\geq 3$ miles $(4.83 \mathrm{~km})$ from all roads & 5 \\
\hline
\end{tabular}


Higher scores represent areas in the higher end of the naturalness continuum. Table 2 shows the list of data that were used to create criteria maps and their original sources.

Table 2. Data types and sources

\begin{tabular}{|c|c|}
\hline Data & Source \\
\hline Logging data 2010 & $\begin{array}{l}\text { West Virginia Division of } \\
\text { Forestry }\end{array}$ \\
\hline Mining data 2010 & $\begin{array}{l}\text { West Virginia Department of } \\
\text { Environmental Protection }\end{array}$ \\
\hline Road data 2012 & U.S. Census Bureau \\
\hline $\begin{array}{l}\text { Slope data from digital elevation } \\
\text { model } 2000\end{array}$ & U.S. Geological Survey \\
\hline $\begin{array}{l}\text { Vegetation data from national land } \\
\text { cover data } 2006 \text { land cover }\end{array}$ & U.S. Geological Survey \\
\hline Wildlife distribution 2002 & $\begin{array}{l}\text { West Virginia University's } \\
\text { Natural Resource Analysis } \\
\text { Center/ U.S. Geological } \\
\text { Survey }\end{array}$ \\
\hline
\end{tabular}

The two criteria, distance from logging and distance from mining, were expressed by three attributes to depict the relative importance of sites for ecotourism. Presence of vegetation and wildlife were shown by five attributes based on the diversity of vegetation cover and wildlife, respectively. The attributes for the remoteness criterion was derived from the Recreation Opportunity Spectrum as explained in Pierskalla, Sinisalchi, Selin, and Fosbender (2007). Pierskalla et al. suggested six attributes for the remoteness criteria. However, for this study roaded natural and rural area were grouped together, as they share same characteristics except the nature of their ownership (public vs. private). The resulting remoteness criterion classified the study area as primitive (score 5) to urban/town area (score 1). Finally, slope was expressed by three attributes adapted from Boyd, Butler, Haider, and Perera (1994). Raster maps of cell size $30 \mathrm{~m}$ by $30 \mathrm{~m}$ were then prepared for each criterion with attribute scores. 


\subsection{Unweighted ecotourism map and its classification}

The unweighted ecotourism map for West Virginia was created by overlaying raster maps of the six criteria. Scores of the combined maps were classified into five classes based on equal interval classification method. Classes V and IV, in the higher range of the continuum, represent sites that are seemingly pristine landscape; the most favorable sites for forest-based ecotourism.

Classes III, II and I, on the lower end of the continuum, represent sites of developed landscape. In order for visitors to experience diverse flora and fauna in a natural setting, only areas 5000 acres (20.23 square kilometers) or greater were considered for classes V, IV and III.

\subsection{Data collection}

A short self-administered questionnaire was designed to elicit visitors' preferences (Appendix 1). The questions were grouped into three sections: trip characteristics, pairwise comparison of the six ecotourism criteria, and socio-demographic characteristics. The first section specifically asked about respondents' purpose of visit, frequency of visits to West Virginia, attractions visited in the past 12 months, and knowledge about the term "ecotourism." The second section explored respondents' relative preferences of criteria through pairwise comparison, and the third section looked at respondents' socio-demographic information such as gender, age, education, income, and place of residence.

The visitor's survey was carried out in the autumn of 2010. Autumn season is very popular among visitors who are attracted by the fall foliage of the mountain state. The survey was conducted in cooperation with the West Virginia Division of Tourism from September to November at two welcome centers located along Interstates 68 (I-68) and 79 (I-79) near Morgantown, West Virginia (Figure 2). 


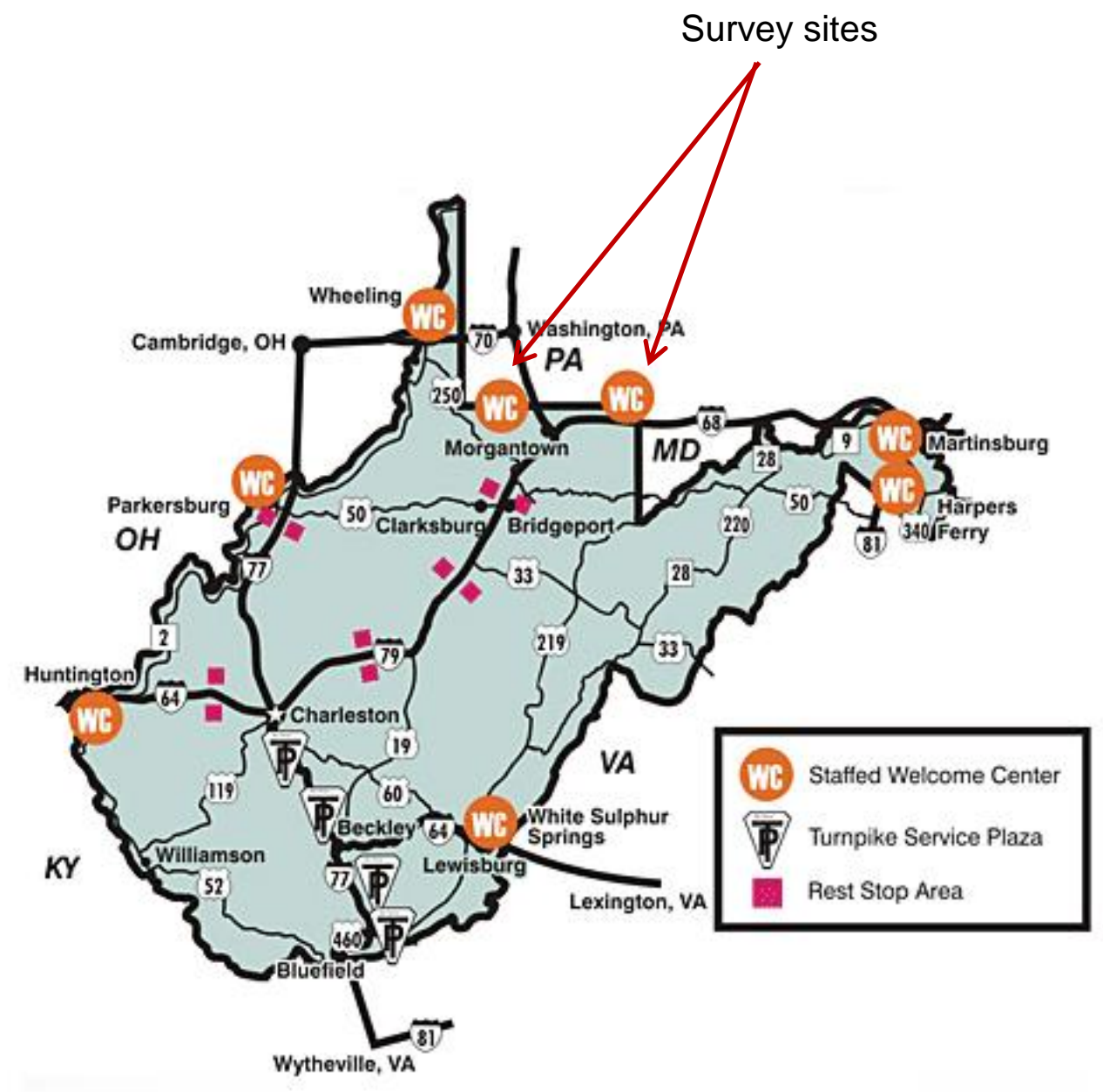

Figure 2. Survey locations for the study. Adapted from Welcome centers, West Virginia Department of Commerce, 2013. Retrieved October 31, 2013, from http://www.wvcommerce.org/travel/gettinghere/welcomecenters/default.aspx

Two surveyors administered the survey on weekends (10am-3pm) during the study period. Prior to the actual survey, 40 visitors were pretested to test the validity and reliability of the questionnaire at the welcome center of I-79. Comments and suggestions from the pretest were used to finalize the questionnaire. A convenience sampling approach was used to survey visitors above the age of 18 . Specifically, a visitor was approached as she/he exited from the 
welcome center. Once the visitor completed the survey, the next available visitor was then approached for the survey (cf. Parsons et al., 2003). A sample size of 400 is considered to be suitable for making generalization at a 95\% confidence level with 5\% margin of error (Vaske, 2008). In the study, 1052 visitors were approached. Of them, 777 were willing to participate, resulting in a response rate of $73.86 \%$.

\subsection{Data analysis}

\subsubsection{Pairwise comparison}

The AHP pairwise comparison method was used to determine the relative weights of the criteria based on visitors' preferences. The criteria were defined and assembled in one matrix for participants to perform pairwise comparisons. The matrix $A=\left[a_{i j}\right]_{n x n}$ can take the following form:

$$
\left[\begin{array}{ccccc}
a_{11} & a_{12} & \cdot & \cdot & a_{1 n} \\
a_{21} & a_{22} & \cdot & \cdot & a_{2 n} \\
\cdot & \cdot & \cdot & \cdot & \cdot \\
a_{n 1} & a_{n 2} & \cdot & \cdot & a_{n n}
\end{array}\right]
$$

To combine the responses of all individuals involved in a decision problem, geometric mean method of Saaty (1989) was used using equation 2.

$$
a_{i j}^{g m}=\sqrt[p]{\prod_{k=1}^{p} a_{i j}^{k}}
$$

Where $a_{i j}^{k}$ is an element of matrix $A$ of an individual $k(k=1,2, \ldots, P)$ and $a_{i j}^{g m}$ is the geometric mean of all individuals $\mathrm{a}_{\mathrm{ij}}^{\mathrm{k}}$. With the geometric mean, a set of numerical weights $w_{1}$, $w_{2}, \ldots w_{n}$ was computed on the basis of eigenvector procedure (Saaty,1980). The calculation of 
the weights consists of two steps. First, the pairwise comparison matrix $A=\left[a_{i j}\right]_{n x n}$ is normalized by equation (3), and then the weights are calculated by equation (4).

$$
a_{i j}^{*}=\frac{a_{i j}}{\sum_{i=1}^{n} a_{i j}}
$$

for all $j=1,2, \ldots, n$.

$$
w_{i}=\frac{\sum_{j=1}^{n} a_{i j}^{*}}{n}
$$

for all $i=1,2, \ldots, n$.

The resultant weights represent the relative degree of importance assigned to each criterion which would be ranked to determine the preferences of the user groups. A consistency index (CI) was calculated to measure the consistency of participants' pairwise comparison of criteria using the following formula:

$$
\mathrm{CI}=\left(\lambda_{\max }-n\right) /(n-1)
$$

where $n$ denotes the size of the comparison matrix (number of rows or columns), and $\lambda_{\max }$ is the maximum eigenvalue of matrix $A$. Eigenvalues are a set of scalars that are associated with the matrix and the more consistent the comparisons are, the closer the value of $\lambda_{\max }$ to $n$. The $C I$ value was then used to estimate the consistency ratio $(\mathrm{CR})$ which measures the coherence of the pairwise comparisons and was computed as:

$$
\mathrm{CR}=(C I / R I)
$$

where $R I$, random index, is a constant which corresponds to the mean random consistency index value according to $n$. A $C R$ value of $10 \%$ or less is considered as acceptable (Kangas, 1994). 
Respondents were asked to assign a number to indicate the relative importance of one criterion against another. For simplicity, traditional nine levels of importance proposed by Saaty (1987) were reduced to five levels of importance. Each of the six criteria was compared against every other criterion using the ratio scale 1,3,5,7, and 9. Since there were six criteria, the respondents had to make 15 pairwise comparisons in order to get the $6 \times 6$ matrix. Table 3 shows the intensity of importance and their explanation used for this study. Expert Choice software was used to calculate weight importance of each criterion.

Table 3. Rating scale for pairwise comparison

\begin{tabular}{ll}
\hline $\begin{array}{l}\text { Intensity of } \\
\text { Importance }\end{array}$ & Determination and Explanation \\
\hline 1 & $\begin{array}{l}\text { Two attributes are equally important } \\
\text { One attribute is slightly more important than the } \\
\text { other } \\
\text { One attribute is moderately important over the } \\
5\end{array}$ \\
$\begin{array}{l}\text { other } \\
\text { One attribute is very important over the other } \\
9\end{array}$ & One attribute is extremely important over the other \\
\hline
\end{tabular}

Source: Adapted from Saaty (1980)

\subsubsection{Weighted ecotourism map and its classification}

Visitors' preferences for ecotourism areas were not included in the unweighted ecotourism map described in section 3.3. To incorporate visitors' preferences, a weighted ecotourism map was created using the suitability index (S) method; a weighted linear combination function that combines preference weights $\left(w_{i}\right)$ and criterion scores $\left(x_{i}\right)$ (Eastman, Jin, Kyem, \& Tolendano, 1995) and expressed as:

$$
S=\sum w_{i} x_{i}
$$


However, MCDM consists of two primary steps: formulation of an evaluation matrix $E$ consisting of $I * J$ standardized criterion scores $(e)$ for $I$ criteria across $J$ alternatives and a group preference weight vector $W$ consisting of preference weights $(w)$ for each criterion $i$ (Jankowski \& Richard, 1994):

$E=\left[\begin{array}{ccccc}e_{11} & \cdot & \cdot & \cdot & e_{1 J} \\ \cdot & \cdot & \cdot & \cdot & \cdot \\ \cdot & \cdot & \cdot & \cdot & \cdot \\ e_{I 1} & \cdot & \cdot & \cdot & e_{I J}\end{array}\right]$

and

$$
W=\left(w_{1}, w_{2}, \ldots \ldots, w_{I}\right), \sum_{i=1}^{I} w_{i}=1
$$

The basic form of the suitability index can then be expressed as

$$
\left[\begin{array}{c}
s_{1} \\
\cdot \\
\cdot \\
s_{I}
\end{array}\right]=\left[\begin{array}{ccccc}
e_{11} & \cdot & \cdot & \cdot & e_{1 J} \\
\cdot & \cdot & \cdot & \cdot & \cdot \\
\cdot & \cdot & \cdot & \cdot & \cdot \\
e_{I 1} & \cdot & \cdot & \cdot & e_{I J}
\end{array}\right] *\left[\begin{array}{c}
w_{1} \\
\cdot \\
\cdot \\
w_{I}
\end{array}\right]
$$

The weighted linear combination method was spatially integrated in GIS using rasterbased map algebra (Strager \& Rosenberger, 2006). In Eq. (8), E was measured in GIS using raster techniques. As each of the criterion scores was standardized to a common numeric range of 1-5 before aggregation, the GIS grid layers represent individual criterion $I$ in a spatial context. The alternative $J$ comprises the cell locations for the extent of a study area and the values from Eq. (10) represent the suitability $S$ for a location. All the thematic layers were overlaid to generate the weighted ecotourism map. The resulting map was then classified into five different classes similar to unweighted ecotourism map. 
Finally, $t$-tests were performed to determine differences in the weights of the ecotourism criteria based on visitors' trip and socio-demographic characteristics. These included prior visits to West Virginia, gender, education, income, and prior knowledge of the term "ecotourism". The classification maps were created using ArcGIS10 while $t$-tests were conducted using SPSS 18.0.

\section{Results}

\subsection{Sample}

\subsection{Trip characteristics}

Of the 777 survey respondents, $50.72 \%$ were male and $49.28 \%$ were female. Further, $61.27 \%$ of respondents were 40 years and above, $76.52 \%$ had at least a college degree, $79.93 \%$ earned more than $\$ 40,000$ per year, and $83.38 \%$ were out of state visitors, primarily from Ohio, Virginia, Pennsylvania, and Maryland.

Just over a third $(37.73 \%)$ of the respondents were visiting family, relatives and friends, while $36.79 \%$ for leisure and vacation. The majority of the respondents $(71.13 \%)$ were repeat visitors, and a notable proportion of whom (27.88\%) had visited scenic byways, national parks $(21.89 \%)$, or state parks $(24.83 \%)$. Golf courses $(6.77 \%)$ were the least visited attraction, followed by wildlife management areas $(9.86 \%)$, and museums $(14.82 \%)$. The majority of the respondents $(59.08 \%)$ were also familiar with the term "ecotourism."

\subsection{Criteria and scores}

Figure 3 shows the resulting maps of the state with scores for the six criteria. Table 4 summarizes the percentage of area associated with criterion scores. 


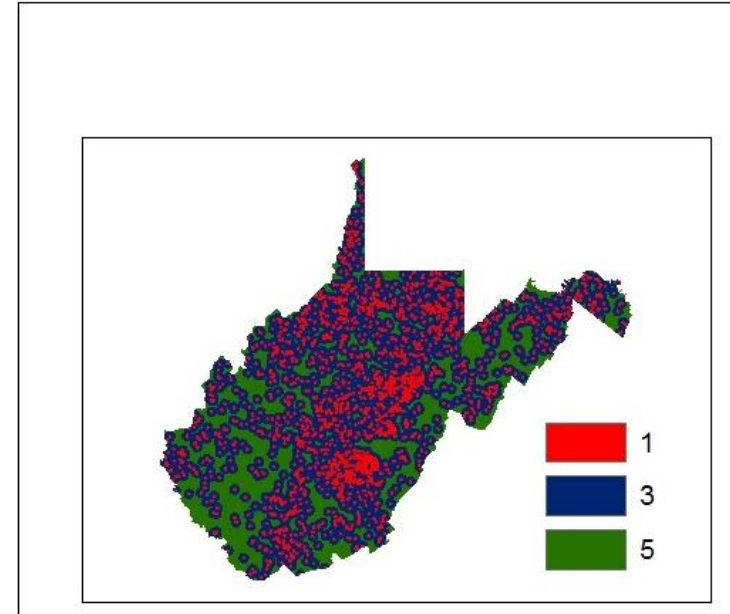

(a)

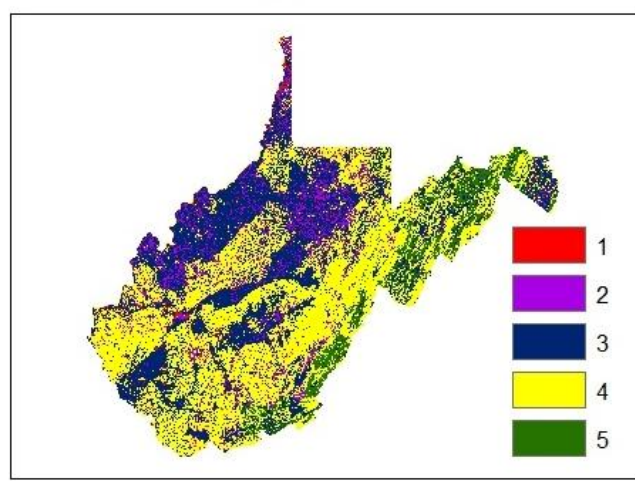

(d)

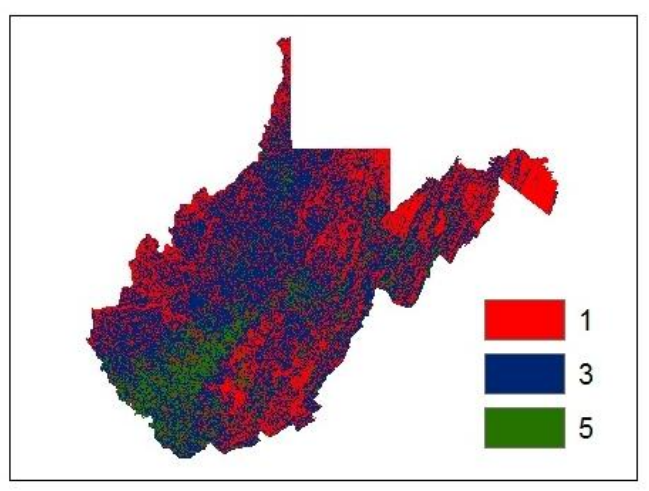

(b)

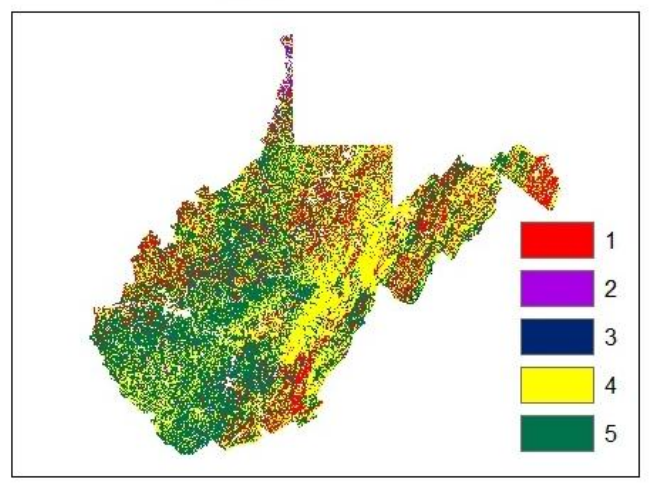

(e)

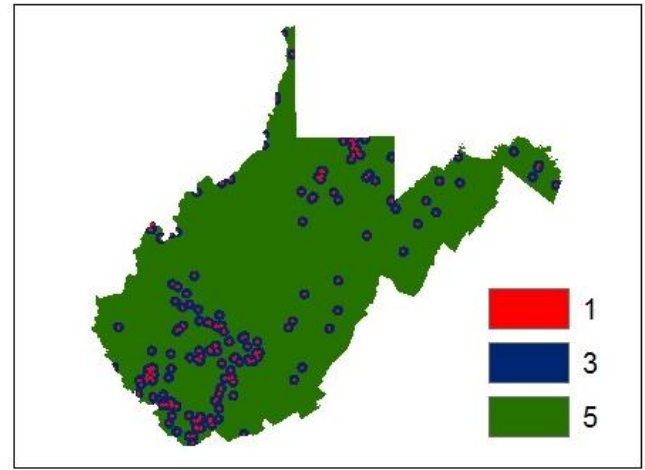

(c)

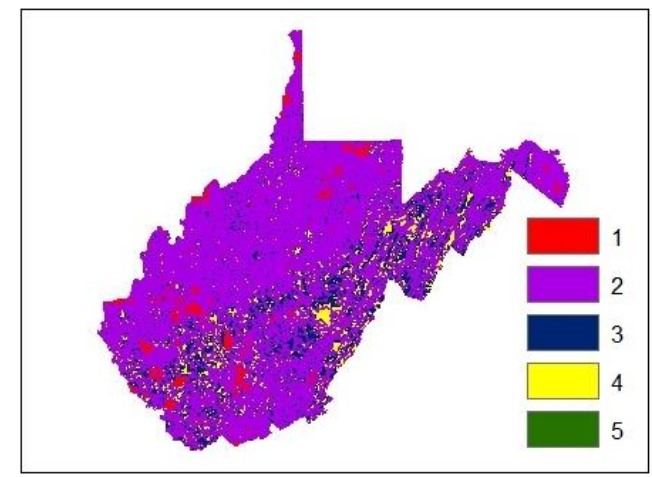

(f)

$0 \quad 75 \quad 150 \quad 300 \quad 450$

Kilometers

Figure 3. Various West Virginia maps based on the criteria score for (a) distance from logging (b) slope (c) distance from mining $(d)$ presence of wildlife (e) presence of vegetation (f) remoteness 
Table 4. Percent distribution of areas for each criterion measured by scores from 1 to 5

\begin{tabular}{llllll}
\hline & \multicolumn{3}{l}{ Scores } & & \\
\cline { 2 - 6 } Criteria & 1 & 2 & 3 & 4 & 5 \\
Distance from logging & 20.80 & - & 55.46 & - & 23.74 \\
Slope & 33.75 & - & 56.61 & - & 9.64 \\
Distance from mining & 2.15 & - & 11.27 & - & 86.58 \\
Presence of wildlife & 1.37 & 9.50 & 35.89 & 46.64 & 6.60 \\
Presence of vegetation & 16.50 & 2.23 & 0.44 & 35.82 & 45.01 \\
Remoteness & 3.29 & 77.87 & 12.37 & 5.47 & 1.00 \\
\hline
\end{tabular}

Based on the aforementioned naturalness continuum framework, 55.46\% of the West Virginia was between 1 mile $(1.61 \mathrm{~km})$ and 3 miles $(4.83 \mathrm{~km})$ from abandoned and/or operational logging sites and $23.74 \%$ were at least 3 miles away from such sites. The state is comprised of medium slopes (56.61\%) with at least 3 miles away from any abandoned and/or operational mining sites $(86.58 \%)$. In terms of the presence of wildlife, just under half of the state (46.64\%) was classified under wildlife setting IV (with 164-217 species), followed by wildlife setting III (110-163 species) (35.89\%). In terms of vegetation, the majority of the state had mixed forests (45.01\%), followed by hardwood forests $(35.82 \%)$, and grasslands and agriculture croplands (16.50\%). Further, the state was found mostly roaded natural and rural $(77.87 \%)$.

\subsection{Pairwise comparisons}

Based on respondents' pairwise comparisons on the relative importance of criteria (Figure 4), the presence of wildlife was the most important criterion $(0.27)$, followed by the presence of vegetation (0.23), while distance from logging, remoteness, and distance from mining had the same weight of 0.13 . Slope was reported as the least important criterion (0.11). The pairwise comparison results were consistent $(\mathrm{CR}=0.01)$. 


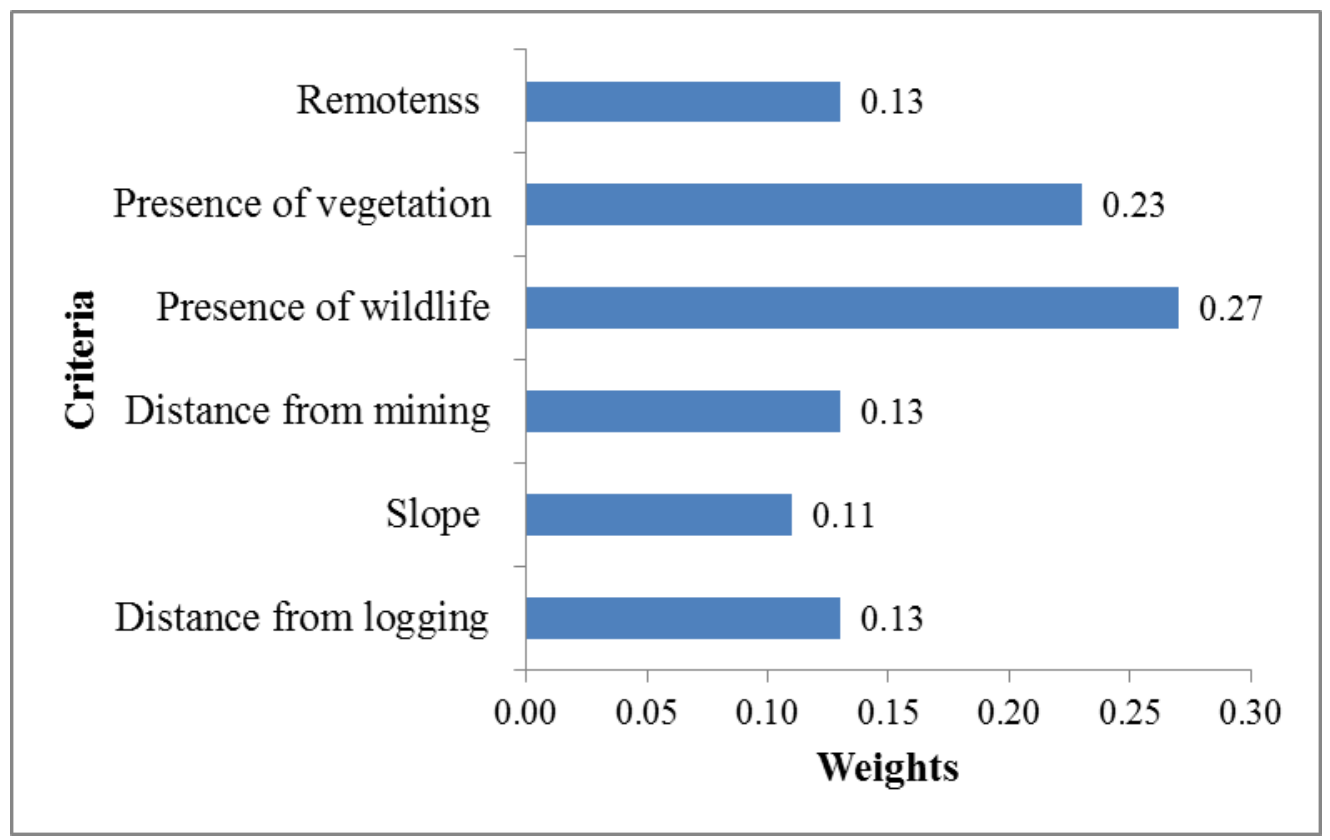

Figure 4. Criteria importance weights

\subsection{Unweighted and weighted ecotourism maps}

As shown in both the unweighted and weighted ecotourism maps (Figure 5), a large part of the state was classified as Class IV while Class V areas were scattered mostly in the eastern parts. Interestingly, after weights of the criteria were applied, there was a slight increase in the area under Class I (from $2.71 \%$ to $2.79 \%$ ), a moderate increase for Class V(1.41\% to $2.71 \%$ ), and Class IV (from 55.46\% to 62.20\%), and a large increase for Class II (from 8.82\% to 24.71\%). On the other hand, Class III exhibited a drastic decrease from $31.60 \%$ to $7.52 \%$ (Table 5). As the size of the area changed, the locations of those classes also changed (Figure 5). 


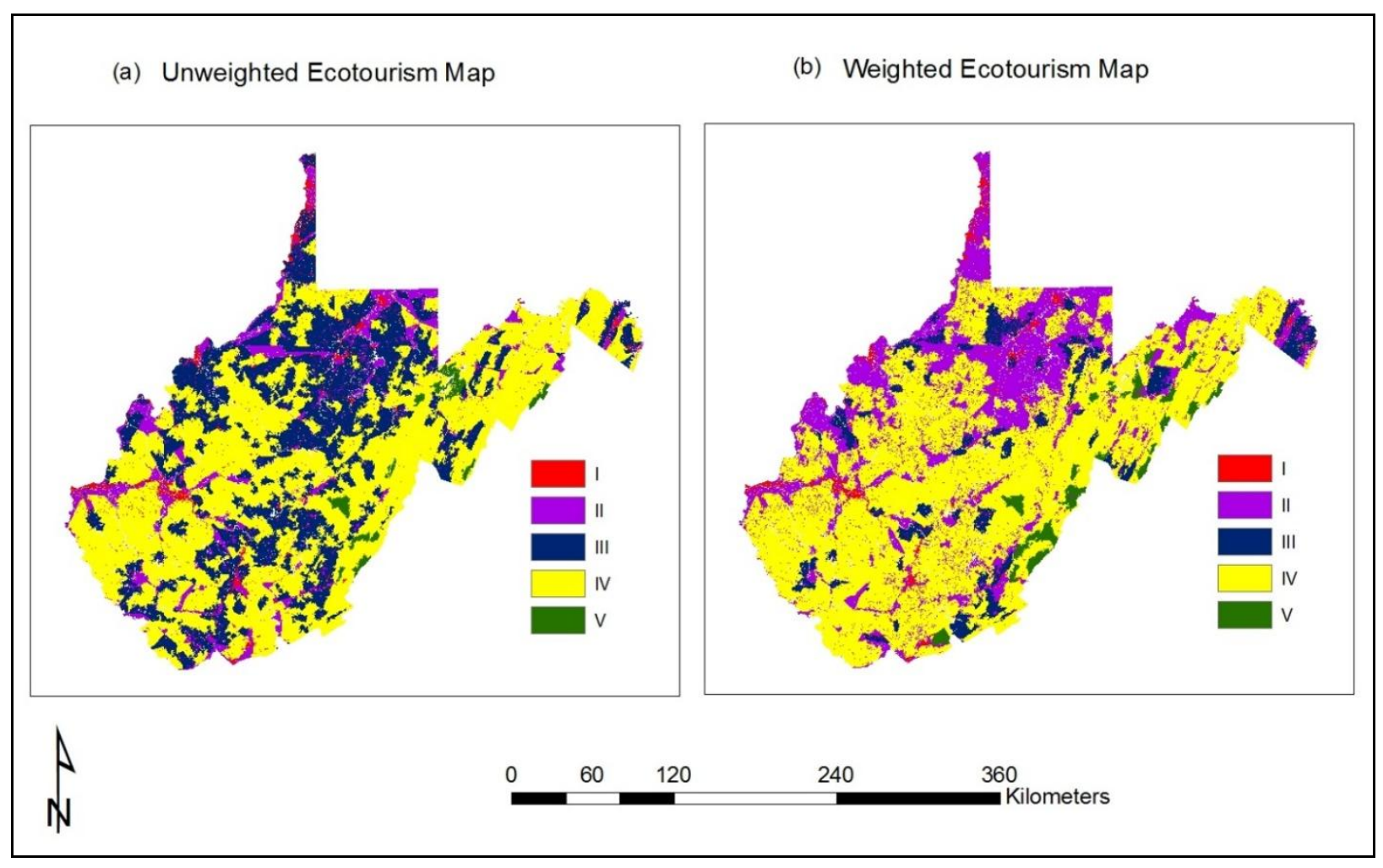

Figure 5 . Ecotourism suitability maps for West Virginia

Table 5. Percent distribution of areas by ecotourism suitability classes

\begin{tabular}{lll}
\hline Suitability class & $\begin{array}{l}\text { Area in unweighted map } \\
(\%)\end{array}$ & $\begin{array}{l}\text { Area in weighted map } \\
(\%)\end{array}$ \\
\hline I & 2.71 & 2.79 \\
II & 8.82 & 24.71 \\
III & 31.60 & 7.52 \\
IV & 55.46 & 62.27 \\
V & 1.41 & 2.71 \\
\hline
\end{tabular}

\subsection{Differences in the weights of the criteria}

Table 6 presents criteria that were statistically significantly different between various groups. Of the six criteria, females, repeat visitors, and respondents aged 40 and above had a significantly higher preference for areas more distant from logging sites than their counterparts. 
Repeat visitors and respondents familiar with the term "ecotourism" reported significantly higher preference for areas more distant from mining sites. Male respondents and respondents with an annual income of $\$ 40,000$ and above were found to prefer areas with high slopes. First time visitors and respondents with at least a high school degree had significantly higher preferences for the presence of wildlife. Female respondents and first time visitors had significantly higher preferences for the presence of vegetation. Finally, male respondents showed significantly higher preferences for remoteness. 
Table 6. Comparison of mean weights of criteria among various visitor groups

\begin{tabular}{|c|c|c|c|c|c|c|}
\hline Variables & $\begin{array}{l}\text { Distance } \\
\text { from } \\
\text { logging }\end{array}$ & Slope & $\begin{array}{l}\text { Distance } \\
\text { from } \\
\text { mining }\end{array}$ & $\begin{array}{l}\text { Presence } \\
\text { of } \\
\text { wildlife }\end{array}$ & $\begin{array}{l}\text { Presence } \\
\text { of } \\
\text { vegetation }\end{array}$ & Remoteness \\
\hline \multicolumn{7}{|l|}{ Demographics } \\
\hline Female & $0.15^{* *}$ & $0.12 *$ & - & - & $0.24 *$ & $0.15 * *$ \\
\hline Male & $0.14 * *$ & $0.13 *$ & - & - & $0.22 *$ & $0.18 * *$ \\
\hline 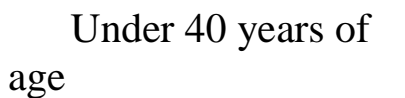 & $0.12 * * *$ & - & - & - & - & - \\
\hline Aged 40 and above & $0.15 * * *$ & - & - & - & - & - \\
\hline $\begin{array}{l}\text { Less than high } \\
\text { school degree }\end{array}$ & - & - & - & $0.12 * *$ & - & - \\
\hline $\begin{array}{l}\text { High school degree } \\
\text { and above }\end{array}$ & - & - & - & $0.19 * *$ & - & - \\
\hline $\begin{array}{l}\text { Annual income } \\
<\$ 40,000\end{array}$ & - & $0.11 * *$ & - & - & - & - \\
\hline $\begin{array}{c}\text { Annual } \\
\text { income }>\$ 40,000\end{array}$ & - & $0.13 * *$ & - & - & - & - \\
\hline Trip characteristics & & & & & & \\
\hline First time visitors & $0.13 * *$ & - & $0.13 *$ & $0.20 * *$ & $0.25 * * *$ & - \\
\hline Repeat visitors & $0.15^{* *}$ & - & $0.14 *$ & $0.18 * *$ & $0.22 * * *$ & - \\
\hline $\begin{array}{l}\text { Be familiar with the } \\
\text { term "ecotourism" }\end{array}$ & - & - & $0.15 * *$ & - & - & - \\
\hline $\begin{array}{l}\text { Not familiar with } \\
\text { the term "ecotourism" }\end{array}$ & - & - & $0.13 * *$ & - & - & - \\
\hline
\end{tabular}

Note: - denotes both groups were not significantly different from each other in their preferences on a criterion.

$$
* p<.1 ; * * p<.05 ; \text { and } * * * p<01 .
$$




\section{Discussion}

This study classified areas in West Virginia in terms of its suitability for forest-based ecotourism. Areas were classified based on naturalness as represented by six criteria. The study also incorporated visitors' preferences for each of the six criteria using AHP and GIS. Visitors preferred presence of wildlife to be the most important criterion and slope to be the least. Results showed that the size of ecotourism areas classified under each class changed when visitors' preferences expressed as weights were applied. Overall, Classes IV and V, which represented the best suited sites for forest-based ecotourism, covered more than half of the state's area in both the unweighted and weighted ecotourism maps, suggesting high prospects for promoting forestbased ecotourism in the state. Class IV and Class V of the weighted ecotourism map covered more areas compared to the corresponding classes in the unweighted ecotourism map.

The ecotourism maps were also compared with a map of the location of protected areas in the state. It was found that the weighted ecotourism map represented the public forested areas more accurately than the unweighted ecotourism map. The Class IV in the weighted ecotourism map represented more state parks, state forests, and national forests than the unweighted one. Further, Class V in the weighted ecotourism map represented more wilderness, wildlife management, and national park areas than the unweighted ecotourism map. The weighted ecotourism map derived from visitors' preferences also delineated potential areas for different classes of forest-based ecotourism along the spectrum. The weighted ecotourism map showed that about $3 \%$ of the state could cater to hard ecotourists who value wilderness (Class V). More than half of the state could be suitable for ecotourists who value wilderness but also desire some form of amenities (Class IV). This was validated by overlaying campsite locations in the weighted ecotourism map which showed that most campsites were in areas classified as Class IV. 
Areas under Classes I, II and III are suitable for soft ecotourists who value amenities and accessibility.

Respondents of various demographic groups and trip characteristics showed variations in their relative preferences among the six criteria. Male respondents and respondents with an annual income of $\$ 40,000$ and above had a higher preference for remoteness and/or slope of the area, perhaps indicating their affinity for adventure tourism activities. Distance from mining and/or logging sites was also highly preferred among female respondents, repeat visitors, respondents aged 40 and above, and also among respondents with prior knowledge about ecotourism. Preference of such areas could be indicative of their preference toward pristine areas and/ or their prior concerns with extractive activities. Similarly, higher preference of locations with vegetation and/or wildlife by first time visitors, female visitors and also by visitors with at least a high school degree could indicate their inclination towards undisturbed areas. Differences found in criteria weight suggest varying interests among different groups while selecting destinations. Therefore, mapping areas that meet the requirements of different interest groups could also help promote ecotourism destinations.

The combined AHP and GIS approach was promising in identifying and mapping forestbased ecotourism destinations in West Virginia using visitors' preferences. There were, however, certain limitations that might have influenced the findings of the study. First, the study used multiple-date images, which may have caused variation in the results. Second, the study used $30 \mathrm{~m}$ resolution. The use of this coarse resolution of the dataset can affect the precision of the area calculation for each class in the ecotourism maps. Third, using welcome centers as survey locations may or may not be representative of the entire state as findings from previous studies are not consistent. For instance, Howard and Gitelson (1989) reported that there were no 
significant differences between vacation travelers who used welcome centers and those visitors who did not. However, the opposite is noted in some other studies (e.g., Perdue \& Botkin, 1988; Stewart, Lue, Fesenmaier, \& Anderson, 1993). In West Virginia, a majority of visitors arrive by personal vehicles through Interstates 68 and 79 (West Virginia Division of Tourism, 2005). Thus, the sample population in our study may represent travel population to and in the state. That being said, the survey was conducted only during the autumn season. Accordingly, the weights and the resulting weighted map of this study may not be generalized. A longer term study that incorporates multiple seasons and locations (including locations outside of welcome centers) is recommended to obtain more insights into visitors' preferences.

Finally, the method of standardization of criteria scores could have affected the final ecotourism maps. The ecotourism maps in our study were classified based on equal interval classification; however, different value ranges of criteria scores can be easily assigned to define the different classes. Additional constraints could also be introduced during classification. For example, in this study, only the areas that spanned at least 5000 acres (20.23 square kilometers) were classified under Class III, IV and V.

\section{Conclusion}

West Virginia was found to be suitable for the entire spectrum of ecotourists from hard to soft, as shown by different classes in both the unweighted and weighted ecotourism maps. The weighted ecotourism map that incorporated visitors' relative preferences for each of the six criteria depicted more practicality compared to the unweighted ecotourism map. Results indicated that the weighted ecotourism map was more accurate in representing the existing public forested areas in West Virginia. Therefore, a weighted ecotourism map could be used to delineate potential forest-based ecotourism areas in the state. 
Mapping forest-based ecotourism destinations according to visitors' preferences is possible because of tools like AHP and GIS. GIS was found to be a useful tool in analyzing and visualizing the outputs of classification, and the AHP pairwise comparison method aided in generating the weighted ecotourism map. The framework demonstrated in this study for mapping visitors' preferences is flexible. New criteria and their corresponding weights can be added or modified during the classification to fit the context of the study area.

The study does not attempt to recommend an ideal mix of preferences of criteria among user groups, but rather, highlights the importance of criteria while selecting sites for ecotourism destinations. One of the main targets of the ecotourism industry is to attract more ecotourists by advertising different kinds of attractions within the destinations. To achieve this objective, destination marketing should not only focus on increasing the number of ecotourists traveling to a region, but also aim to locate ecotourism destinations that suit their preferences. The study suggests that incorporating visitors' preferences in determining ecotourism destinations could provide helpful information in terms of destination development, marketing and promotion. This study provides an understanding of how ecotourists and potential ecotourists view and choose their destinations; and therefore, it can help concerned agencies to make decisions with respect to the establishment of ecotourism destinations. Development of user friendly software that allows visitors to input their preferences through pairwise comparisons of criteria such that the resulting weights can be used to produce individualized weighted ecotourism map could help identify best sites and thus promote ecotourism in the area.

The results of the study could also be incorporated within the overall land use planning scheme to strengthen the efforts for forest and wildlife conservation and to minimize the practice of logging and mining near ecotourism destinations. As preferences of visitors change over time, 
long term studies of similar kind could provide important insights in better planning for sustainable ecotourism in the area. 


\section{References}

Aguilar-Manjarrez, J., \& Ross, L.G. (1995). Geographical information systems (GIS) environmental models for aquaculture development in Sinaloa state, Mexico. Aquaculture International, 3(2), 103-115.

Boyd, S.W., Butler, R.W., Haider, W., \& Perera, A. (1994). Identifying areas for ecotourism in Northern Ontario: application of a geographical information system methodology. Journal of Applied Recreation Research, 19(1), 41-66.

Bukenya, J. O. (2012). Application of GIS in ecotourism development decisions: Evidence from the Pearl of Africa. In Research paper for natural resource economics program, West Virginia University, Morgantown, West Virginia. Retrieved October 20, 2013, from http://www.rri.wvu.edu/wp-content/uploads/2011/03/bukenya2012.pdf

Bunruamkaew, K., \& Murayama, Y. (2011). Site suitability evaluation for ecotourism using GIS \& AHP: a case study of Surat Thani province, Thailand. Procedia-Social and Behavioral Sciences, 21, 269-278.

Ceballos-Lascurain, H. (1987). The future of ecotourism. Mexico Journal, 1(17), 13-19.

Chuang, P.T. (2001). Combining the analytic hierarchy process and quality function deployment for a location decision from a requirement perspective. The International Journal of Advanced Manufacturing Technology, 18(11), 842-849.

Decrop, A. (1999). Tourists' decision-making and behavior processes. In A. Pizam, \& Y. Mansfeld (Eds.), Consumer behavior in travel and tourism (pp.103-133). New York: The Haworth Hospitality Press.

Dellaert, B. G. C., Etterma, F., \& Lindh, C. (1998). Multi-faceted tourist travel decisions: a constraint-based conceptual framework to describe tourists' sequential choice of travel components. Tourism Management, 19(4), 313-320.

Deng, J., King, B., \& Bauer, T. (2002). Evaluating natural attractions for tourism. Annals of Tourism Research, 29(2), 422-438.

Drumm, A., \& Moore, A. (2002). Ecotourism development: a manual for conservation planners and managers. Arlington, Virginia: The Nature Conservancy.

Eagles, P. F. J. (1992). The motivations of Canadian ecotourists. Journal of Travel Research, $3(1), 3-7$.

Eastman, J.R., Jin, W., Kyem, W., \&Tolendano, P. (1995). Raster procedures for multicriteria/multi-objective decisions. Photogrammetric Engineering \& Remote Sensing, 61(5), 539-547.

Font, X., \& Mihalic, T. (2002). Beyond hotels: nature-based certification in Europe. In M. Honey (Eds.), Ecotourism \& certification: Setting standards in practice (pp. 211-236). Washington: Island Press.

Fung, T., \& Wong, F.K.K. (2007). Ecotourism planning using multi-criteria evaluation with GIS. Geocarto International, 22(2), 87-105.

Gemitzi, A., Tsihrintzis, V. A., Voudrias, E., Petalas, C., \& Stravodimos, G. (2007). Combining geographic information system, multi-criteria evaluation techniques and fuzzy logic in siting MSW landfills. Environmental Geology, 51(5), 797-811.

Goodall, B., \& Ashworth, G. (1988). Marketing in the tourism industry. United Kingdom: Croom Helm. 
Goodall, B. (1991). Understanding holiday choice. In C. Cooper (Eds.), Progress in tourism, recreation and hospitality management (pp. 103-133). London: Belhaven.

Heung, V. C. S., Qu, H., \& Chu, R. (2001). The relationship between vacation factors and sociodemographic and traveling characteristics: The case of Japanese leisure travelers. Tourism Management, 22(3), 259-269.

Ho, W. (2008). Integrated analytic hierarchy process and its applications: a literature review. European Journal of Operation Research, 186(1), 211- 228.

Hossain, M. S., Chowdhury, S.R., Das, N.J., Sharifuzzaman, S.M., \& Sultana, A. (2009). Integration of GIS and multi-criteria decision analysis for urban aquaculture development in Bangladesh. Landscape and Urban Planning, 90(3-4), 119-133.

Howard, D. R., \& Gitelson, R. (1989). An analysis of the differences between state welcome center users and nonusers: a profile of Oregon vacationers. Journal of Travel Research, 27(4), $38-40$.

Hsu, T.K., Tsai, Y.F., \& Wu, H.H. (2009). The preference analysis for tourist choice of destination: a case study of Taiwan. Tourism Management, 30(2), 288-297.

Jankowski, P., \& Richard, L. (1994). Integration of GIS-based suitability analysis and multicriteria evaluation in a spatial decision support system for route selection. Environment and Planning B: Planning and Design, 21(3), 323-340.

Jankowski, P. (1995). Integrating geographical information systems and multiple criteria decision-making methods. International Journal of Geographical Information systems, 9(3), 251-273.

Kangas, J. (1994). An approach to public participation in strategic forest management planning. Forest Ecology and Management, 70(1-3), 75-88.

Kumari, S., Behera, M.D., \& Tewari, H.R. (2010). Identification of potential ecotourism sites in West District, Sikkim using geospatial tools. Tropical Ecology, 51(1), 75-85.

Lam, T., \& Hsu, H. C. (2006). Predicting behavioral intention of choosing a travel destination. Tourism Management, 27(4), 589-599.

Lee, C., Huang, H.I., \& Yeh, H.R. (2010). Developing an evaluation model for destination attractiveness: sustainable forest recreation tourism in Taiwan. Journal of Sustainable Tourism, 18(6), 811-828.

Lundberg, D.E. (1990). The tourist business. New York: Van Nostrand Reinhold.

Parsons, E. C. M., Warburton, C. A., Woods-Ballard, A., Hughes, A., Johnston, P., Bates, H., \& Lück, M. (2003). Whale-watching tourists in West Scotland. Journal of Ecotourism, 2(2), 93113.

Pearce, D. (1988). Tourist-time budgets. Annals of Tourism Research, 15(1), 106-121.

Perdue, R. R., \& Botkin, M. R. (1988). Visitor survey versus conversion study. Annals of Tourism Research, 15(1), 76-87.

Pérez, O.M., Telfer, T.C., \& Ross, L.G. (2003). On the calculation of wave climate for offshore cage culture site selection: a case study in Tenerife (Canary Islands). Aquacultural Engineering, 29(1-2), 1-21.

Pierskalla, C.D., Sinisalchi, J.M., Selin, S. W., \& Fosbender, J. (2007). Using events as a mapping concept that complement existing ROS methods. Leisure Science, 29(1), 71-89.

Saaty, T.L. (1980). The analytic hierarchy process. New York: McGraw-Hill.

Saaty, T.L. (1987). Concepts, theory, and techniques rank generation, preservation, and reversal in the analytic hierarchy decision process. Decision Sciences, 18, 157-177. 
Saaty, T. L. (1989). Group decision making and the AHP. In In B.L. Golden, E.A. Wasil, and P.T. Harker (Eds), The Analytic Hierarchy Process: application and studies (pp. 59-67). Berlin: Springer.

Sener, B., Suzen, M. L. \& Doyuran, V. (2006). Landfill site selection by using geographic information systems. Environmental Geology, 49(3), 376-388.

Strager, M.P., \& Rosenberger, R.S. (2006). Incorporating stakeholder preferences for land conservation: weights and measures in spatial MCA. Ecological Economics, 58(1), 79-92.

Stewart, W. P., Lue, C. C., Fesenmaier, D. R., \& Anderson, B. S. (1993). A comparison between welcome center visitors and general highway auto travelers. Journal of Travel Research, 31(3), 40-46.

Stronza, A., \& Durham, W. (2008). Ecotourism and conservation in the Americas. Wallingford: CAB International.

Suh, Y. K., \& McAvoy, L. (2005). Preferences and trip expenditures: a conjoint analysis of visitors to Seoul, Korea. Tourism Management, 26(3), 325-333.

The International Ecotourism Society. (2006). Fact sheet: Global ecotourism. Retrieved October 31, 2013, from http://mekongtourism.org/website/wpcontent/uploads/downloads/2011/02/Fact-Sheet-Global-Ecotourism-IETS.pdf

Tseng, C., Chen, S., Huang, C. \& Liu, C. (2001). GIS-assisted site selection for artificial reefs. Fisheries Science, 67(6), 1015-1022.

Tzu-Kuang, H., Tsai, Y.F., \& Wu, H.H. (2009). The preference analysis for tourist choice of destination: a case study of Taiwan. Tourism Management, 30(2), 288-297.

Ullah, K.M., \& Hafiz, R. (2013). Finding suitable locations for ecotourism development in Cox's Bazar using geographical information system and analytical hierarchy process. Geocarto International, 1-12 DOI: 10.1080/10106049.2012.760005

Um, S., \& Crompton, J. L. (1990). Attitude determinants in tourism destination choice. Annuals of Tourism Research, 17(3), 432-448.

U.S. Census Bureau. (2012). Statistical Abstract of United States: Art, Recreation, and Travel. Retrieved October 31, 2013, from http://www.census.gov/compendia/statab/cats/arts_recreation_travel/travel_and_tourism.html

Vaske, J.J. (2008). Survey research and analysis: applications in parks, recreation and human dimensions. State College, Pennsylvania: Venture Publishing, Inc.

West Virginia Department of Health and Human Resources. (2013). State Narrative for West Virginia. Retrieved October 31, 2013, from http://www.wvdhhr.org/mcfh/blockgrant/wv-narratives.pdf

West Virginia Division of Forestry. (2006). West Virginia's forests: a growing resource for our future. Charleston, West Virginia. Retrieved October 31, 2013, from http://www.wvforestry.com/A\%20Growing\%20Resource\%20for\%20our\%20Future.pdf

West Virginia Division of Tourism. (2005). West Virginia Division of Tourism: 2005 annual report. Charleston, West Virginia: The author.

West Virginia Division of Tourism. (2010). West Virginia Division of Tourism: 2010 annual report. Charleston, West Virginia: The author.

Yalcin, A. (2008). GIS-based landslide susceptibility mapping using analytical hierarchy process and bivariate statistics in Ardesen (Turkey): comparisons of results and confirmations. Catena, 72(1), 1-12.

Yang, J., \& Lee H., (1997). An analytic hierarchy process decision model for facility location selection. Facilities, 15(9/10), 241-254. 
Ziffer, K.A. (1989). Ecotourism: The uneasy alliance. Washington, DC: Conservation International.

Zhou, L., Cheng, X., \& Zhou, T. (2006). A Research on the willingness to pay for certificated ecotourism product-the empirical analysis based on the tourists of Zhejiang's four scenic spots. Economic Geography, 26(1), 141-144. 
Appendix 1

\section{People's perception of criteria for identifying forest-based ecotourism in West Virginia}

\section{Survey Questionnaire}

This research study is voluntary and if, for any reason, you feel you do not want to answer an item, just leave it blank and proceed to the next. All information collected will be kept confidential and will be used for academic purposes. Thank you for your participation!

\section{Section I: Trip Characteristics}

1. Purpose for this trip (please circle the single best answer)
a. Visit family and relatives
b. Leisure/vacation
c. Business
d. Others (please specify)

2. Including yourself, how many people are traveling with you on this trip?

Number of female and male in your group?

3. Of those with you today, how many children are in the following age groups?

$$
\begin{array}{lll}
\text { Infant - 2 Yrs__ } & 3-5 \mathrm{Yrs}_{1} & 6-9 \text { Yrs } \\
10-13 \mathrm{Yrs} & 14-17 \mathrm{Yrs} & \text { Not applicable }
\end{array}
$$

4. Please indicate how many times you have visited the following West Virginia destinations in the past 12 months?

\begin{tabular}{|l|l|}
\hline Destinations /attractions visited in West Virginia in the past 12 & Total number of \\
\hline 1. National Parks (e.g., New River Gorge) & \\
\hline 2. National Forests (e.g., Monongahela National Forest) & \\
\hline 3. State Parks & \\
\hline 4. State Forests & \\
\hline 5. Scenic Byways & \\
\hline 6. Wildlife Management Areas & \\
\hline 7. Museums & \\
\hline 8. Historic sites (i.e., battlefield) & \\
\hline 9. Festivals & \\
\hline 10. Golf courses & \\
\hline Others (please specify): & \\
\hline
\end{tabular}


5. How many times have you visited West Virginia in the past 12 months?

a. This is my first time b. 2-5 times c. 6-10 times d. More than 10 times e. Other (West Virginia resident)

6. Have you heard of term Ecotourism before? Yes___ No

\section{Section II: Comparing criteria for identification of forest-based ecotourism}

Please follow the example given below to compare the forest based ecotourism related criteria on the next page of this survey.

Example: If you are planning to buy a new car, you consider several criteria like price, style, make, etc. Looking at the sample response below:

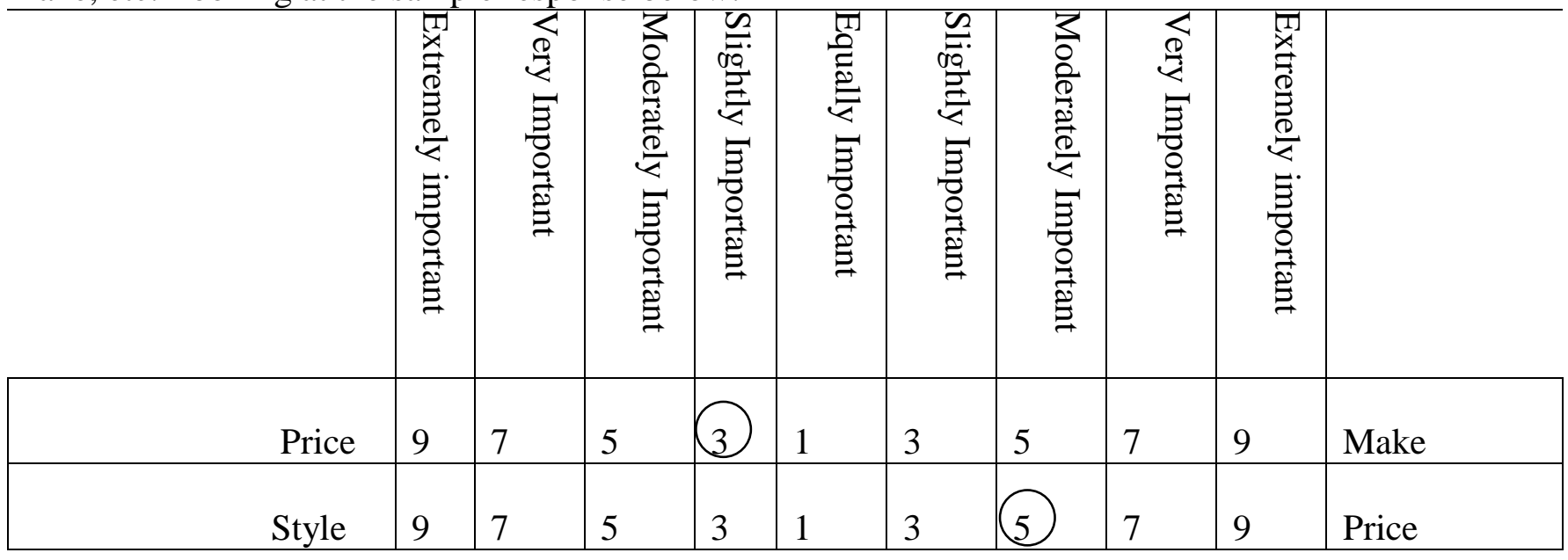

In comparing criteria, if price is slightly more important than make, you encircle 3 , and if price is moderately important over style, you encircle 5.

Note: If the left side is circled, left side criterion is more important than the criterion on the right side. Conversely, if the right side is circled, it means the criterion on this side is more important than the criteria on the left side.

For this study we will consider this definition of forest-based ecotourism:

Forest-based ecotourism areas in this study refer to areas that are primarily dominated by forest environment.

The criteria considered for this study are:

Remoteness (distance from road)

Slope (Steepness, Terrain)

Presence of wildlife

Distance from mining

Distance from logging

Presence of vegetation (forest) 
Following the above example, please compare the relative importance of the criteria listed below in choosing sites for forest-based ecotourism. Please circle the number for your response.

Remoteness

Slope

Presence of wildlife

Distance from mining

Distance from logging

Presence of vegetation

Remoteness

Presence of wildlife

Distance from logging

Slope

Presence of vegetation

Distance from mining

Remoteness

Distance from mining

Presence of vegetation

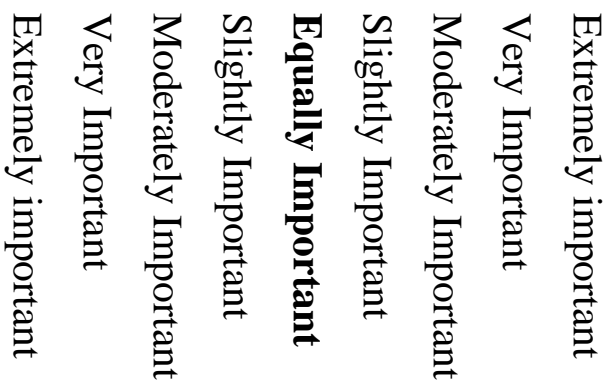

$\begin{array}{llllllllll}9 & 7 & 5 & 3 & 1 & 3 & 5 & 7 & 9 & \text { Slope }\end{array}$

$\begin{array}{llllllllll}9 & 7 & 5 & 3 & 1 & 3 & 5 & 7 & 9 & \text { Presence of wildlife }\end{array}$

$\begin{array}{llllllllll}9 & 7 & 5 & 3 & 1 & 3 & 5 & 7 & 9 & \text { Distance from mining }\end{array}$

$\begin{array}{llllllllll}9 & 7 & 5 & 3 & 1 & 3 & 5 & 7 & 9 & \text { Distance from logging }\end{array}$

$\begin{array}{llllllllll}9 & 7 & 5 & 3 & 1 & 3 & 5 & 7 & 9 & \text { Presence of vegetation }\end{array}$

$\begin{array}{llllllllll}9 & 7 & 5 & 3 & 1 & 3 & 5 & 7 & 9 & \text { Remoteness }\end{array}$

$\begin{array}{llllllllll}9 & 7 & 5 & 3 & 1 & 3 & 5 & 7 & 9 & \text { Presence of wildlife }\end{array}$

$\begin{array}{llllllllll}9 & 7 & 5 & 3 & 1 & 3 & 5 & 7 & 9 & \text { Distance from logging }\end{array}$

$\begin{array}{llllllllll}9 & 7 & 5 & 3 & 1 & 3 & 5 & 7 & 9 & \text { Slope }\end{array}$

$\begin{array}{llllllllll}9 & 7 & 5 & 3 & 1 & 3 & 5 & 7 & 9 & \text { Presence of vegetation }\end{array}$

$\begin{array}{llllllllll}9 & 7 & 5 & 3 & 1 & 3 & 5 & 7 & 9 & \text { Distance from mining }\end{array}$

$\begin{array}{llllllllll}9 & 7 & 5 & 3 & 1 & 3 & 5 & 7 & 9 & \text { Remoteness }\end{array}$

$\begin{array}{llllllllll}9 & 7 & 5 & 3 & 1 & 3 & 5 & 7 & 9 & \text { Distance from logging }\end{array}$

$\begin{array}{llllllllll}9 & 7 & 5 & 3 & 1 & 3 & 5 & 7 & 9 & \text { Slope }\end{array}$

$\begin{array}{llllllllll}9 & 7 & 5 & 3 & 1 & 3 & 5 & 7 & 9 & \text { Presence of wildlife }\end{array}$ 
Section III: Background Information

1. Gender Female__ Male

2. Age

$18-25$

26-39

$40-54$

$55-60$

$61+$

3. What is the highest level of education you have completed?

Less than high school degree___ High school degree or equivalent

Undergraduate or post-secondary degree____ Graduate school degree

4. What was your approximate gross household income from all sources before taxes in the previous year?

Less than $\$ 20,000$

60,000

$\$ 20,001$ to 40,000

$\$ 40,001$ to

$\$ 60,001$ to $\$ 80,000$

$\$ 80,001$ to 100,000

$\$ 100,000$

$+$

5. Place of Residence (If from another country, only country name is needed)

Country or State of Residence

Zip Code

Do you have any other comments about this study that you would like to add?

Thank you once again for your time and cooperation. 


\title{
CHAPTER 4: Essay 3
}

\section{Sensitivity Analysis of Multi-Criteria Weights for Forest-based Ecotourism Areas in West Virginia}

\begin{abstract}
The study highlights the importance of sensitivity analysis of criteria weights in mapping forest-base ecotourism areas. Stated preferences from visitors and experts were used to calculate relative weights for criteria based on the Analytic Hierarchy Process. Sensitivity analysis was carried out by varying the criteria weights derived from a visitor and expert survey, first by doubling their values and then decreasing them by a half. Results showed that the presence of vegetation was the most important criterion followed by the remoteness, for both groups. Combined suitability and sensitivity maps showed that about one third of the state's area was highly suitable/less sensitive to variations in criteria weights. The resultant map created shows the existing robust areas suitable for forest based ecotourism and also provides information on potential stable areas for promoting ecotourism in the state. This information could be helpful in destination development, marketing and promotion.
\end{abstract}

Keywords: Forest-based ecotourism, Geographic Information System, Analytic Hierarchy Process, Pairwise comparison, Criteria weight, Sensitivity analysis 


\section{Introduction}

Studies on identification of ecotourism destinations are primarily focused on criteria weights derived from Multi Criteria Decision Making (MCDM) methods and Geographic Information system (GIS) (Fung \& Wong, 2007; Bukenya, 2012). MCDM approaches such as Analytic Hierarchy Process (AHP) have been used to calculate weights of various sets of criteria which are then integrated in GIS to show the location of those ranked destinations (Kumari, Behera \& Tewari, 2010; Bunruamkaew \& Murayama, 2011; Ullah \& Hafiz, 2013; Dhami, Deng, Burns \& Pierskalla, 2013). Although AHP is popular in calculating criteria weights and ranking the input criteria according to their relative importance, it does not address the uncertainity in decision maker's preferences. The uncertainties could arise from the involvement of multiple decision makers leading to more than one set of criteria weights, decision makers not being aware of preferences regarding the criteria, and due to the incomprehensible nature and scale of criteria. Uncertainty can also come from original data, data processing, criteria selection, and their thresholds (Chen, Yu \& Khan, 2010). Among many sources, criteria weights are recognized as a major contributor to uncertainty (Chen, Yu \& Khan, 2010) and thus decrease the stability of the outputs. In order to reduce uncertainties of input criteria weights for stable outputs, sensitivity analysis of criteria weights is crucial and has been widely suggested for its use with MCDM to obtain stable model outputs (Chen, Yu \& Khan, 2010; Pisoni, Carnevale \& Volta, 2010; Chen, Wood, Linstead \& Maltby, 2011).

Sensitivity analysis is defined as the examination of the variations in the output of a model with slight changes in input (Saltelli, Chan \& Scott, 2000). Sensitivity analysis helps in examining the relationships between the inputs and the output of a modeling application and can be used to check the robustness of the final outcome against changes in the input data (Merritt, 
Croke \& Jakeman, 2005; Zoras, Triantafyllou, \& Hurley., 2007, Ravalico, Dandy \& Maier, H. R, 2010). Thus, it has been applied for model development and refinement (Saltelli, Chan \& Scott, 2000; Fraedrich \& Goldberg, 2000; Chen, Yu \& Khan, 2010; Allaire \& Willcox, 2012). A suitability model of ecotourism destinations identified in previous studies used criteria weights, however; criteria weight uncertainties were not examined. Therefore, this study addresses previous deficiencies by examining the sensitivity of multi-criteria weights using sensitivity analysis to map stable suitable areas. The general objective of this study is to use sensitivity analysis in multi-criteria weights for identifying stable areas for forest-based ecotourism areas in West Virginia, USA. The specific objectives are to: (i) create a weighted ecotourism suitability map using preferences of visitors and experts, (ii) create criteria weights with a sensitivity map, and (iii) create a sensitivity map for the areas suitable for forest-based ecotourism in the state.

\section{Literature review}

GIS with MCDM, also known as spatial MCDM, can be understood as a process that combines geographical data and individuals' preferences into a resultant decision (Malczewski, 2006). GIS involves spatially referenced geographic units (e.g. polygons in vectors, or grids in rasters) and MCDM consists of techniques and procedures to derive criteria weights based on the relative importance of criteria (Chen, Yu \& Khan, 2010).

Among various MCDM methods, AHP is one of the most common methods to determine criteria weights (Saaty, 1980; Huang \& Bian, 2009)). Several studies have used AHP for ranking stakeholders' preferences in the field of travel and tourism. For example, Tsaur, Chang and Yen (2002) used AHP to calculate the criteria weights for evaluating the service quality for the Taiwan airline travel market. Deng, King, and Bauer (2002) proposed a hierarchical structure to evaluate and rate national parks for nature-based tourism in Victoria, Australia. Lee, Huang and 
Yeh (2010) used AHP to elicit expert opinions on the factors affecting the attractiveness of forest-based recreation and tourism in Taiwan.

Integration of GIS and AHP has been widely used in site selection studies. For example, finding ecologically suitable sites for Eucalyptus plantations in eight municipalities in southcentral state of Sinaloa, Mexico (Bustillos-Herrera,Valdez-Lazalde \& Aldrete, 2007); mapping landslide susceptibility in the 2005 Kashmir earthquake region (Kamp, Growley, Khattak \& Owen, 2008); characterizing and assessing potential landfill sites in the Polog Region, Macedonia (Gorsevski, Donevska, Mitrovski \& Frizdo, 2012); and selecting solar farm sites in Karapinar region, Konya, Turkey (Uyan, 2013). These studies demonstrated GIS as a useful tool for integrating information and assisting in the decision-making process in combination with MCDM methods like AHP.

More recently, several studies have incorporated AHP and GIS to assess ecotourism destinations. For example, Kumari, Behera and Tewari (2010) identified potential ecotourism sites in West District of Sikkim, India based on five indices: wildlife distribution, ecological value, ecotourism attractiveness, environmental resiliency, and ecotourism diversity. Bunruamkaew and Murayama (2011) prioritized the potential ecotourism sites in Surat Thani Province, Thailand based on five criteria and nine factors. Criteria weights and factors were calculated by applying the hierarchical structure of AHP where experts were asked to determine the relative importance of each criterion and factor. The final ecotourism map was classified into four classes: highly suitable to least suitable. Similar to Bunruamkaew and Murayama (2011), Ullah and Hafiz (2013) identified suitable locations for ecotourism development in Cox's Bazar, Bangladesh using five factors and fifteen criteria. However, the final map was classified into three classes from highly suitable to marginally suitable. These studies were focused on 
identifying important criteria or factors but did not consider visitors' preferences. Dhami et al., 2013 identified and mapped forest-based ecotourism in West Virginia, USA into five classes using naturalness continuum and visitors' preferences. Although, the study used visitors' preferences in determining criteria weights, it did not investigate the variations in the output with change in inputs (criteria weights). The study also did not incorporate preferences of ecotourism experts in the study. While visitors' knowledge is important in providing experiential knowledge, experts' knowledge is perceived as universal guidance of what is best suited for any location (Fischer, 2000; Skogen, 2003). Therefore, this study performs sensitivity analysis on criteria weights from visitors and experts preferences and identifies robust ecotourism areas in West Virginia using AHP and GIS.

Various techniques like Monte Carlo simulation, sensitivity indices (Saltelli, 2002; Allaire \& Willcox, 2012; Mara \& Tarantola, 2012), regression or correlation methods (Manache \& Melching, 2008), and Bayesian approach (Oakley \& O'Hagan, 2004) have been used for sensitivity analysis. However, this study used One-At-a-Time (OAT) sensitivity measures as it is a common method for conducting MCDM sensitivity analysis (Crosetto \& Tarantola, 2001; Hyde \& Maier, 2006; Ravalico, Dandy \& Maier, 2010, Chen, Yu \& Khan, 2010). OAT is easy to develop and is logically simple as any observed changes in the output will be entirely due to the change in the value of the single input value (Chen, Yu \& Khan, 2010).

Several studies have used GIS-based sensitivity analysis of multi-criteria weights for suitability modeling. For example, Store and Kangas (2001) applied sensitivity analysis in habitat suitability modeling of old-forest polypore, Skeletocutis odora in Finland; Strager and Rosenberger (2006) used sensitivity analysis in multicriteria framework and mapped priority areas for land conservation using GIS in the Cacapon River Watershed of West Virginia. Chen, 
Yu \& Khan (2010) presented GIS-based AHP and sensitivity analysis methodology for analysis criteria weights sensitivity in MCDM and classified irrigated cropping landuse in the Macintyre Brook catchment of Queesland, Australia. Al-Mashreki, Akhir, Rahim, Lihan and Haider (2011) classified croplands in Yemen into five classes from highly suitable to permanently unsuitable areas using GIS-based sensitivity analysis of multicriteria weights. However, there are no studies to the authors' knowledge that consider sensitivity analysis of spatial multi-criteria weights for the identification of ecotourism destinations. Thus, this study investigates the spatial dimension of multi-criteria weights sensitivity in identifying and mapping highly suitable and forest-based ecotourism areas in West Virginia.

\section{Methods}

This study used the criteria and scores used by Dhami et al. (2013) to accomplish the objectives of the study. The criteria includes: distance from logging, slope, distance from mining, presence of wildlife, presence of vegetation, and remoteness.

\subsection{Experts' survey}

In addition to visitors' preferences used by Dhami et al., 2013, this study also incorporated preferences of ecotourism experts to determine the criteria weight. A total of 1080 ecotourism experts were selected from CIRET (International Center for Research and Study on Tourism) database and Google search engine. Of the 1080 experts, 500 were randomly selected for the survey.

A preliminary correspondence introducing the upcoming survey on determining the relative importance of various criteria (Table 1) for identifying forest-based ecotourism sites in West Virginia was sent out via email in the first week of March, 2011 to the randomly selected 
experts. It also informed experts that they would be receiving another email within the following week that would formally invite them to participate in web-based survey. 
Table 1. Pairwise comparison of the criteria for forest-based ecotourism in West Virginia

\begin{tabular}{|c|c|c|c|c|c|c|c|c|c|c|}
\hline & 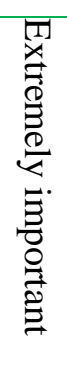 & 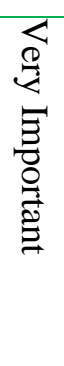 & 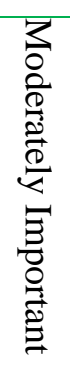 & 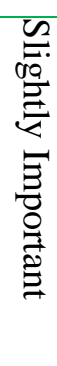 & 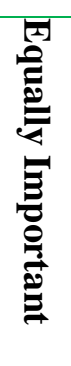 & 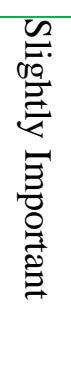 & 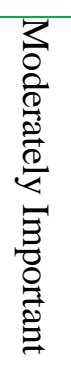 & 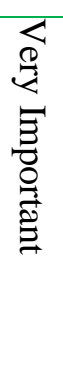 & 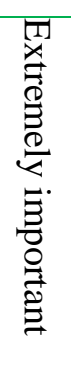 & \\
\hline Remoteness of the area & 9 & 7 & 5 & 3 & 1 & 3 & 5 & 7 & 9 & Slope of the area \\
\hline Slope of the area & 9 & 7 & 5 & 3 & 1 & 3 & 5 & 7 & 9 & Presence of wildlife \\
\hline Presence of wildlife & 9 & 7 & 5 & 3 & 1 & 3 & 5 & 7 & 9 & Distance from mining \\
\hline Distance from mining area & 9 & 7 & 5 & 3 & 1 & 3 & 5 & 7 & 9 & Distance from logging area \\
\hline Distance from logging area & 9 & 7 & 5 & 3 & 1 & 3 & 5 & 7 & 9 & Presence of vegetation \\
\hline Presence of vegetation & 9 & 7 & 5 & 3 & 1 & 3 & 5 & 7 & 9 & Remoteness of the area \\
\hline Remoteness of the area & 9 & 7 & 5 & 3 & 1 & 3 & 5 & 7 & 9 & Presence of wildlife \\
\hline Presence of wildlife & 9 & 7 & 5 & 3 & 1 & 3 & 5 & 7 & 9 & Distance from logging area \\
\hline Distance from logging area & 9 & 7 & 5 & 3 & 1 & 3 & 5 & 7 & 9 & Slope of the area \\
\hline Slope of the area & 9 & 7 & 5 & 3 & 1 & 3 & 5 & 7 & 9 & Presence of vegetation \\
\hline Presence of vegetation & 9 & 7 & 5 & 3 & 1 & 3 & 5 & 7 & 9 & Distance from mining area \\
\hline Distance from mining area & 9 & 7 & 5 & 3 & 1 & 3 & 5 & 7 & 9 & Remoteness of the area \\
\hline Remoteness of the area & 9 & 7 & 5 & 3 & 1 & 3 & 5 & 7 & 9 & Distance from logging area \\
\hline Distance from mining area & 9 & 7 & 5 & 3 & 1 & 3 & 5 & 7 & 9 & Slope of the area \\
\hline Presence of vegetation & 9 & 7 & 5 & 3 & 1 & 3 & 5 & 7 & 9 & Presence of wildlife \\
\hline
\end{tabular}

During the second week in March, invitation emails were sent out to the same experts. The email reiterated the survey's objectives, provided a link to the web-based survey and informed 
experts that the survey would take them approximately 10 minutes to complete. The email also assured experts that their participation was voluntary, anonymous, and that the survey was encrypted to ensure that experts' identities were not traceable and that their responses could not be linked back to their email addresses. The instructions also reminded them that they could skip questions for which they were not comfortable and they could quit the survey at any time.

Experts participated in the survey via a link in their invitation email which connected them to the survey questionnaire in SurveyMonkey, a web-based survey program. SurveyMonkey is a user friendly program that allows respondents to navigate easily through a series of questions. An advanced version of SurveyMonkey with encryption was used to ensure respondents' privacy. The questions were grouped into two sections: comparing the criteria for identification of ecotourism and socio-demographic characteristics. The first section explored respondents' preference of criteria by asking them to carry out pairwise comparisons among considered criteria. Socio-demographic section consisted of questions about as gender, age, education level, working experience in the field of ecotourism, working institution, and country of residence.

Two follow-up reminder emails were also disseminated to the experts. The first reminder email was sent out one week after the initial invitation and the final reminder was sent out a month later. The follow-up emails replicated much of the information from the original invitation email and contained the same link to the web-based survey questionnaire.

\subsection{AHP pairwise comparison}

AHP is a popular mathematical method for the calculation of criteria weights when analyzing complex decision problems (Saaty, 1980). It calculates the weights through pairwise comparisons of criteria. Weight for each criterion was calculated by taking the eigenvector 
corresponding to the largest eigenvalue of pairwise comparison matrix and then by normalizing the sum of the components to a unity. The determination of Consistency Ratio (CR) value was critical and this study adopted a standard CR threshold value of 0.10 which has been widely used as a measure of the consistency in a set of judgments of AHP applications in literature (Saaty \& Vargas, 2001).

Weighted arithmetic mean method and geometric mean method are the most common methods for aggregating individuals' preferences obtained from pairwise comparision of AHP (Dyer \& Forman, 1992). Geometric mean method is used to aggregate preferences from pairwise comparison matrix whereas weighted arithmetic mean method is used to aggregate final priority weights.

For each participant, criteria weights and CR were calculated using pairwise comparison method and weighted arithmetic mean method was used to obtain a single collective preference which indicated weighted aggregation of different individual preferences.

\subsection{Test of statistical differences}

The weights from the AHP test were analyzed to determine whether the visitors' preferences for criteria were substantially different from the experts'. T-tests are used to test for statistical differences in inter-group preference weights.

\subsection{Ecotourism suitability map}

Ecotourism suitability map was created using the suitability index $(\mathrm{S})$ method which is a weighted linear combination function that combines preference weights $\left(\mathrm{w}_{i}\right)$ and criterion scores $\left(\mathrm{x}_{i}\right)$ (Eastman, Jin, Kyem, \& Tolendano, 1995) and expressed as:

$$
S=\sum w_{i} x_{i}
$$




\subsection{Ecotourism sensitivity map}

The two most important elements to consider in sensitivity analysis are criteria weights and criteria scores, and of the two, sensitivity to criteria weights is considered more important (Malczewski, 1999; Chen, Yu \& Khan, 2010). This study therefore examines the sensitivity of criteria weights using OAT method. Each criterions weight obtained from visitors and experts survey was doubled and halved. After altering the weight of a criterion, weights of all the criteria were normalized so that sum of all criteria weights equaled one. Twelve different suitability maps were created from each of the twelve different criteria weights combinations with their summary statistics.

Finally, the standard deviation of the different weights was mapped for each cell and combined map was used to show the areas sensitive to variation in the weights. Cells with highest standard deviation values indicate highly sensitive areas and cells with lowest standard deviation values represent less sensitive areas.

\subsection{Classified ecotourism suitability and sensitivity map}

An ecotourism suitability map was created and reclassified into two classes. Cells with $25 \%$ of highest value from ecotourism suitability map were given value 1 (highly suitable) and the rest were given value 0 (less suitable). Similarly, cells with $25 \%$ of the highest value from standard deviation map were given value 0 (highly sensitive) and others were given value 1 (less sensitive). Both the maps were combined to have four classes: highly suitable/highly sensitive, highly suitable/less sensitive, less suitable/highly sensitive, and less suitable/less sensitive. Areas that were 5000 acres (20.23 square kilometers) or greater were only considered as suitable areas so that visitors can experience diverse flora and fauna in its natural setting. Finally, less suitable 
areas were grouped into one and the resultant map consisted of three classes: highly suitable/highly sensitive, highly suitable/less sensitive and less suitable.

\section{Results}

\subsection{Sample}

A total of 777 visitors and 143 experts participated in this study. Out of them only 470 visitors and 91 experts were found to be consistent in pairwise comparison of criteria $(\mathrm{CR}<0.1)$ and were considered for further analysis. Of the 470 visitors, majority were female $(59.43 \%)$; 40 years and above (82.24\%); had at least a college degree (77.48\%); earned more than $\$ 40,000$ per year $(85.87 \%)$; and were out of state visitors (86.29\%), primarily from Ohio, Virginia, Pennsylvania, and Maryland. Furthermore, just over a third (35.68\%) of the respondents were visiting family, relatives, and friends while $35.52 \%$ for leisure and vacation. The majority of the respondents were repeat visitors $(71.30 \%)$, and a notable proportion of whom $(26.31 \%)$ had visited scenic byways, state parks $(23.3 \%)$, or national parks $(22.43 \%)$. Golf courses $(7.52 \%)$ were the least visited of the West Virginia attractions followed by wildlife management areas $(9.76 \%)$, and museums $(14.71 \%)$. The majority of the respondents $(59.06 \%)$ were also familiar with the term ecotourism.

Of the 91 experts, the majority were male $(59.62 \%)$; 40 years and above $(73.31 \%)$; had PhD degree (77.79\%); were associated with the academic field (90.83\%); and had more than 10 years of experience in ecotourism research (55.34\%). In addition, $46.27 \%$ of them were professors, followed by associate professors (15.93\%) and researcher (15.93\%), and consultants (6.14\%). Finally, 39.33\% were from North America, followed by Europe (26.23\%) and Austrailia (11.91\%), and Asia (11.91\%). 


\subsection{Pairwise comparision}

The visitors' survey and experts' survey on the relative preferences for the six criteria showed similar preference rankings. For both the survey groups, the presence of vegetation was the most important criterion, followed by remoteness, presence of wildlife, distance from mining, and distance from logging (Figure 1). Slope was found to be the least important criterion for both the groups.

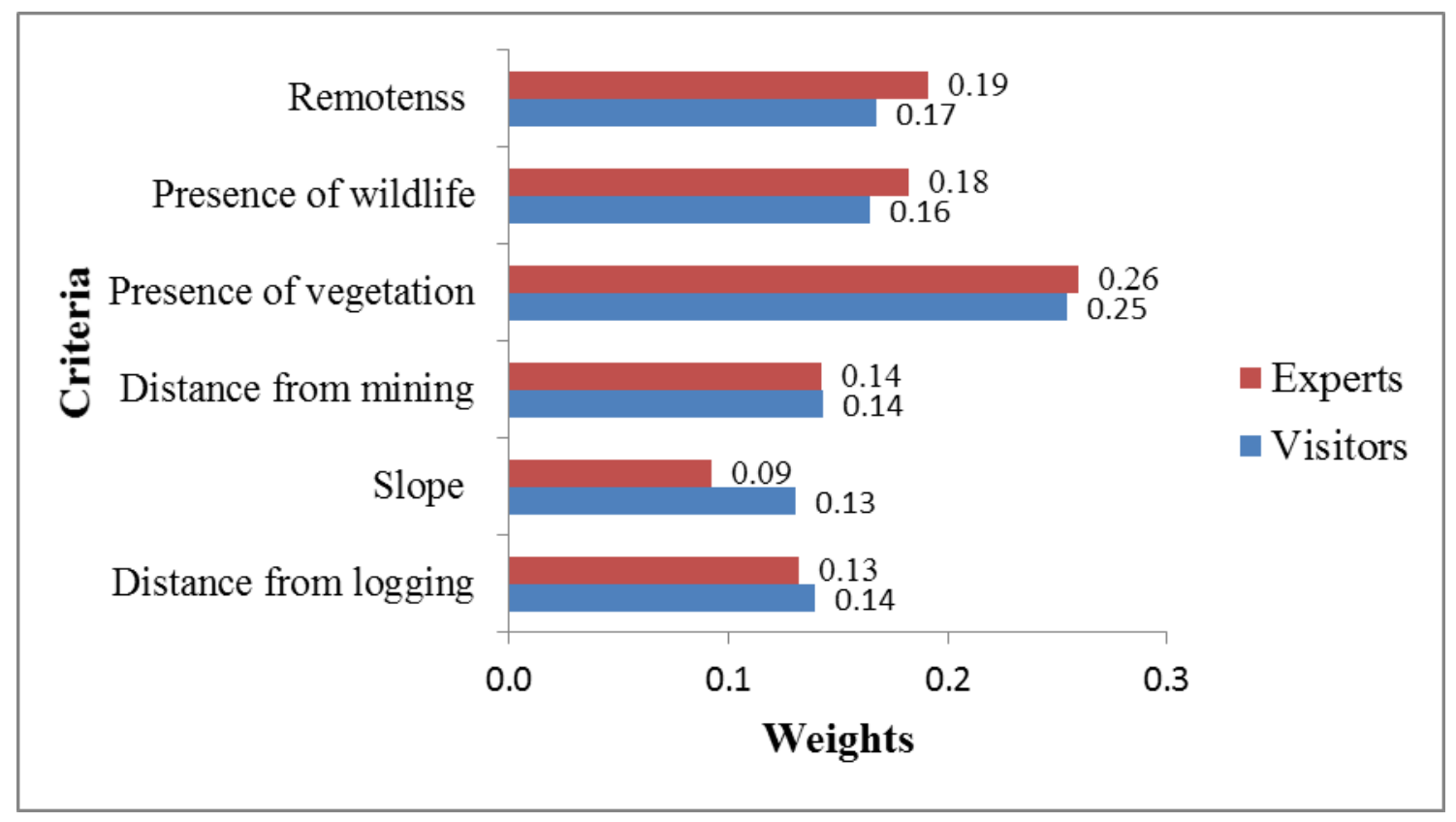

Figure 1. Criteria importance weights from the visitors' and experts' preferences

\subsection{Test of statistical differences}

T-test statistics on the difference in criteria weights calculated for the visitors' survey group and the experts' survey group were not significantly different except for the slope criterion (Table 2). Since the variations in criteria weights were too small between the groups for most of the criteria, the mean values of criteria weights of the two groups were used to represent their preferences for further analysis. The mean values of criteria weights for presence of vegetation, 
remoteness, presence of wildlife, distance from mining, distance from logging, and slope were $0.26,0.18,0.17,0.14,0.14$, and 0.11 , respectively.

Table 2. T-test statistics for the difference in criteria weights calculated for the visitors' survey and the experts' survey

\begin{tabular}{lllllc}
\hline \multirow{2}{*}{$\begin{array}{l}l \\
\text { Criteria }\end{array}$} & \multicolumn{2}{l}{ Eisitors $(N=470)$} & \multicolumn{2}{l}{ Experts $(N=91)$} & T-test \\
\cline { 2 - 6 } Distance from logging & $M$ & $S D$ & $M$ & 0.11 & 0.73 \\
\cline { 2 - 5 } Slope & 0.14 & 0.09 & 0.13 & 0.09 & $3.79 * *$ \\
Distance from mining area & 0.13 & 0.09 & 0.09 & 0.12 & 0.03 \\
Presence of wildlife & 0.14 & 0.11 & 0.14 & 0.11 & -1.64 \\
Presence of vegetation & 0.16 & 0.09 & 0.18 & 0.14 & -0.37 \\
Remoteness & 0.25 & 0.12 & 0.26 & 0.13 & -1.56 \\
\hline
\end{tabular}

Notes; $M=$ Mean and $S D=$ Standard Deviation $* * p<0.01$

\subsection{Ecotourism suitability map}

The mean values of criteria weights were used to create weighted criteria maps which were then aggregated to produce a weighted ecotourism map (Figure 2). The resultant map, considered as the base map for sensitivity analysis, shows spatial pattern and distribution of highly and less suitable areas for ecotourism. The most suitable locations were shown in green, and the unsuitable areas in red. 


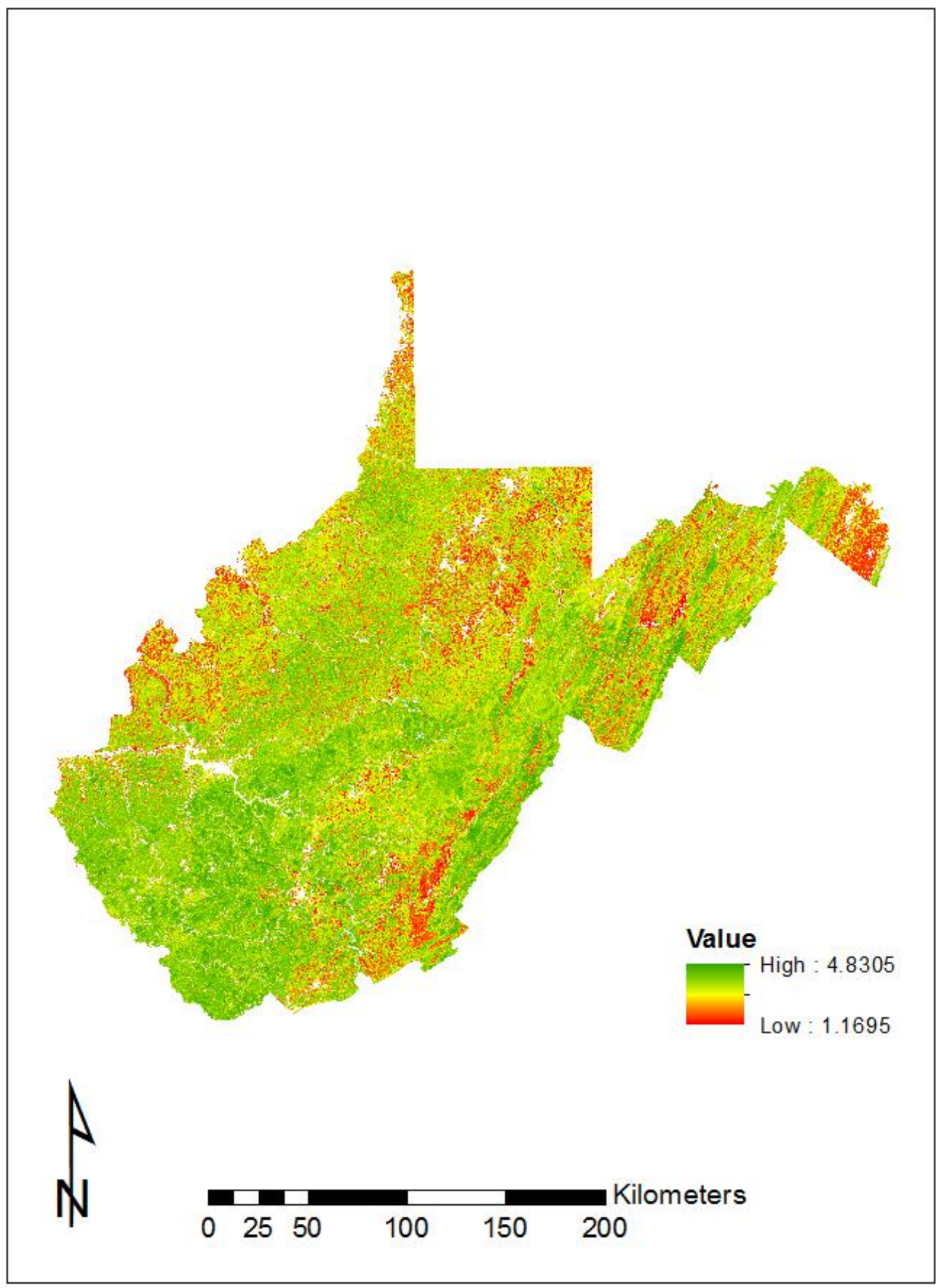

Figure 2. Weighted ecotourism map (base map) 


\subsection{Ecotourism sensitivity map}

In order to test for the stability of the suitability map, each of the criterion weights used to create the suitability map (referred to as the base map) was first doubled and then halved (Table $3)$.

Table 3. Criteria with different weights with base weight and altered value of criterion in each row represented in bold

\section{Criteria}

\begin{tabular}{|c|c|c|c|c|c|c|}
\hline Description & $\begin{array}{l}\text { Distance } \\
\text { from logging }\end{array}$ & Slope & $\begin{array}{l}\text { Distance } \\
\text { from mining }\end{array}$ & $\begin{array}{l}\text { Presence of } \\
\text { wildlife }\end{array}$ & $\begin{array}{l}\text { Presence of } \\
\text { vegetation }\end{array}$ & Remoteness \\
\hline $\begin{array}{l}2 \text { times } \\
\text { remoteness }\end{array}$ & 0.14 & 0.11 & 0.14 & 0.17 & 0.26 & 0.36 \\
\hline $\begin{array}{l}\text { Normalized } \\
\text { remoteness }\end{array}$ & 0.12 & 0.09 & 0.12 & 0.15 & 0.22 & 0.30 \\
\hline $\begin{array}{l}2 \text { times } \\
\text { vegetation }\end{array}$ & 0.14 & 0.11 & 0.14 & 0.17 & 0.52 & 0.18 \\
\hline $\begin{array}{l}\text { Normalized } \\
\text { vegetation }\end{array}$ & 0.11 & 0.09 & 0.11 & 0.14 & 0.41 & 0.14 \\
\hline $\begin{array}{l}2 \text { times } \\
\text { wildlife }\end{array}$ & 0.14 & 0.11 & 0.14 & 0.34 & 0.26 & 0.18 \\
\hline $\begin{array}{l}\text { Normalized } \\
\text { wildlife }\end{array}$ & 0.12 & 0.10 & 0.12 & 0.30 & 0.21 & 0.15 \\
\hline 2 times mining & 0.14 & 0.11 & 0.28 & 0.17 & 0.26 & 0.18 \\
\hline $\begin{array}{l}\text { Normalized } \\
\text { mining }\end{array}$ & 0.12 & 0.10 & 0.25 & 0.15 & 0.22 & 0.16 \\
\hline 2 times slope & 0.14 & 0.22 & 0.14 & 0.17 & 0.26 & 0.18 \\
\hline $\begin{array}{l}\text { Normalized } \\
\text { slope }\end{array}$ & 0.12 & 0.20 & 0.13 & 0.16 & 0.23 & 0.16 \\
\hline $\begin{array}{l}2 \text { times } \\
\text { Logging }\end{array}$ & 0.28 & 0.11 & 0.14 & 0.17 & 0.26 & 0.18 \\
\hline $\begin{array}{l}\text { Normalized } \\
\text { logging }\end{array}$ & 0.24 & 0.10 & 0.12 & 0.15 & 0.23 & 0.16 \\
\hline Base weight & 0.14 & 0.11 & 0.14 & 0.17 & 0.26 & 0.18 \\
\hline $\begin{array}{l}\text { Normalized } \\
\text { logging }\end{array}$ & 0.07 & 0.12 & 0.15 & 0.19 & 0.28 & 0.19 \\
\hline $\begin{array}{l}1 / 2 \text { times } \\
\text { logging }\end{array}$ & 0.07 & 0.11 & 0.14 & 0.17 & 0.26 & 0.18 \\
\hline
\end{tabular}




\begin{tabular}{|c|c|c|c|c|c|c|}
\hline \multicolumn{7}{|c|}{ Table 3 (continued) } \\
\hline \multirow[b]{2}{*}{ Description } & \multicolumn{5}{|c|}{ Criteria weight } & \multirow[b]{2}{*}{ Remoteness } \\
\hline & $\begin{array}{l}\text { Distance } \\
\text { from logging }\end{array}$ & Slope & $\begin{array}{l}\text { Distance } \\
\text { from mining }\end{array}$ & $\begin{array}{l}\text { Presence of } \\
\text { wildlife }\end{array}$ & $\begin{array}{l}\text { Presence of } \\
\text { vegetation }\end{array}$ & \\
\hline $\begin{array}{l}\text { Normalized } \\
\text { slope }\end{array}$ & 0.14 & 0.06 & 0.15 & 0.19 & 0.28 & 0.18 \\
\hline $1 / 2$ times slope & 0.14 & 0.06 & 0.14 & 0.17 & 0.26 & 0.18 \\
\hline $\begin{array}{l}\text { Normalized } \\
\text { mining }\end{array}$ & 0.15 & 0.12 & 0.07 & 0.19 & 0.28 & 0.19 \\
\hline $\begin{array}{l}1 / 2 \text { times } \\
\text { mining }\end{array}$ & 0.14 & 0.11 & 0.07 & 0.17 & 0.26 & 0.18 \\
\hline $\begin{array}{l}\text { Normalized } \\
\text { wildlife }\end{array}$ & 0.15 & 0.12 & 0.16 & 0.09 & 0.28 & 0.20 \\
\hline $\begin{array}{l}1 / 2 \text { times } \\
\text { wildlife }\end{array}$ & 0.14 & 0.11 & 0.14 & 0.09 & 0.26 & 0.18 \\
\hline $\begin{array}{l}\text { Normalized } \\
\text { vegetation }\end{array}$ & 0.16 & 0.13 & 0.16 & 0.19 & 0.15 & 0.21 \\
\hline $\begin{array}{l}1 / 2 \text { times } \\
\text { vegetation }\end{array}$ & 0.14 & 0.11 & 0.14 & 0.17 & 0.13 & 0.18 \\
\hline $\begin{array}{l}\text { Normalized } \\
\text { remoteness }\end{array}$ & 0.15 & 0.12 & 0.16 & 0.19 & 0.28 & 0.10 \\
\hline $\begin{array}{l}1 / 2 \text { times } \\
\text { remoteness }\end{array}$ & 0.14 & 0.11 & 0.14 & 0.17 & 0.26 & 0.09 \\
\hline
\end{tabular}

Normalized weights shown in Table 3 were used to create 12 different suitability maps.

Highly suitable sites were represented in green color and less suitable sites in red (Figures 3 and 4). 


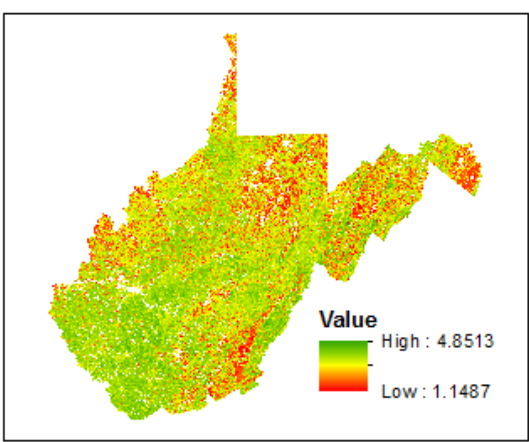

(a)

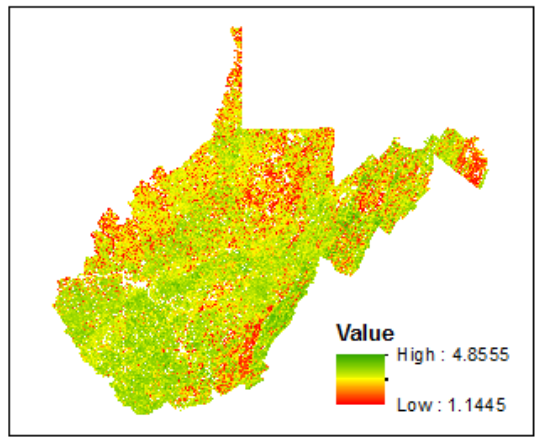

(d)

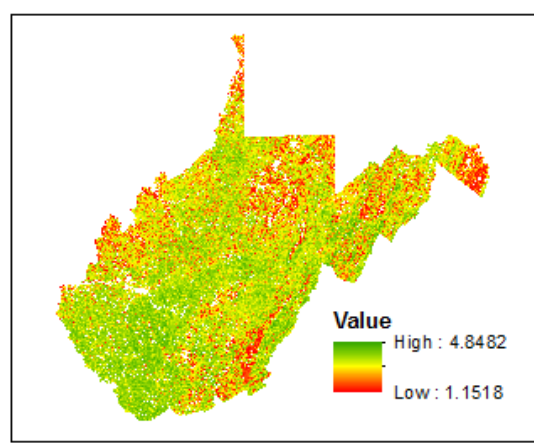

(b)

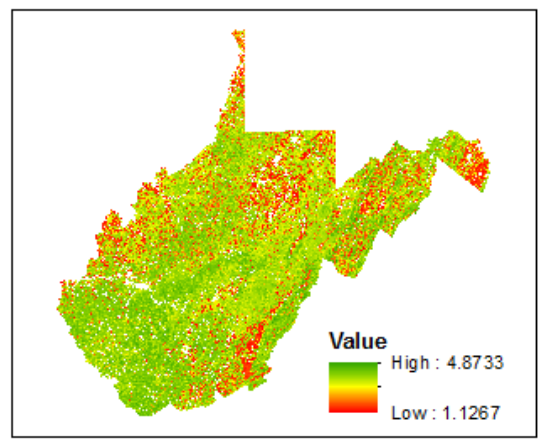

(e)

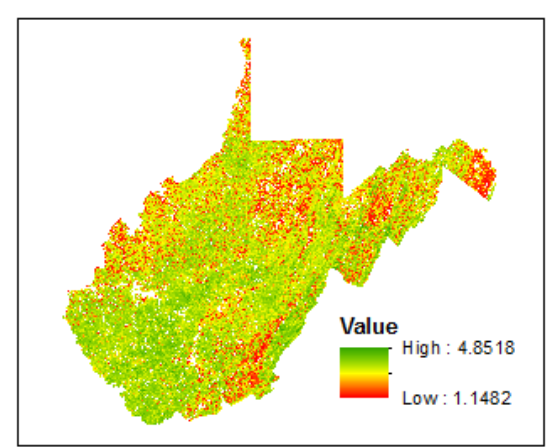

(c)

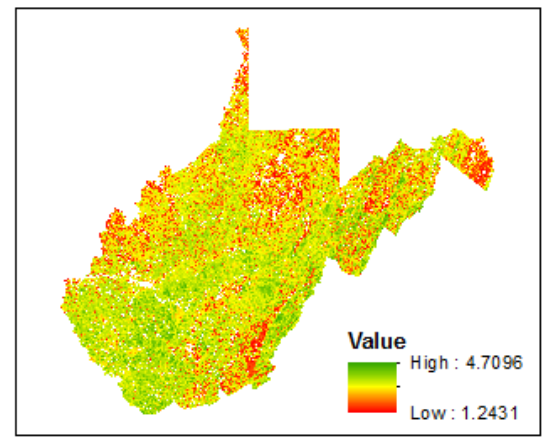

(f)

$N$

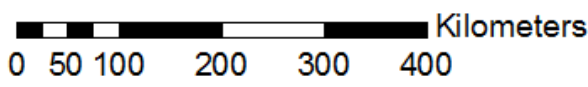

Figure. 3. Ecotourism suitability maps created each with double the criteria weights of the base map (a) distance from logging (b) Slope (c) distance from mining (d) presence of wildlife (e) presence of vegetation (f) remoteness 


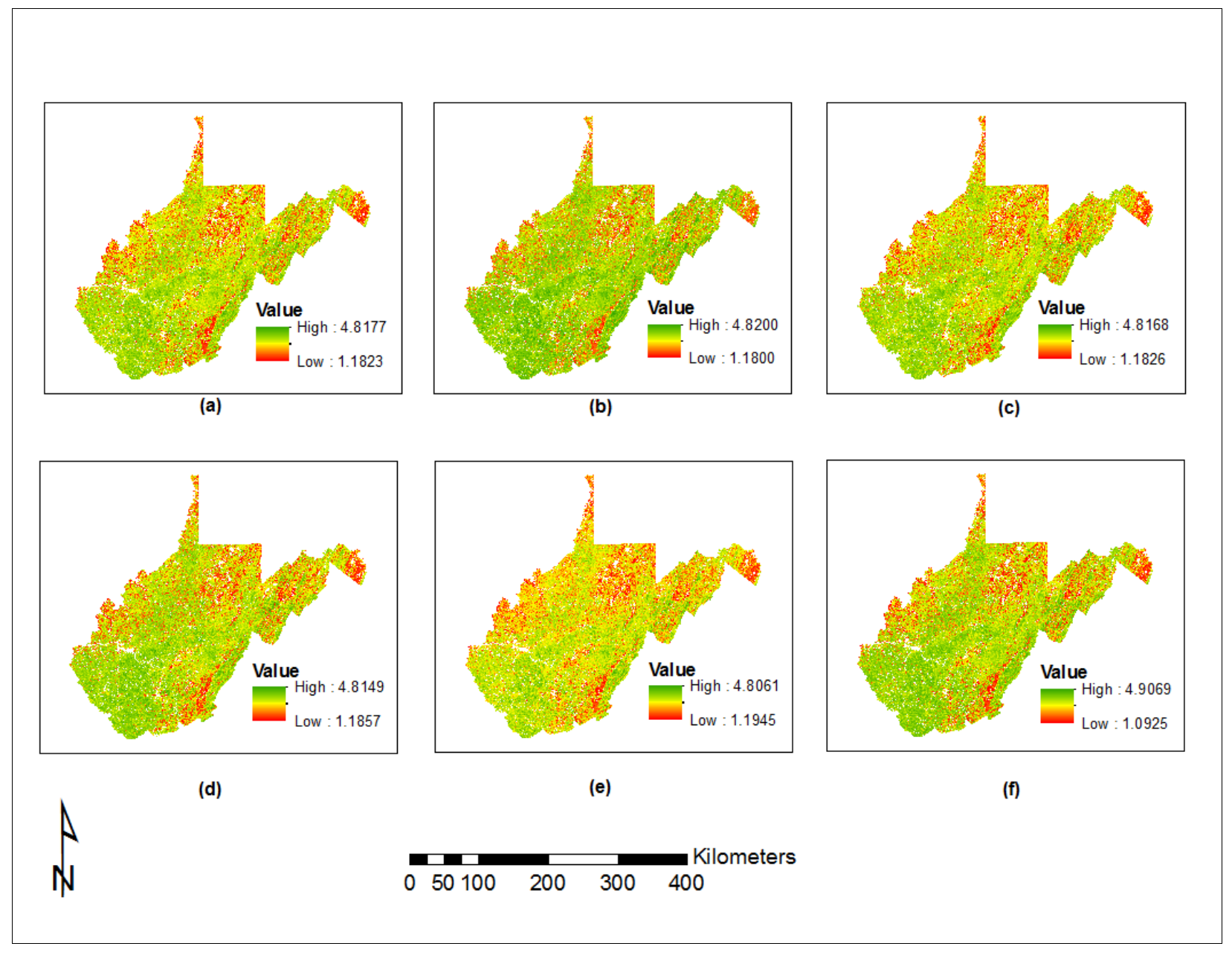

Figure 4. Ecotourism suitability maps created each with half the criteria weights of base map (a) distance from logging (b) slope (c) distance from mining (d) presence of wildlife (e) presence of vegetation (f) remoteness

Table 4 shows the summary statistics of all ecotourism suitability maps. It was found that remoteness criterion was the most sensitive, followed by distance from mining and distance from logging while vegetation was the least sensitive criteria followed by wildlife and slope. 
Table 4. Summary statistics of ecotourism suitability maps

\begin{tabular}{|c|c|c|c|c|c|c|}
\hline & Max & Min & Mean & $\begin{array}{l}\text { Standard } \\
\text { deviation }\end{array}$ & Range & $\begin{array}{l}\text { Change } \\
\text { in Mean }\end{array}$ \\
\hline 2 times remoteness & 4.71 & 1.24 & 3.52 & 0.48 & 3.47 & 0.22 \\
\hline 2 times vegetation & 4.87 & 1.13 & 3.76 & 0.67 & 3.75 & -0.02 \\
\hline 2 times wildlife & 4.86 & 1.14 & 3.71 & 0.51 & 3.71 & 0.03 \\
\hline 2 times mining & 4.85 & 1.15 & 3.90 & 0.46 & 3.70 & -0.16 \\
\hline 2 times slope & 4.85 & 1.15 & 3.69 & 0.56 & 3.70 & 0.05 \\
\hline 2 times logging & 4.85 & 1.15 & 3.86 & 0.49 & 3.70 & -0.12 \\
\hline Base & 4.83 & 1.17 & 3.74 & 0.53 & 3.66 & 0 \\
\hline $1 / 2$ times logging & 4.82 & 1.18 & 3.67 & 0.56 & 3.64 & 0.07 \\
\hline $1 / 2$ times slope & 4.82 & 1.18 & 3.77 & 0.52 & 3.64 & -0.03 \\
\hline $1 / 2$ times mining & 4.82 & 1.18 & 3.65 & 0.57 & 3.63 & 0.09 \\
\hline $1 / 2$ times wildlife & 4.81 & 1.19 & 3.77 & 0.55 & 3.63 & -0.03 \\
\hline $1 / 2$ times vegetation & 4.81 & 1.19 & 3.72 & 0.43 & 3.61 & 0.02 \\
\hline $1 / 2$ times remoteness & 4.91 & 1.09 & 3.88 & 0.56 & 3.81 & -0.14 \\
\hline
\end{tabular}

Figure 5 shows the standard deviation map created from all the ecotourism suitability maps. The resultant standard deviation map shows spatial pattern and distribution of highly sensitive (high values) and less sensitive areas (low values) for ecotourism. The less sensitive locations were shown in green color, and the highly sensitive were in red. 


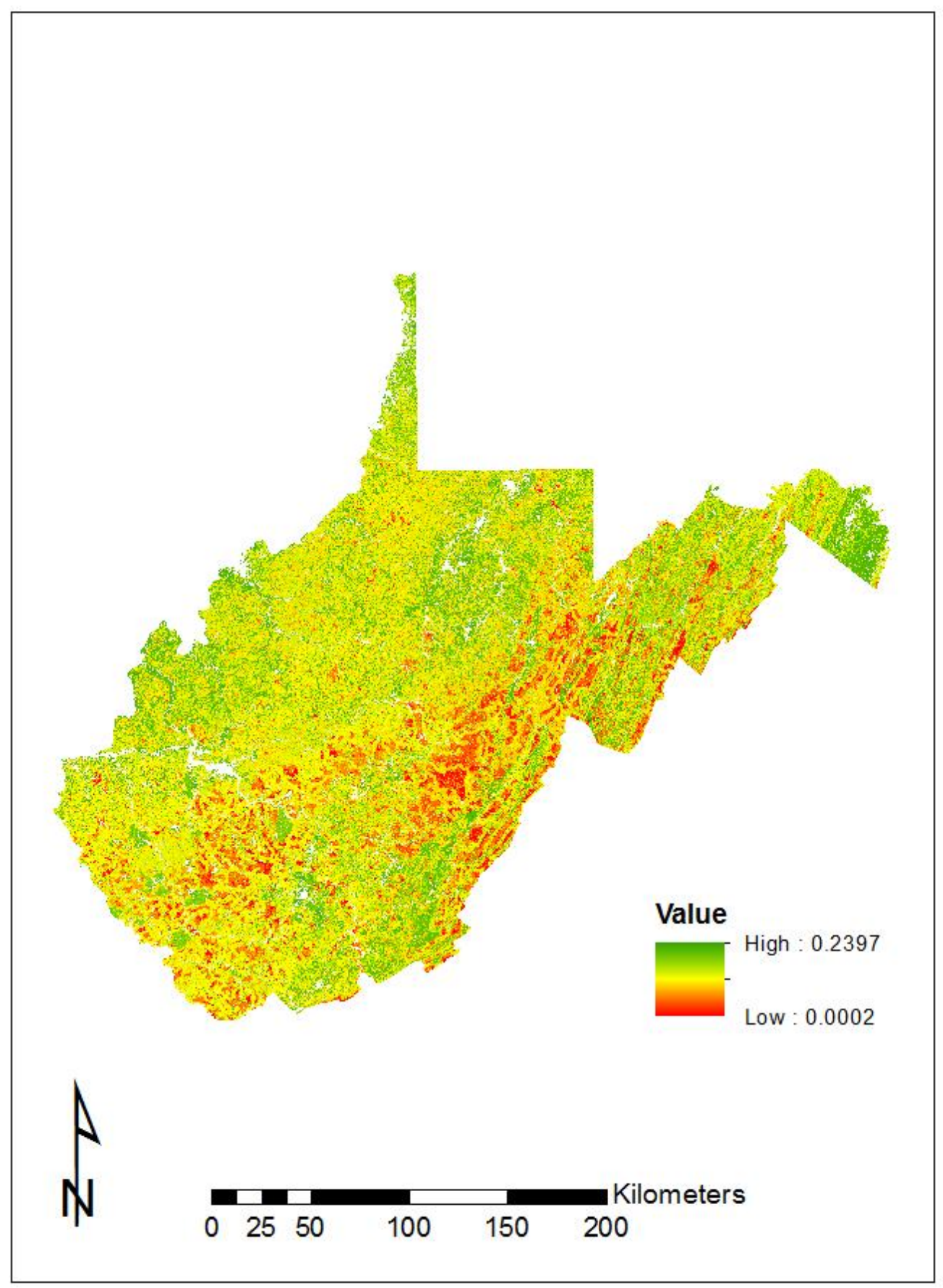

Figure 5. Standard deviation map based on the base map, maps with criteria weights doubled, and maps with criteria weights halved 


\subsection{Classified ecotourism suitability and sensitivity map}

It was found that $52.45 \%$ of the areas in the state were highly suitable and $24.17 \%$ of areas were highly sensitive to the change in criteria weights (Figure 6).

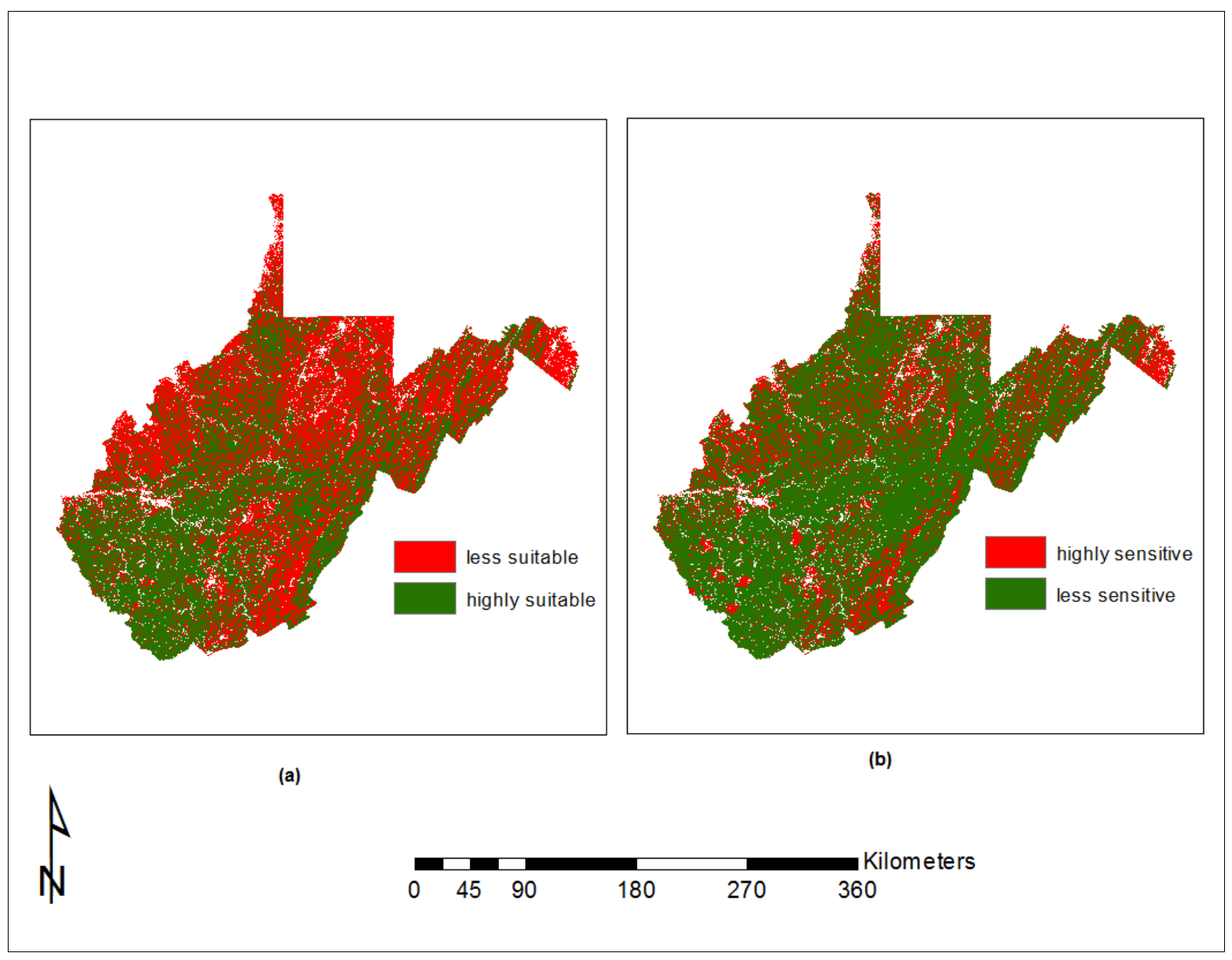

Figure 6. (a) Ecotourism suitability map with $25 \%$ of the high scored areas as highly suitable and and (b) ecotourism sensitivity map with $25 \%$ of the highest scores classified as highly sensitive

A combined map for ecotourism suitability and sensitivity (Figure 7) showed that 50.57\% of land was highly suitable/ less sensitive, $1.58 \%$ was highly suitable/ highly sensitive, $22.58 \%$ was less suitable/ less sensitive, and $25.27 \%$ was less suitable /highly sensitive. 


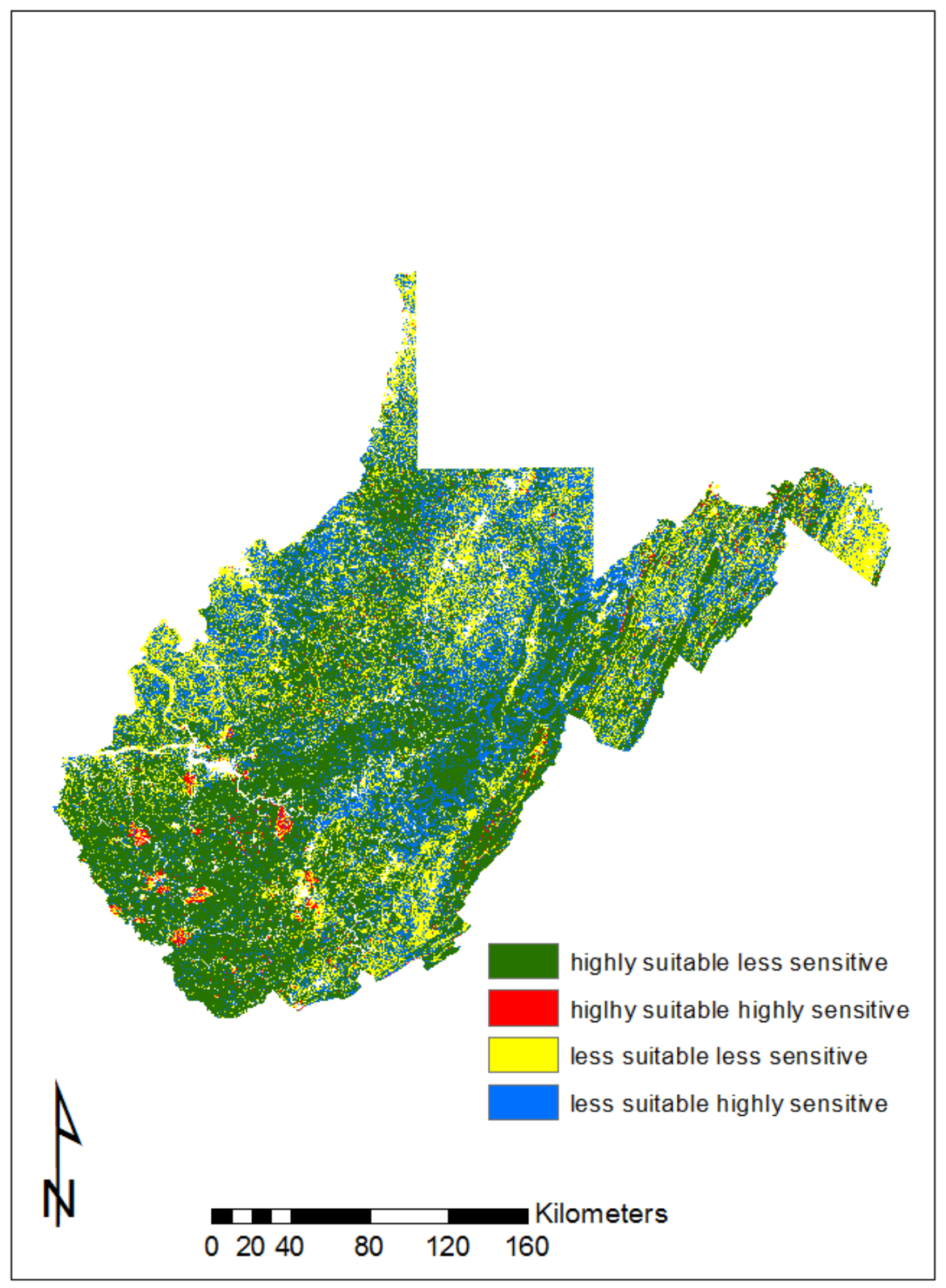

Figure 7. Combined ecotourism suitability and sensitivity map

The areas that were classified as highly suitable but did not meet the minimum 5000 acres area threshold were adjusted. The resultant map displayed that $32.98 \%$ of land was highly suitable/less sensitive, $0.05 \%$ was highly suitable/highly sensitive, and $66.97 \%$ was less suitable for forest-based ecotourism development in the state (Figure 8). 


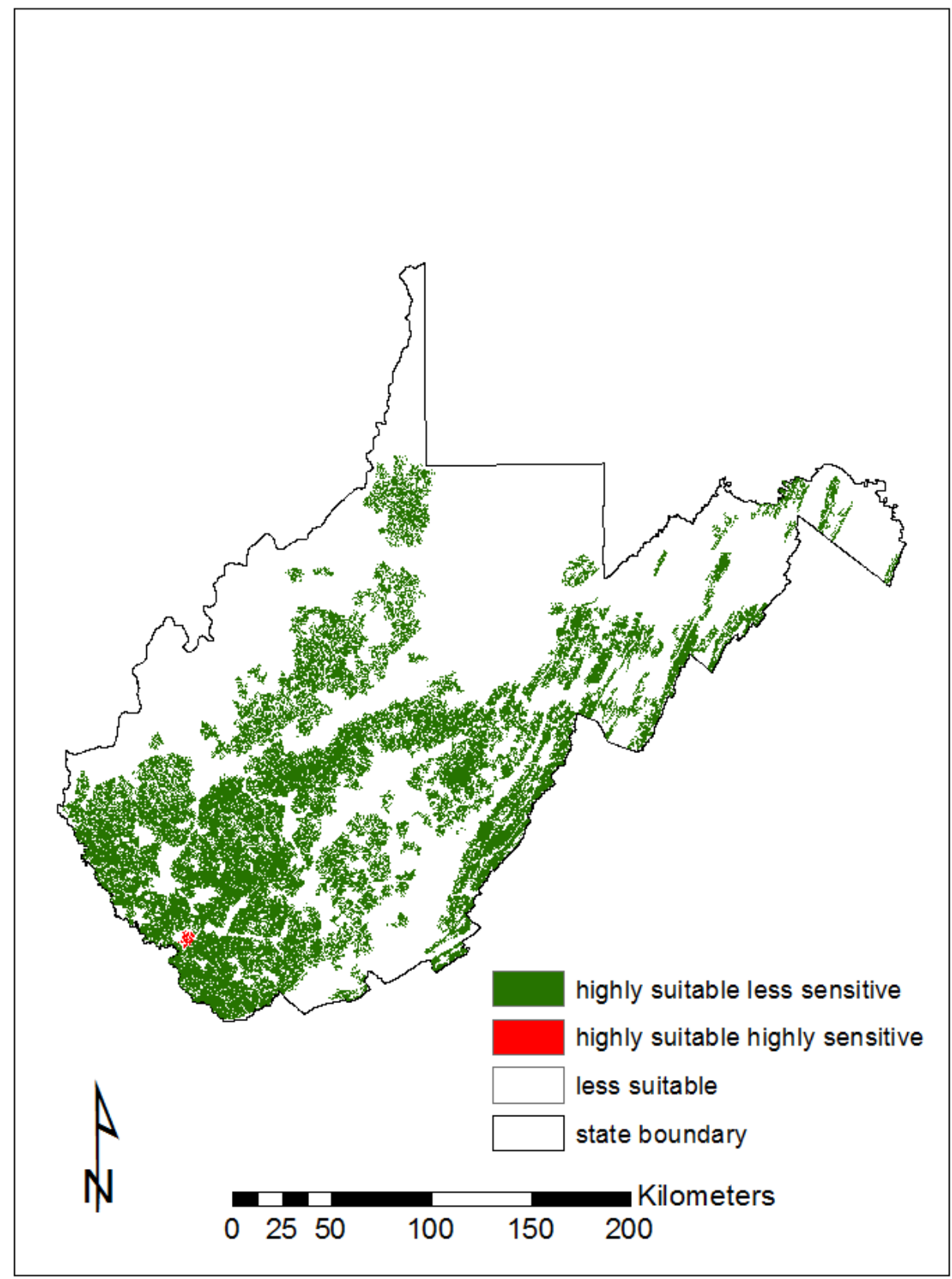

Figure 8. Suitability map with three different classes 


\section{Discussion}

This study presented a new approach for investigating suitable areas for forest-based ecotourism in West Virginia by conducting a sensitivity analysis of criteria weights. The study incorporated visitors' and experts' preferences for each of the six criteria and created ecotourism suitability map using AHP and GIS. Relative preferences for the two survey groups, visitors and experts, were found to be similar. Both the groups considered areas with vegetation to be the most important criterion, followed by remoteness, and presence of wildlife. This indicated their preference towards pristine areas with vegetation and wildlife. Slope was found to be least preferred criteria by both the groups followed by distance from logging and distance from mining. Multi-criteria weights sensitivity was carried out by changing the weights of the criteria using OAT method. Twelve different combinations of criteria weights were mapped. Sensitivity analyses showed that presence of remoteness was the most sensitive criterion followed by distance from mining and distance from logging. This indicated that variations in weights of remoteness, distance from mining and distance from logging would have the most impact in identifying forest-based ecotourism areas in the state and should be given more importance compared to other criteria. About one third of the state was classified as highly suitable and less sensitive. Only $0.05 \%$ of the highly suitable areas were found to be highly sensitive.

The resultant highly suitable and less sensitive areas for ecotourism in the state were also compared with a map of public areas in the state (Figure 9). It was found that most of the designated land classified as wildlife management areas (Anawalt Lake, Becky Creek, Beech Fork Lake, Berwind Lake, Burnsville Lake, East Lunn Lake, Elk River, Horse Creek Lake, Laurel Lake, Lewis Wetzel, Nathaniel Mountain, Plum Orchard Lake, Sleepy Creek, and Wallback), national forests (Monongahela and, George Washington and Jefferson), national park 
units (New River Gorge National River), wilderness areas (Cranberry and Dolly Sods), state forests (Cabwaylingo, Calvin Price, Camp Creek, Greenbrier, Kanawha, Kumbrabow, and Panther) and state parks (Cacapon, Pipestem, and Twin Falls) lie within the highly suitable and less sensitive category. This indicates that these areas would always be suitable for forest-based ecotourism regardless of the preferences. The suitability and sensitivity combined map indicated the existing stable and highly suitable ecotourism areas and also depicts potential areas for the further development of forest-based ecotourism in the state. 


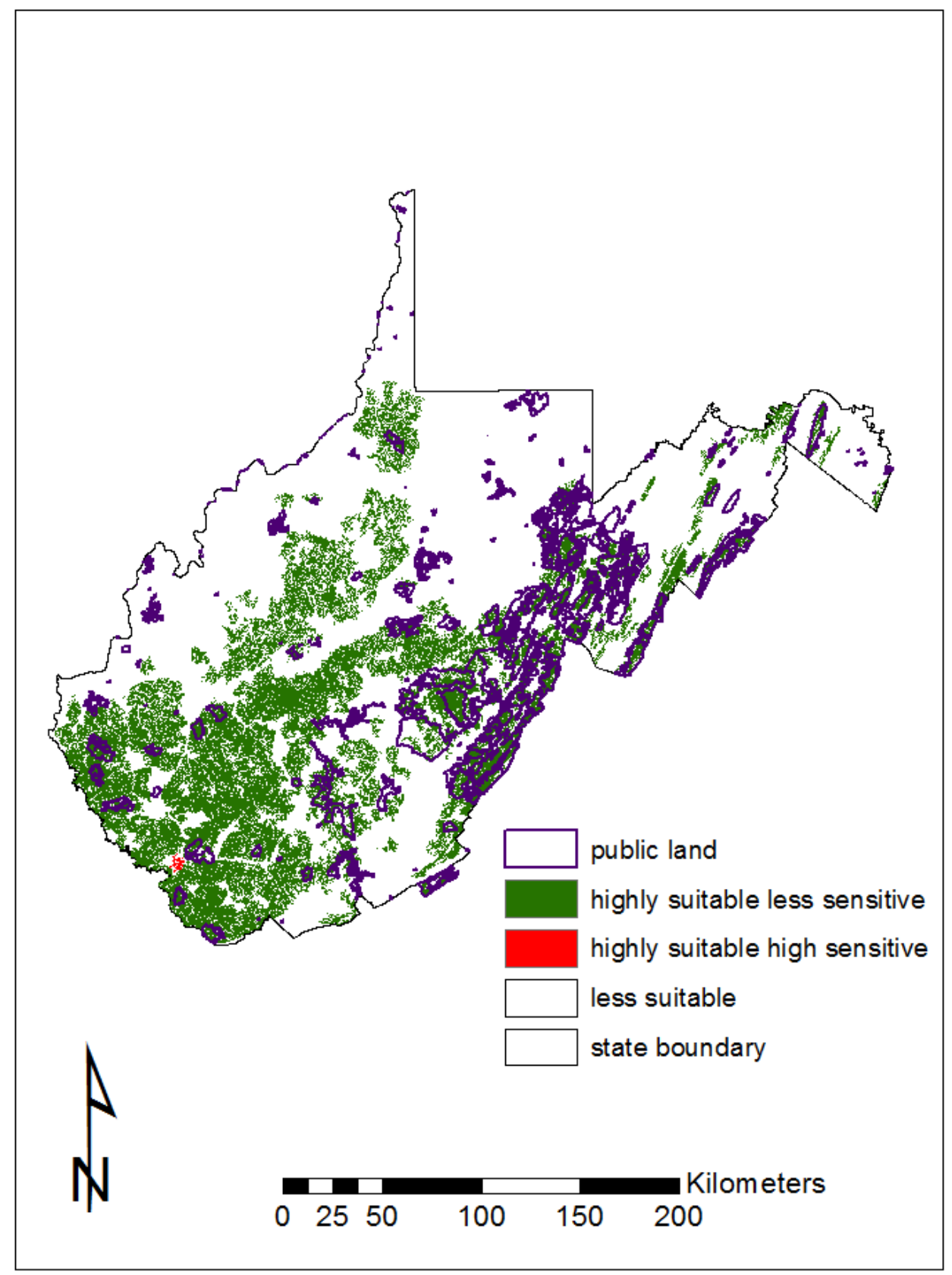




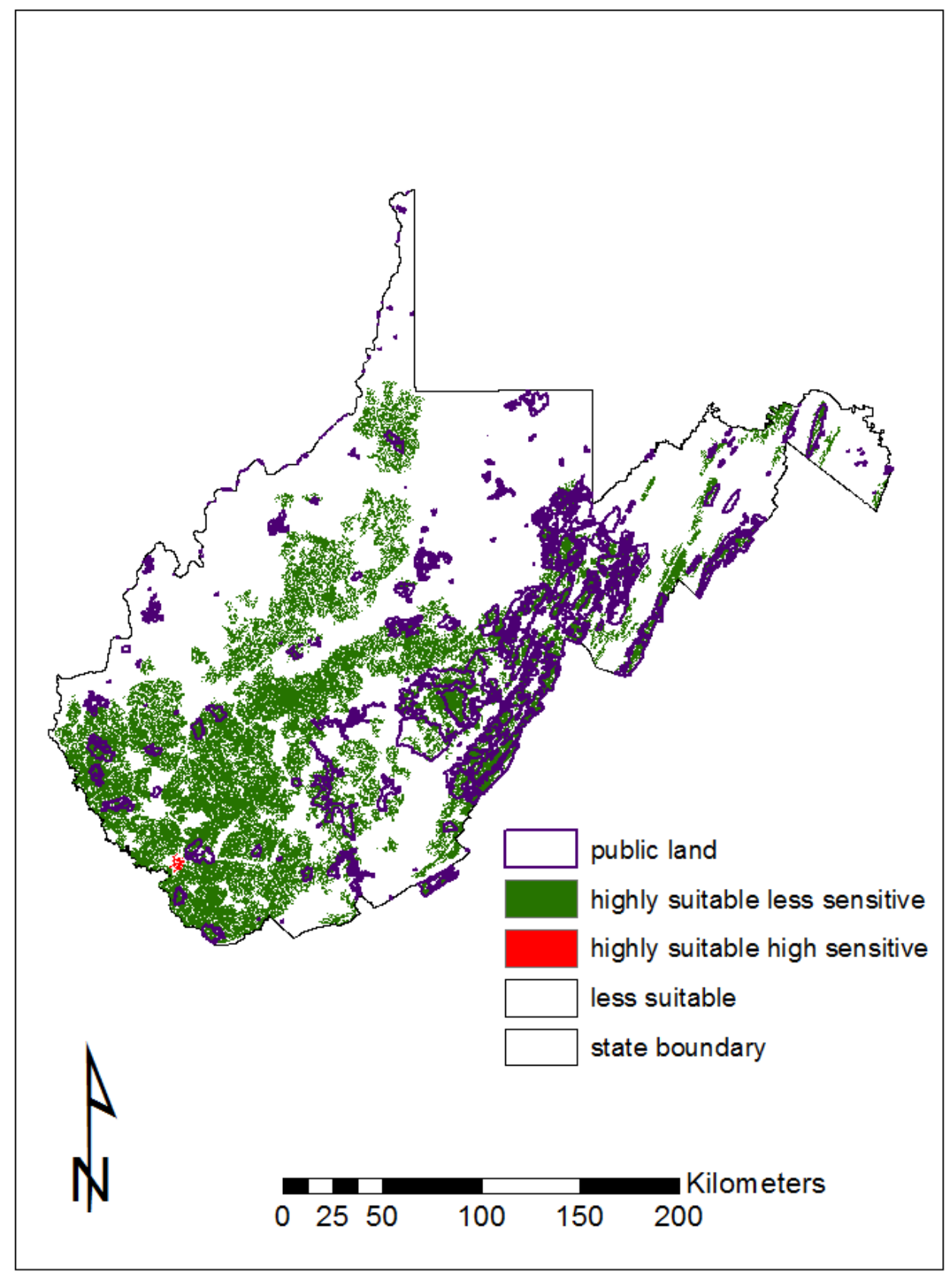

Figure 9. Suitability map with public land

The combined, OAT, AHP, and GIS approach was found promising in identifying and mapping suitable and sensitive areas for forest-based ecotourism destinations in West Virginia. There were, however, certain limitations that might have influenced the findings of the study. First, the study used multiple-date images, which may have affected the results. Second, the 
study used $30 \mathrm{~m}$ resolution. This coarse resolution of dataset can affect the precision of the area calculation for each class in the ecotourism map. Third, this study used internet survey of experts and one of the disadvantages of internet survey is that respondents are unable to get clarification on questions, language, and instructions during the survey process. Although the survey was pretested for simplicity and clarity, the complexities of the pairwise comparison of criteria might have been confusing to some respondents. Finally, the threshold value used for suitability and sensitivity maps can affect the final ecotourism suitability maps. The highest $25 \%$ of the values for both suitability and sensitivity maps were used to differentiate highly suitable areas from less suitable areas, and highly sensitive areas from less sensitive areas in this study. However, different threshold values can be easily assigned to define different classes. In this study, only the areas that spanned at least 5000 acres or 20.23 square kilometers were classified under highly suitable/less sensitive areas. Additional constraints could also be introduced during classification if required. The study does not attempt to recommend an ideal threshold or constraints to define class, but rather, highlights the effects they can bring to the final classification.

\section{Conclusion}

This study presented a sensitivity analysis methodology for analyzing criteria weights in MCDM using GIS and AHP. It shows the importance of examining criteria weight sensitivity in order to make robust decisions when performing a suitability analysis. About one third of the areas were found to be highly suitable and less sensitive for forest-based ecotourism in West Virginia. The resultant suitable ecotourism map which incorporated visitors' and experts' relative preferences and sensitivity analysis for each of the six criteria depicted more practicality compared to ecotourism suitability studies conducted in the past. Mapping of robust areas suitable for forest-based ecotourism according to visitors' and experts' preferences is possible 
because of tools like GIS, AHP, and OAT methods of sensitivity analysis. The methodology demonstrated in this study is simple and flexible as new criteria and their corresponding weights can be added and threshold values can be modified during the classification to fit the context of the study area.

The study highlights the importance of sensitivity analysis of criteria weights while mapping the sites for ecotourism destinations. The study results suggest that incorporating preferences and examining sensitivity of criteria weights in determining ecotourism destinations could provide helpful information in terms of destination development, marketing, and promotion. This study provided information on current and potential ecotourism destinations in the state; and therefore can help concerned agencies when making decisions regarding establishment, management, and/or promotion of ecotourism destinations. Classifying resultant suitable areas into different classes of suitability spectrum would help ecotourists (soft and hard) identify their preferred areas along the spectrum. 


\section{References}

Allaire, D.L., \& Willcox, K.E. (2012). A variance-based sensitivity index function for factor prioritization. Reliability Engineering and System Safety, 107, 107-114.

Al-Mashreki, M. H., Akhir, J. B. M., Rahim, S. A., Lihan, K. M. D. T., \& Haider, A. R. (2011). GIS-based sensitivity analysis of multi-criteria weights for land suitability evaluation of sorghum crop in the Ibb Governorate Republic of Yemen.Journal of basic and applied scientific research, $1(9), 1102-1111$.

Bukenya, J. O. (2012). Application of GIS in ecotourism development decisions: Evidence from the Pearl of Africa. Research paper, 30.

Bunruamkaew, K., \& Murayam, Y. (2011). Site suitability evaluation for ecotourism using GIS \& AHP: A case study of Surat Thani province, Thailand.Procedia-Social and Behavioral Sciences, 21, 269-278..

Bustillos-Herrera, J. A., Valdez-Lazalde, J. R., \& Aldrete, A. (2007). Land suitability for eucalyptus (Eucalyptus grandis Hill ex Maiden) plantations: Definition through the analytic hierarchy process and GIS. Agrociencia, 41(7), 787-796.

Chen, H., Wood, M.D., Linstead, C., \& Maltby, E. (2011). Uncertainity analysis in a GIS-based multi-criteria analysis tool for river catchment management. Environmental Modelling and Software, 26, 395-405.

Chen, Y., Yu, J., \& Khan, S. (2010). Spatial sensitivity analysis of multi-criteria weights in GISbased land suitability evaluation. Environmental modelling \& software, 25(12), 1582-1591.

Crosetto, M., \& Tarantola, S. (2001). Uncertainty and sensitivity analysis: tools for GIS-based model implementation. International Journal of Geographical Information Science, 15(5), 415-437.

Deng, J., King, B., \& Bauer, T. (2002). Evaluating natural attractions for tourism. Annals of Tourism Research, 29(2), 422-438.

Dyer, R. F., \& Forman, E. H. (1992). Group decision support with the analytic hierarchy process. Decision Support Systems, 8(2), 99-124.

Dhami, I, Deng, J., Burns, R.C., Pierskalla, C. (2013). Identifying and mapping forest-based ecotourism areas in West Virginia incorporating visitors' preferences. Tourism Management. DOI: $10.1016 / j$.tourman.2013.11.007.

Eastman, J.R., Jin, W., Kyem, W., \&Tolendano, P. (1995). Raster procedures for multicriteria/multi-objective decisions. Photogrammetric Engineering \& Remote Sensing, 61(5), 539-547.

Fischer, F. (2000). Citizens, experts, and the environment: the politics of local knowledge. Duke University Press.

Fraedrich, D., \& Goldberg, A. (2000). A methodological framework for the validation of predictive simulations. European Journal of Operational Research,124(1), 55-62.

Fung, T., \& Wong, F.K.K. (2007). Ecotourism planning using multi criteria evaluation with GIS. Geocarto International, 22(2), 87-105.

Gorsevski, P. V., Donevska, K. R., Mitrovski, C. D., \& Frizado, J. P. (2012). Integrating multicriteria evaluation techniques with geographic information systems for landfill site selection: a case study using ordered weighted average. Waste management, 32(2), 287-296. 
Huang, Y., \& Bian, L. (2009). A Bayesian network and analytic hierarchy process based personalized recommendations for tourist attractions over the Internet. Expert Systems with Applications, 36(1), 933-943.

Hyde, K. M., \& Maier, H. R. (2006). Distance-based and stochastic uncertainty analysis for multi-criteria decision analysis in Excel using Visual Basic for Applications. Environmental Modelling \& Software, 21(12), 1695-1710.

Kamp, U., Growley, B. J., Khattak, G. A., \& Owen, L. A. (2008). GIS-based landslide susceptibility mapping for the 2005 Kashmir earthquake region.Geomorphology, 101(4), 631-642.

Kumari, S., Behera, M.D., \& Tewari, H.R. (2010). Identification of potential ecotourism sites in West District, Sikkim using geospatial tools. Tropical Ecology, 51(1), 75-85.

Lee, C., Huang, H.I., \& Yeh, H.R. (2010). Developing an evaluation model for destination attractiveness: sustainable forest recreation tourism in Taiwan. Journal of Sustainable Tourism, 18(6), 811-828.

Malczewski, J. (1999). GIS and multicriteria decision analysis. John Wiley \& Sons.

Malczewski, J. (2006). GIS-based multicriteria decision analysis: a survey of the literature. International Journal of Geographical Information Science, 20(7), 703-726.

Mara, T., \& Tarantola, S. (2012). Variance-based sensitivity indices for models with dependent inputs. Reliability Engineering \& System Safety, 107, 115-121.

Manache, G., \& Melching, C. S. (2008). Identification of reliable regression-and correlationbased sensitivity measures for importance ranking of water-quality model parameters. Environmental Modelling \& Software, 23(5), 549-562.

Merritt, W. S., Croke, B. F., \& Jakeman, A. J. (2005). Sensitivity testing of a model for exploring water resources utilisation and management options.Environmental Modelling \& Software, 20(8), 1013-1030.

Oakley, J. E., \& O'Hagan, A. (2004). Probabilistic sensitivity analysis of complex models: a Bayesian approach. Journal of the Royal Statistical Society: Series B (Statistical Methodology), 66(3), 751-769.

Pisoni, E., Carnevale, C., \& Volta, M. (2010). Sensitivity to spatial resolution of modeling systems designing air quality control policies. Environmental Modelling \& Software, 25(1), 66-73.

Ravalico, J. K., Dandy, G. C., \& Maier, H. R. (2010). Management Option Rank Equivalence (MORE)-A new method of sensitivity analysis for decision-making.Environmental Modelling \& Software, 25(2), 171-181.

Saaty, T.L. (1980). The analytic hierarchy process. New York: McGraw-Hill.

Saaty, T., \& Vargas, L. L. G. (Eds.). (2001). Models, methods, concepts, and applications of the analytic hierarchy process (Vol. 34). Springer.

Saltelli, A., Chan, K.,\& Scott, M. (2000). Sensitivity analysis, probability and statistics series. New York: Wiley.

Saltelli, A. (2002). Making best use of model evaluations to compute sensitivity indices. Computer Physics Communications, 145(2), 280-297.

Skogen, K. (2003). Adapting adaptive management to a cultural understanding of land use conflicts. Society \&Natural Resources, 16(5), 435-450.

Store, R., \& Kangas, J. (2001). Integrating spatial multi-criteria evaluation and expert knowledge for GIS-based habitat suitability modeling. Landscape and Urban Planning, 55(2), 79-93. 
Strager, M. P., \& Rosenberger, R. S. (2006). Incorporating stakeholder preferences for land conservation: Weights and measures in spatial MCA.Ecological Economics, 58(1), 79-92.

Tsaur, S. H., Chang, T. Y., \& Yen, C. H. (2002). The evaluation of airline service quality by fuzzy MCDM. Tourism management, 23(2), 107-115.

Ullah, K.M., \& Hafiz, R. (2013). Finding suitable locations for ecotourism development in Cox's Bazar using geographical information system and analytical hierarchy process. Geocarto International, 1-12 DOI: 10.1080/10106049.2012.760005.

Uyan, M. (2013). GIS-based solar farms site selection using analytic hierarchy process (AHP) in Karapinar region, Konya/Turkey. Renewable and Sustainable Energy Reviews, 28, 11-17.

Zoras, S., Triantafyllou, A. G., \& Hurley, P. J. (2007). Grid sensitivity analysis for the calibration of a prognostic meteorological model in complex terrain by a screening experiment. Environmental Modelling \& Software, 22(1), 33-39. 